
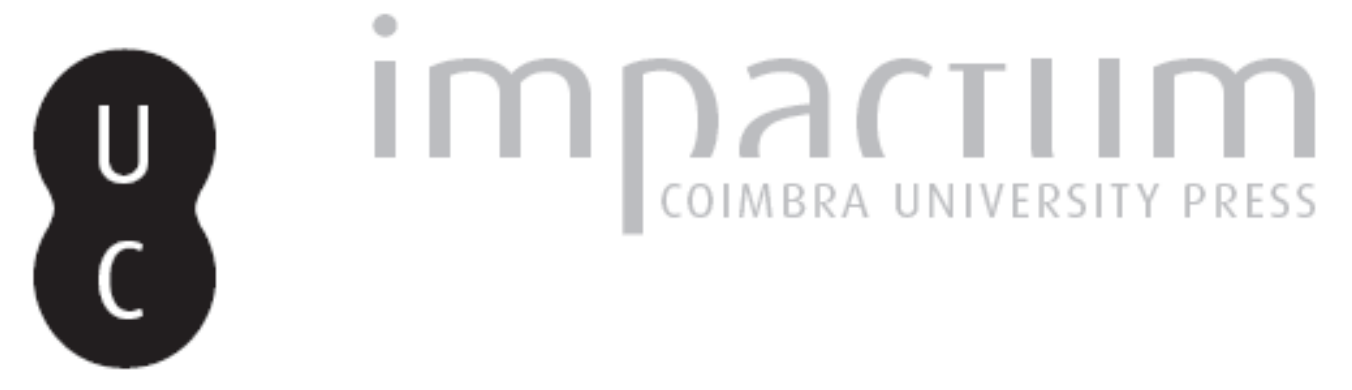

\title{
Platon und die bildende Kunst: eine Revision
}

\author{
Autor(es): Hub, Berthold
}

Publicado por: Imprensa da Universidade de Coimbra

URL persistente:

URI:http://hdl.handle.net/10316.2/42200

DOI:

DOl:https://doi.org/10.14195/2183-4105_9_2

Accessed : $\quad$ 26-Apr-2023 15:53:46

A navegação consulta e descarregamento dos títulos inseridos nas Bibliotecas Digitais UC Digitalis, UC Pombalina e UC Impactum, pressupõem a aceitação plena e sem reservas dos Termos e Condições de Uso destas Bibliotecas Digitais, disponíveis em https://digitalis.uc.pt/pt-pt/termos.

Conforme exposto nos referidos Termos e Condições de Uso, o descarregamento de títulos de acesso restrito requer uma licença válida de autorização devendo o utilizador aceder ao(s) documento(s) a partir de um endereço de IP da instituição detentora da supramencionada licença.

Ao utilizador é apenas permitido o descarregamento para uso pessoal, pelo que o emprego do(s) título(s) descarregado(s) para outro fim, designadamente comercial, carece de autorização do respetivo autor ou editor da obra.

Na medida em que todas as obras da UC Digitalis se encontram protegidas pelo Código do Direito de Autor e Direitos Conexos e demais legislação aplicável, toda a cópia, parcial ou total, deste documento, nos casos em que é legalmente admitida, deverá conter ou fazer-se acompanhar por este aviso.

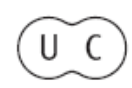




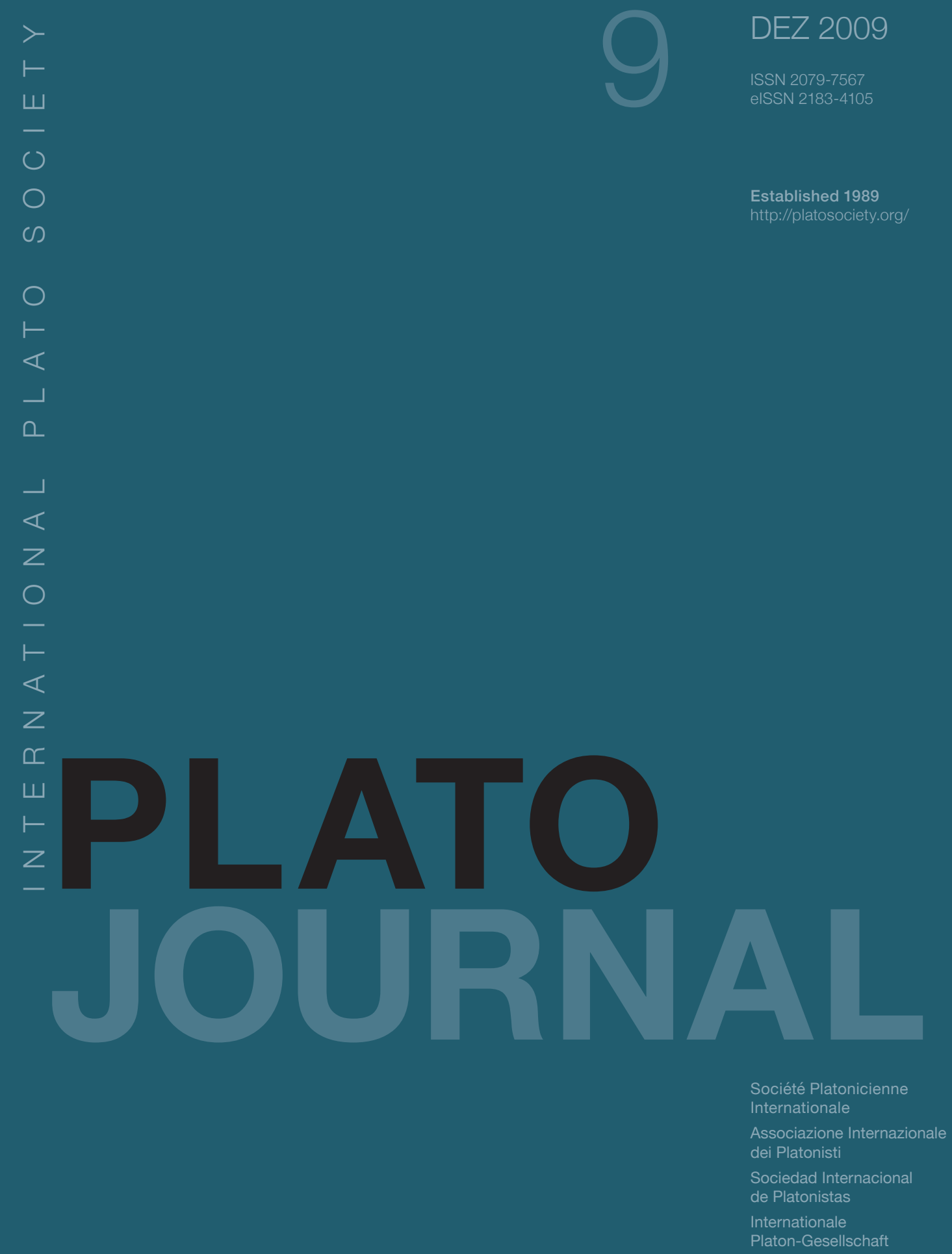




\title{
Platon Und DIE BILDENDE KUnST. EINE REVISION
}

\begin{abstract}
Plato's statements on art have met with countless commentators and almost as many different interpretations. In most cases, comments and hints that are scattered through various dialogues are taken out of context and played off against each other-depending on whether the intention is to portray Plato as a modern art lover or as an ageing political reactionary. In the face of the confusing range of contending opinions, there is an urgent need to examine and clarify the textual basis in Plato. For thispurpose, a meticulous analysis of Book 10 of the Politeia is initially carried out - the only part of the corpus of Plato's works that is concerned with art in detail and exclusively. The results are surprisingly clear. The corrupting and dangerous aspect of art is not attributed to individual artists or a specific artistic orientation, nor to the style of the depiction, nor to the content that is narrated or presented; instead, it is ascribed to its essential nature as the $\mu i \mu \eta \sigma \iota s$ of a $\mu i \mu \eta \sigma \iota$. Since even the objects of sense perception are imitations of the archetypal Ideas, which are ultimately accessible only to rational cognition, the artist is an imitator of something imitated. He merely touches on the (subjective) appearance of a reality that is in turn already a defective, mutable and ephemeral imitation of the only true, immutable and eternal archetypal Ideas. As the imitation of an imitation, art is insurmountably distant from truth and knowledge, ontologically and therefore also epistemologically worthless and useless - and also damaging, because it attempts to shackle us and domesticate us at a level three steps below truth. However, it not only holds us captive, but also corrupts us even further by appealing not to reason, but to the lower part of the soul with its desires and affections. It is because of this that it is corrupting and dangerous, initially for the individual character and individual spiritual welfare, and ultimately - through the individual - also for human society as a whole. Art thus creates precisely the situation which for the philosopher represents the fundamentally distorted condition from which he is attempting to liberate people. Art is constantly re-fastening the shackles that the philosopher releases. This is why art has to be excluded from Plato's ideal state, with philosophy alone taking its place. The condemnation of all forms of art could not be expressed more clearly. Despite this, repeated efforts have been made to weaken the condemnation or even disprove its existence, either in order to save art from Plato or, conversely, to save Plato from condemning art. To achieve this, alleged contradictions between Books 10 and 3 of
\end{abstract}

PLATO, The electronic Journal of the International Plato Society, n 9, 2009.

http://gramata.univ-paris 1.fr/Plato

(C) All rights of reproduction of any form reserved. 
the Politeia have been pointed out (1); a differentiation or alteration in Plato's

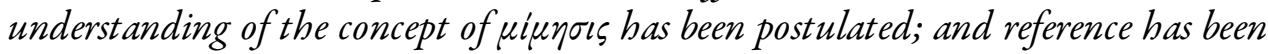
made to passages in Plato's works in which, it is claimed, the philosopher concedes that art has direct access to the world of the Ideas (2) or in which he speaks of the artist's divine inspiration (3), as well as the numerous passages that discuss Beauty (4). Finally, it is claimed that Plato did not condemn all art, but only a certain contemporary trend in art $(5,6)$, or more generally, only illusionistic art in contrast to an abstract form of art (7) - namely Egyptian art (8). In the second part of the study, these lines of argumentation are discussed individually and in detail and their content is tested. In each case, the findings obtained initially in the analysis of Book 10 of the Politeia are confirmed. The present study does not offer any new hypotheses; instead, its goal is to use a detailed and differentiated examination of the relevant texts to clearly distinguish Plato's view of art from later neo-Platonic views, as well as from obfuscations created by modern interpreters, in order to obtain a secure basis for future investigations of Plato's view of art in particular, as well as of ancient aesthetics in general. The extensive review of the secondary literature also documents part of the history of twentieth-century scholarship. 
"Alle nachahmende Dichtung", mit dieser These eröffnet das 10. Buch der Politeia, "ist Gift für den Verstand all derjenigen Hörer, denen nicht die Kenntnis der wahren Natur der Dinge dagegen zur Verfügung steht" (595 b). ${ }^{1}$ Von seinem Gesprächspartner Glaukon aufgefordert, dies näher zu erläutern, hebt Sokrates zu einer ausführlichen Rede gegen die Kunst im Allgemeinen an, deren erster Teil vor dem Hintergrund der metaphysischen und epistemologischen Unterscheidungen des 5., 6. und 7. Buches geführt wird, Letzterer die SeelenLehre des 4. Buches voraussetzt. Genauerhin lassen sich sechs Argumente unterscheiden.

\section{Argument: Fern der Wahrheit}

Das Verderbliche und Gefährliche an Dichtung und Malerei, ja an Kunst überhaupt, liegt in ihrem Wesen und nicht an einzelnen Künstlern oder an den durch

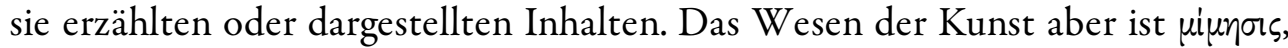
"Nachahmung". ${ }^{2}$ Doch Nachahmung wovon? Zur Beantwortung dieser Frage sei,

1 Die Übersetzung der platonischen Dialoge ist, wenn nicht anders angegeben, die von OTTO APELT (Platon, Sämtliche Dialoge, 3. Auflage Leipzig 1923).

2 Insbesondere KOLLER 1954, ELSE 1958, und SÖRBOM 1966, haben versucht, den sprach- und

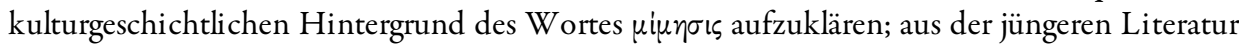
seien hervorgehoben ZIMBRICH 1984, MELBERG 1995 und HALLIWELL 2002; ferner KARDAUN 1993 und 2000, allerdings mit zweifelhaften Schlussfolgerungen. Den besten ersten Überblick geben GEBAUER \& WULF 1992, 41 ff.. Etymologie und Herkunft von $\mu$ i $u \eta$ เ (Verb

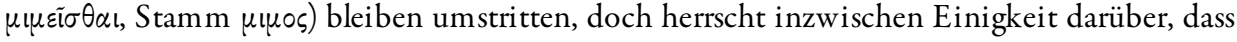
Mimesis keineswegs nur Nachahmung meinen muss, sondern vielmehr und auch zur gleichen Zeit zahlreiche heterogene Bedeutungen haben kann: neben Nachahmung, Darstellung, Ausdruck, auch Nacheifern, Verwandeln, Schaffen von Ähnlichkeit, Erzeugen von Erscheinungen und Schein. Alle diese Bedeutungen finden sich auch im platonischen Korpus wieder. Auch für Platons Verwendung des Wortes gilt, dass der Wert der Mimesis und also die jeweilige Übersetzung von ihrem Objekt und also vom Wert des Vorbildes abhängen, auf den sich die Mimesis bezieht. Mit anderen Worten, die Übersetzungen des Wortes $\mu$ i $\mu \eta \sigma \varsigma s$ sind so zahlreich wie ihre Objekte. Dennoch bleibt hinsichtlich Malerei und Dichtung "Nachahmung" weiterhin die brauchbarste Übersetzung, insofern diese im Urteil Platons wie wir noch sehen werden - nur und ausschließlich die äußerlichen und unwesentlichen Aspekte der Konkreta zur Darstellung zu bringen vermögen; ihre Darstellungen sind bloße Nachahmungen gemäß der Trivialität ihrer Objekte. Eine andere Übersetzung verlangt hingegen z.B. Kratylos 423ff., wo $\mu \mu \varepsilon i \sigma \theta \alpha$ เ als ein bildhaftes Klarmachen von Begriffsinhalten in die Diskussion eingeführt wird, oder Politeia 388 c, wenn es heißt: "Wir werden Homer bitten, sich nicht zu unterfangen, den größten der Götter so $\dot{\alpha} \nu \circ \mu \circ i \omega \varsigma \mu \ell \mu \dot{\eta} \sigma \alpha \sigma \theta \alpha$, dass er sagt: Oh weh...": "unähnlich nachahmen" wäre eine contradictio in terminis; hier muss also mit

PLATO, The electronic Journal of the International Plato Society, n 9, 2009.

http://gramata.univ-paris $1 . \mathrm{fr} /$ Plato

(C) All rights of reproduction of any form reserved. 
so Platon, "nach unserer gewohnten Methode", davon auszugehen, dass "für jede Gruppe von Dingen, die wir mit demselben Namen bezeichnen, jeweils eine Idee anzusetzen" ist (596 a). Obwohl es beispielsweise eine Vielzahl von Stühlen ( $\kappa \lambda i \nu \eta$, also eigentlich Liege) oder Tischen gibt, so gibt es doch deren jeweils nur

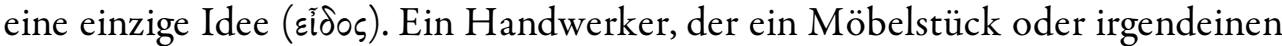
anderen Gebrauchsgegenstand herstellt, hat "seinen Blick auf die Idee gerichtet", aber "die Idee selbst kann er nicht verfertigen" (596 b). ${ }^{3}$ Nun gebe es aber einen Meister, "der alles macht, was jeder einzelne dieser Handwerker hervorbringt", ja dieser ist "imstande, nicht nur alle Geräte zu verfertigen, sondern er macht auch alles, was auf der Erde wächst, und erschafft alle Lebewesen, sowohl alle anderen als auch sich selbst. Und dazu schafft er die Erde und den Himmel und die Götter

"darstellen" oder "als handelnde und sprechende Person auftreten lassen" übersetzt werden. Als außerplatonisches Beispiel sei Xenophon, Memorabilia III,10, angeführt, wo Sokrates sich mit einigen Künstlern darüber unterhält, ob sie neben den äußerlichen Merkmalen auch den Charakter der Seele $\mu$ ц $\varepsilon \tilde{\sigma} \theta \alpha \iota$ können; der Charakter der Seele ist nicht nachzuahmen, wohl aber wiederzugeben, auszudrücken, darzustellen, oder zu gestalten.

3 "Für jede Gruppe von Dingen, die wir mit demselben Namen bezeichnen, jeweils eine Idee anzusetzen" würde eine unbeschränkte Zahl an Ideen ergeben: Für alle Handlungen, die wir gerecht nennen, gäbe es eine Idee Gerechtigkeit, für alle Gegenstände, die wir Tisch nennen, gäbe es eine Idee Tischheit, usw.. Vgl. dazu Parmenides 130, wo Platon zu zögern scheint, auch bei niederen Dinge eine transzendente Idee vorauszusetzen. Dass sein Standpunkt in dieser Beziehung manchen Schwankungen und Wandlungen unterworfen war, geht auch aus manchen Äußerungen des Aristoteles hervor (beispielsweise Metaphysik I, 991 b 6 oder XII, 1070 a 13ff.). Vgl. auch Politikos 262 d, wo Platon hervorhebt, dass die Teilung des Menschengeschlechtes in Griechen und Barbaren unzulässig sei, da Letztere, auch wenn sie einen eigenen Namen tragen, keine eigene Gattung bilden. Ähnlich problematisch innerhalb der Ideenlehre erweist sich die hier vorgetragene Ansicht, der Handwerker, wenn er einen konkreten Gegenstand herstelle, habe qua Handwerker Zugang zu den Ideen. Das widerspricht den in Buch 5-7 vorgetragenen Ansichten, wonach nur der Philosoph, nach langer Übung, zu den Ideen vorzudringen vermag. (Auch in Kratylus 389 b wird vom Handwerker gesagt, er blicke auf die Ideen, doch ist unklar, ob dort der Begriff der Idee in dem transzendentalen Sinne der Politeia verwendet wird.) Problematisch schließlich auch die im Folgenden vertretene Annahme, die Idee des Stuhles sei von Gott hergestellt worden. Das hat zwar die Phantasie vor allem christlicher Interpreten beflügelt, doch widerspricht es der sonst von Platon vertretenen Ansicht, dass die Ideen absolut unabhängiges und ewig existierendes Sein sind. Im Timaios erschafft der göttliche Demiurg deshalb auch nicht die Ideen, sondern die sichtbare Welt nach dem Modell der Ideen. Alle diese aus der vorliegenden Stelle der Politeia für die Ideenlehre sich ergebenden Probleme seien hier nur angedeutet. Ihre Verfolgung überschreitet Ziel und Umfang dieser Arbeit, der es an dieser Stelle nur auf die Klarheit und Eindeutigkeit der platonischen Haltung der Kunst gegenüber, aber nicht auf die Konsistenz des platonischen Denkens überhaupt ankommen kann.

PLATO, The electronic Journal of the International Plato Society, n 9, 2009.

http://gramata.univ-paris 1.fr/Plato

(C) All rights of reproduction of any form reserved. 
und alles, was im Himmel, und auch alles, was unter der Erde im Hades ist." Danach gefragt, welchen Namen er einem solchen Meister geben würde, nennt Glaukon diesen "einen ganz wunderbaren Sophisten" (596 d). Mit jenem Meister, der alles Mögliche herzustellen weiß, ist also keineswegs ein transzendenter Schöpfer gemeint, sondern der Redner, der von allem Möglichen zu sprechen versteht, womit Sokrates seinen, neben den Dichtern und Malern, größten Gegnern, den Sophisten, einen Seitenhieb versetzt und gleichzeitig die Kategorie vorbereitet, in die auch die Künstler fallen werden. "Sag mir", fährt Sokrates fort, "bis du der Meinung, einen solchen Meister gebe es nicht, oder glaubst du, er sei bloß in einem gewissen Sinn Schöpfer aller dieser Dinge, in einem anderen aber nicht? Merkst du denn nicht, dass sogar du selbst imstande bist, auf gewisse Art alle diese Dinge zu erschaffen. ...wenn du einfach einen Spiegel zur Hand nimmst und ihn überall herumträgst. Dann hast du bald eine Sonne gemacht und was am Himmel ist, bald auch die Erde, bald dich selbst und alle übrigen Lebewesen und Gerätschaften und Pflanzen und überhaupt alles, was wir vorhin aufgezählt haben" (596 d - e). ${ }^{5}$ Wie die Metapher vom Spiegel bereits anklingen lässt, gehören zu den Meistern dieser Art auch die Maler. Was ein Maler macht, das kann jedes Kind; dazu benötigt es bloß einen Spiegel, den es mal hierhin, mal dorthin hält. Der Maler ist also ein Tausendsassa, aber nicht kraft Wissens, sondern kraft Nicht-Wissens, und dadurch dass er den Weg des Scheins beschreitet. Denn was auf diese Weise hergestellt wird, sind nur "Erscheinungen", aber keine "wahren Dinge" (596 e).

Wenn ein Maler beispielsweise einen Stuhl malt, haben wir es mit drei Stühlen zu tun: der eine, "der in der Natur ist und von Gott gemacht ist" (597 b), jenen, den der Zimmermann herstellt, und jenen, den der Maler macht. Gott hat logischerweise nur eine Idee des Stuhles geschaffen, "welche ist, was der Stuhl als solcher wirklich ist", denn "hätte er auch nur zwei gemacht ... so würde sich darüber wieder ein dritter zeigen, an dessen Idee jene beiden anderen wiederum Anteil hätten, und dann wäre es jener und nicht die anderen beiden, welcher das

4 Vgl. Sophistes 231 ff., v.a. 234 b ff.. Zur Parallelität von Kunst und Sophistik auch WELSCH 1983 , v.a. $232 \mathrm{f} .$.

5 Zu einem positiven Verständnis der Natur im Spiegel des Malers zur Zeit der Renaissance, sowie der Umkehrung der Hierarchie von Philosophie und Kunst bei Leonardo da Vinci, WELSCH 1983. Allerdings findet sich gerade bei Leonardo auch eine platonisch anmutende Verwendung der Spiegelmetapher: "Wer malt ... ohne Vernunft, der ist wie ein Spiegel, der alles verdoppelt ... ohne Wissen." (The Notebooks of Leonardo da Vinci, hg. Irma A. Richter, Oxford 1952, 225).

PLATO, The electronic Journal of the International Plato Society, n 9, 2009.

http://gramata.univ-paris 1.fr/Plato

(C) All rights of reproduction of any form reserved. 
ist, was der Stuhl als solcher wirklich ist" (597 c). ${ }^{6}$ Gott kann nur jeweils eine Idee geschaffen haben, sonst wäre die Frage nach der Herkunft einem unendlichen Regress ausgesetzt. Gott ist der Hersteller des einzigen wahrhaft seienden Stuhles. Der Handwerker dagegen verfertigt einen beliebigen, konkreten und sinnlich erfahrbaren Stuhl "mit Blick auf die göttliche Idee" des Stuhles, kann also immer nur einen dieser Idee ähnlichen oder ihr angenäherten Stuhl herstellen, "etwas, das dem (wahrhaft) Seienden nur gleicht, es aber nicht ist", ein Werk, das "im Vergleich zu der Wahrheit etwas Trübes ist" (597 a). Der Maler aber kann nicht als Verfertiger eines solchen Gegenstandes gelten. Er ist nur "Nachahmer des Gegenstandes, von dem jene die Hersteller sind" (597 e). Der Maler ist also Nachahmer einer Nachahmung und deshalb "Urheber des auf dritter Stufe abwärts von der reinen Wirklichkeit stehenden Erzeugnisses" (ibid.). Dasselbe gelte für die Tragödiendichter "und ebenso alle übrigen Nachahmer"; sie alle befinden sich "drei Stufen abwärts vom König und von der Wahrheit" (ibid.). Für den Fall des Malers wird dann noch einmal eigens hervorgehoben, dass er keinesfalls Nachahmer der Ideen (des einzig wirklich und wahrhaft Seienden) sein kann, sondern nur Nachahmer der Erzeugnisse der Handwerker, und obendrein der Werke der Handwerker nicht so, wie sie sind, sondern bloß so, wie sie erscheinen, was Sokrates seinem Gesprächspartner folgendermaßen verdeutlicht: "Einen Stuhl, ob du ihn von der Seite oder von vorn anschaust oder von wo aus immer, ist doch nicht etwa von sich selbst verschieden. Vielmehr verhält es sich doch wohl so, dass er zwar nicht von sich selbst verschieden ist, wohl aber verschieden erscheint?" (598 a). Und dasselbe gelte für alle anderen Gegenstände, die der Maler zur Darstellung bringen mag.

Vor dem Hintergrund der in den mittleren Büchern der Politeia entwickelten Ideenlehre werden also drei Grade der Realität von Objekten unterschieden: 1. die absolute, ewige, unwandelbare, transzendente und also unsichtbare, und deshalb allein denkbare Idee des Gegenstandes, zum Beispiel eines Stuhles; 2. der Gegenstand in Raum und Zeit, zum Beispiel der konkrete Stuhl, auf dem ich gerade sitze; 3. die Abbildung dieses konkreten Gegenstandes, beispielsweise in einem an der Wand meines Zimmers hängenden Gemäldes, auf das ich gerade blicke. Dieses hat ein Maler nach dem Stuhl, auf dem ich sitze, gemalt; diesen wiederum hat ein Handwerker mit Blick auf das Urbild aller Stühle angefertigt;

6 Derselben Art ist der von Parmenides im gleichnamigen Dialog (126 a - 135 d, va. 131 e $132 \mathrm{~b})$ gegen die sokratische Ideenlehre vorgetragene Einwand, der in der Platon-Literatur als "Third Man Argument" bezeichnet wird; dazu, neben den Parmenides-Kommentaren von Allen 1983, Meinwald 1991 und Graeser 2003, v.a. Vlastos 1954, CoHen 1971, SHARVY 1986, TURNBULL 1989, JIYUAN 1991, FINE 1993, 204-224.

PLATO, The electronic Journal of the International Plato Society, n 9, 2009.

http://gramata.univ-paris 1.fr/Plato

(C) All rights of reproduction of any form reserved. 
die Idee selbst, so Sokrates an dieser Stelle, habe ein Gott erschaffen. Das Kunstwerk steht so hinter der Idee und dem konkreten Gegenstand nur in dritter Reihe. Es ist die Nachahmung einer Nachahmung. Ja schlimmer noch: Bilder dreidimensionaler Gegenstände haben nur zwei Dimensionen und vermögen deshalb wesenhaft den dargestellten Gegenstand nur aus einer bestimmten Perspektive wiederzugeben, auch wenn sie uns Dreidimensionalität vorzugaukeln versuchen.

Diese Unterscheidungen werden von Platon im Sophistes (233 ff. und 264 ff.) wieder aufgegriffen, mit dem Ziel, den Redner auf dieselbe Stufe wie den Maler $\mathrm{zu}$ stellen. Zunächst wird dort unterschieden zwischen der "hervorbringenden Kunst" ( $\pi \circ \imath \tau \tau \kappa \dot{\eta} \tau \dot{\varepsilon} \chi \nu \eta)$ und der "nachahmenden Kunst" ( $\mu \mu \eta \tau \iota \kappa \dot{\eta} \tau \dot{\varepsilon} \chi \nu \eta)$ oder "bildschaffenden Kunst" ( $\varepsilon \dot{\delta} \delta \omega \lambda \circ \pi \circ u k \eta \dot{\eta} \tau \chi \chi \eta)$ (266 d). Letztere wiederum wird geschieden in eine "abbildende" ( $\varepsilon i \kappa \alpha \tau \iota k \eta \dot{\eta} \tau \dot{\varepsilon} \chi \nu)$ und eine "scheinbildenden Kunst" ( $\phi \alpha \nu \tau \alpha \sigma \tau \iota \kappa \eta \dot{~} \tau \dot{\varepsilon} \chi \nu \eta)(235 \mathrm{~d}-236 \mathrm{c})$. Die abbildende Kunst besteht darin, "dass man bei der Herstellung der Nachahmung die Maßverhältnisse des Originals nach Länge, Breite und Tiefe beibehält und außerdem noch jedem Teil die ihm zukommende natürliche Farbe auferlegt" (236 e); d.h. sie reproduziert die Proportionen und Oberflächeneigenschaften des Gegenstandes und schafft so eine getreue Kopie.7 Die scheinbildende Kunst hingegen verändert diese in Hinblick auf einen bestimmten Betrachterstandpunkt. Was die Künste im modernen Sinne betrifft, so lässt sich den "herstellenden Künsten" alleine die Architektur zuordnen. ${ }^{8}$ Den "(genau) abbildenden Künsten" ließe sich vielleicht

7 Vgl. die Forderung nach Richtigkeit in Nomoi 668 b - 969 b, die nur erfüllt werden kann, wenn man ein Wissen von dem darzustellenden Gegenstand besitzt. Ferner Kratylos 432, wo ausgeführt wird, dass die Beziehung zwischen Begriff ("wie jede Art von Bild") und Gegenstand keine (genau) abbildende, sondern sinnvollerweise nur eine "nachahmende" sein kann, sodass der Einwurf des Kratylos, dass, wenn man die Buchstabenfolge eines Wortes ändert, sofort ein anderes entstehe und die Beziehung zum Gegenstand zerstört sei, nicht trifft.

8 Die Architektur gehört nicht zu den nachahmenden Künsten. In 266 a wird sie ausdrücklich der herstellenden Kunst zugerechnet: "Soll nicht das Haus selbst ein Erzeugnis der Baukunst, ein andersartiges Haus aber das Erzeugnis der Malkunst sein, gleichsam ein Traum, für Wachende zubereitet." Vgl. Philebos 56 b, wo die Architektur als Beispiel für die Genauigkeit eines auf Maß und Werkzeug gestützten Verfahrens erwähnt und als kunstgemäßer als viele Wissenschaften gepriesen wird: "Was aber die Baukunst betrifft, die sich vor allem der Maße und Werkzeuge bedient, so erheben, glaube ich, diese Hilfsmittel, die ihr einen hohen Grad von Genauigkeit verleihen, sie zu einer höheren Stufe der Kunst, als es bei den meisten Wissensfächern der Fall ist."; vgl. Politeia 438 d. In Nomoi 793 c kann sie Platon deshalb als Bild der höchsten Ideale dienen, des Staatsgebäudes und des Weltenbaus. Auch Aristoteles (in der Poetik wird sie nicht erwähnt; vgl. Politik 1182 a 3) und Plotin (Enneaden V,9,11) trennen die Architektur von den mimetischen Künsten.

PLATO, The electronic Journal of the International Plato Society, n 9, 2009.

http://gramata.univ-paris $1 . \mathrm{fr} /$ Plato

(C) All rights of reproduction of any form reserved. 
die Skulptur zurechnen, wenn nicht bereits auch in diese subjektive Kriterien der Gestaltung eingezogen wären, insofern die oberen Partien von Kolossalstatuen vergrößert werden, um die durch die Entfernung des Betrachters bewirkte optische Verzerrung zu kompensieren (235 e). ${ }^{9}$ In diesem Fall gibt die Skulptur nicht die wirklichen Proportionen und Eigenschaften wieder, sondern diejenigen, die von einem gewissen Betrachterstandpunkt aus richtig erscheinen werden. Die Malerei aber ist mit ihren zweidimensionalen Darstellungen dreidimensionaler Gegenstände wesenhaft eine scheinbildende Kunst; sie vermag die Forderung nach Reproduktion der Tiefe nicht zu leisten. ${ }^{10}$ Deshalb kann der Maler nichts darstellen wie es ist, sondern alles immer nur so, wie es erscheint. Er ist höchstens der Erzeuger einer Ähnlichkeitsillusion beim Betrachter. Seine Produkte sind "Phantasmen" oder "Traumbilder" (Sophistes 266 c) und stehen auf derselben Stufe wie Spiegelbilder und andere trügerische optische Phänomene (Politeia $\left.509 e-510 a^{11}, 602 c-603 b\right)$.

\section{Argument: Fern dem Wissen}

Das nun folgende Argument setzt sich mit Verteidigern und Freunden der Dichtung auseinander, die behaupten, "dass diese Dichter von allen Künsten

9 Nach BIANCHI BANDINELli 1955 (diesem folgend beispielsweise ADORNO 1965) sei an dieser Stelle nicht die Skulptur, sondern die Malerei der zeitgenössischen Theaterbühnen gemeint. Dies hat keinen Anhalt im Text, und auch die allgemeine Situation im zeitgleichen Theater spricht dagegen, wo die überwiegende Mehrzahl der Zuschauer einen hinsichtlich der Malerei hohen Blickpunkt einnahmen, sodass eine optische Korrektur in der umgekehrten Richtung durchzuführen gewesen wäre, hätte man auf einen solchen Ausgleich der Erscheinung wertgelegt.

10 Mit Blick auf den Sophistes wird die scheinbildende Kunst in zwei weitere Unterarten geschieden: "Die eine vollzieht sich durch Werkzeuge, die andere dadurch, dass der das Scheinbild Hervorbringende sich selbst zum Werkzeug macht." (267 a) "Die Gerechtigkeit und überhaupt die ganze Tugendhaftigkeit" hat wie alle Gegenstände entsprechende Ideen, die von uns "nachgeahmt", also ausgedrückt, dargestellt, ansichtig gemacht werden, und zwar nicht nur in Gesetzeswerken o.ä., sondern und vorzugsweise durch uns selbst, unsere Worte und Taten, wodurch wir uns selbst zu ihrem Werkzeug machen. Beim Philosophen, heißt es im Folgenden, handelt es sich um "auf Wissen beruhende $\mu$ i $\mu \eta \sigma \varsigma$ ", beim Sophisten hingegen um "auf bloßer Meinung beruhende $\mu$ i $\mu \eta \sigma \varsigma "$ " Ersterer spricht und handelt aus wahrer Einsicht, Letzterer mimt ohne Einsicht Ersteren. Doch wird hierbei keine Analogie mehr von Künstler und Sophist verfolgt. Zum Sophistes zuletzt NOTOMI 1999, v.a. 147-155.

11 Diese Stelle ist Teil des sogenannten Liniengleichnis vom Ende des 6. Buches (509 d - 511 e); dazu nach dem folgenden (dritten) Argument ausführlicher.

PLATO, The electronic Journal of the International Plato Society, n 9, 2009.

http://gramata.univ-paris 1.fr/Plato

(C) All rights of reproduction of any form reserved. 
etwas verstehen" (598 d). ${ }^{12}$ An ihre Adresse ist die Schlussfolgerung gerichtet, dass nur der alles nachahmend hervorbringen kann, der von allem nichts als die sinnliche Erscheinung kennt. "Wenn die Nachahmekunst alles mögliche zustande bringt, so offenbar deshalb, weil sie nur ein wenig von jedem erfasst, nämlich sein (äußeres) Bild" (598 b). Nach Platons Auffassung der $\tau \dot{\varepsilon} \chi \nu \eta$ ist es unmöglich, dass ein einziger alle $\tau \dot{\varepsilon} \chi \nu \alpha \iota$ versteht, denn eine solche erfordert ein Wissen um die Natur des Gegenstandes, mit dem sie es zu tun hat. Alles Mögliche herzustellen impliziert deshalb davon notwendigerweise kein Wissen zu haben. "So malt uns, sagen wir, zum Beispiel der Maler einen Schuster, einen Schreiner oder einen anderen Handwerker, ohne dass er von einem dieser Berufe etwas versteht. Ist er ein guter Maler, so vermag er Kinder und unverständige Menschen trotzdem zu täuschen, indem er einen Schreiner malt und von weitem vorzeigt und so den Eindruck erweckt, als sei es ein wirklicher Schreiner" (598 c). Die Unwissenheit der Maler und Dichter bleibe aber nur den Unwissenden verborgen: "Wenn uns jemand verkündet, er habe einen Menschen getroffen, der

12 Platons Kritik an den Dichtern ist einerseits bestimmt durch sein eigenes philosophisches System, andererseits orientiert an dem Selbstverständnis der Dichter und an dem Bild, das die allgemeine Meinung von ihnen und ihren Werken hatte. Die Dichter galten als Erzieher und Führer des Volkes. Ihre Werke waren vorrangiges und meistbenutztes Unterrichtsmaterial der Schulen. Ihre Helden dienten als Modellfiguren für die private Lebensführung wie für den öffentlichen Bereich. Aber nicht nur Lernende wie Lehrende suchten in allen möglichen Fragen die Antworten bei den Dichtern, auch Politiker und Richter argumentierten mit ihnen. Dabei zeigt die Selbstverständlichkeit, mit der vor Gericht und vor der Volksversammlung aus den Werken der Dichter zitiert wurde, den Grad der allgemeinen Vertrautheit mit diesen. Von der fälschlichen Geltung der Dichter als Lehrer und Erzieher spricht Platon noch in Protagoras 325 d ff., Kratylos 391 b ff., Hippias Maior 228 b ff., Charmides 163, Kritias 162 c - d, Nomoi 810 ff. u.ö.. Zur Rolle der Dichtung in der griechischen Gesellschaft und dem "alten Streit zwischen Philosophie und Poesie" (Politeia 607 b): KUHN 1942, JAEGER 1954, D ALFEN 1974, ROSEN 1988 und LEVIN 2001, v.a. $127 \mathrm{ff.}$ Der Ausgangspunkt von Platons Dichterkritik ist expliziert im 7. Brief (325 c ff.): die Erfahrung der heillosen Verderbtheit des gesamten politischen Lebens seiner Zeit und die Erkenntnis, dass die notwendige Besserung nur von der Philosophie geleistet werden kann. Die Einsicht, dass die Dichtung die ihr zugeschriebenen Funktionen nicht erfüllt, führt über die Entlarvung ihrer Unwissenheit, Nutzlosigkeit und schädlichen Wirkung zu ihrem Ausschluss aus dem idealen Staat und zur Übertragung ihrer Funktionen auf die Philosophie. In diesem Sinne wird in den Nomoi (817 a ff.) den alten Dichtern, vertreten durch die Tragiker, die um Aufnahme in den neuen Staat ansuchen, von den Gründern des Staates, den Philosophen, erklärt, sie selbst seien Dichter der schönsten und besten Tragödie und ihr Staatsentwurf sei $\mu$ i $\mu \eta \sigma \varsigma s$ des schönsten und besten Lebens. Im Folgenden geht es um die Unwissenheit der Dichter. Zur verderblichen Wirkung s. Argument 5 und 6. Zur Kritik ihrer göttlichen Inspiriertheit s. unten den entsprechend betitelten Abschnitt.

PLATO, The electronic Journal of the International Plato Society, n 9, 2009.

http://gramata.univ-paris $1 . \mathrm{fr} /$ Plato

(c) All rights of reproduction of any form reserved. 
sich nicht nur auf sämtliche Handwerke verstehe, sondern auch von allem anderen, was sonst nur ein einzelner beherrscht, besser Bescheid wisse als sonst irgend jemand, dann müssen wir so einem entgegnen, er sei ein einfältiger Mensch und offenbar einem Gaukler und Nachahmer in die Hände gefallen, der ihn angeführt und ihm die Meinung beigebracht habe, er sei allwissend - weil er eben selbst nicht imstande sei, Wissen und Unwissenheit und Nachahmung prüfend zu unterscheiden" (598 c - d). An anderer Stelle wird auch den Sophisten dieser Vorwurf gemacht, nämlich vorzugeben auf allen Gebieten bewandert zu sein, tatsächlich aber in keinem dieser Gebiete ein Wissen zu besitzen (Sophistes 231 ff.). Auch der Redner wird deshalb mit dem Maler verglichen und mit ganz ähnlichen Worten verurteilt (v.a.234 b - c): Wie die Maler mit Farben ihre Bilder malen, so die Sophisten ihre Werke mit Worten ( $\left.\varepsilon^{\prime} \delta \omega \lambda \alpha \lambda \varepsilon \gamma^{\prime} \dot{\delta} \mu \varepsilon \nu \alpha\right)$; wie jener erzeugt auch dieser lediglich Phantasmen und Trugwelten, die beim Zuhörer die Illusion der Wahrheit hervorrufen sollen; das Publikum wird nicht durch Einsicht überzeugt, sondern durch "Scheinwissen" überredet. Sophist wie Maler sind deshalb "Nachahmungskünstler", und insofern "Wunderkünstler" und "Gaukler" (Politeia 598 d, 602 d, Sophistes 235 a - b u.ö.). ${ }^{13}$ Dass sie beide keine Einsicht besitzen, erweist sich schließlich auch an dem Umstand, dass sich jeder tatsächlich Wissende von den Künsten notwendigerweise abwenden müsste. Ein

13 Vgl. Gorgias 463 b und 500 e ff., wo die Redekunst der Dichtung an die Seite gestellt wird und beide als "Schmeichelkünste" abgetan werden; sie seien nur $\xi \mu \pi \varepsilon ı \dot{\alpha} \alpha$ und $\tau \rho \nmid \beta \dot{\eta}$, nicht aber $\tau \dot{\varepsilon} \chi \nu \alpha \iota$, wofür sie gehalten werden. Sie gehen nicht aus von der Betrachtung ihres Gegenstandes und geben sich keine Rechenschaft über Grund und Zweck ihres Tuns. Wie die Kochkunst so der Vergleich an dieser Stelle - gehört die Redekunst keineswegs zu den $\tau \dot{\varepsilon} \chi \nu \alpha$, denn wie diese hat sie keine "höhere Einsicht", sondern ist "reine Übung und Erfahrungssache". Die Gleichsetzung von Dicht- und Redekunst ergibt sich auch aus der gemeinsamen Zielsetzung: Ihr Bemühen ist nicht nur nicht auf die Wahrheit gerichtet, sondern auf die Erzeugung von Lust in der Seele berechnet. Die Unwissenheit der Menge, die sie kritiklos macht, kommt ihnen dabei entgegen. Sie lässt sich durch den vom Sophisten und vom Dichter vorgegaukelten Schein täuschen und ist bereit, das Vergnügen dadurch zu honorieren, dass sie den Gaukler als den Allweisen bewundert und ihm damit die Anerkennung zollt, nach der er strebt. Dichtkunst und Redekunst sind also gemeinsam: die Unwissenheit, die verwerfliche Zielsetzung, sowie die diese beiden Anklagepunkte verstärkende Abhängigkeit vom Publikum. Zur gegenseitigen Beeinflussung von Dichter/Redner und Menge zum Schlechten s. unten Anm. 25. Zur Redekunst vgl. auch Euthydemos 289 e - 290 a: Die Redekunst "ist Teil der Beschwörungskunst und steht nur wenig hinter der eigentlichen Beschwörungskunst zurück. Die Letztere nämlich zeigt ihre Zaubermacht in der Behandlung von Schlangen, Spinnen, Skorpionen und anderen Tieren und Krankheiten, jene in der Behandlung und Beeinflussung von Gerichtshöfen, Volksversammlungen sowie anderer Massenanhäufungen"; oder Protagoras 315 a - b: der Sophist bezaubert durch seine Stimme die Schar seiner Anhänger, die er wie ein Rattenfänger hinter sich herzieht.

PLATO, The electronic Journal of the International Plato Society, n 9, 2009.

http://gramata.univ-paris 1.fr/Plato

(C) All rights of reproduction of any form reserved. 
wissender Künstler, der Philosoph als Künstler oder der Künstler als Philosoph, ist Platon eine contradictio in terminis: "Wenn nun jemand beides machen könnte, das Nachzuahmende und das Abbild, glaubst du, er werde sich dann ernsthaft um die Verfertigung von Bildern bemühen und sich das als Ziel seines Lebens vorsetzen, als gebe es kein besseres?... Sondern ich denke, wenn er von dem, was er nachahmt, wirklich etwas versteht, dann wird er sich doch viel eher um die Werke selbst als um die Nachahmungen bemühen und versuchen, viele schöne Werke als Denkmäler seiner selbst zu hinterlassen. Und er würde viel lieber der Gepriesene sein als der Preisende" (599a - b).

\section{Argument: Ohne Nutzen}

Dass allen voran Homer, die Identifikationsfigur griechischer Kultur schlechthin, tatsächlich kein Wissen besessen hat, lässt sich auch an einer empirischen Bestandsaufnahme seiner Wirkung zeigen. Wenn der größte aller Dichter tatsächlich der allwissend und universell Gebildete war, für den ihn die Leute halten, wieso hat er dann die Welt nicht verbessert? Hat er als Dichter "über das Wichtigste und Schönste geredet, ... über Krieg und Feldherrenkunst und Staatsverwaltung und über die Erziehung des Menschen", so muss er sich die folgende Frage gefallen lasse: "Lieber Homer ..., wenn du also hinsichtlich der menschlichen Tüchtigkeit nicht bloß dritter im Abstand von der Wahrheit und nicht nur der Erschaffer eines Bildes bist, als den wir den Nachahmer definiert haben, sondern wenn du auch zweiter bist und also erkennen konntest, welche Bestrebungen die Menschen im häuslichen und im öffentlichen Leben besser oder schlechter machen, so sag uns nun, welche Stadt durch dich zu einer besseren Verfassung gekommen ist..." (599 d - e). Auch von einem Krieg, der durch den berühmten Dichter gewonnen worden wäre, oder von einem Bereich, das durch eine brauchbare Erfindung von ihm bereichert worden wäre, weiß niemand zu berichten. Wäre Homer tatsächlich ein "trefflicher Mann" und verdienter Bürger gewesen, dann hätte man ihn nicht als Rhapsoden herumziehen lassen - oder wäre ihm doch zumindest überallhin gefolgt, sagt Sokrates verschmitzt $(600 \mathrm{c}-\mathrm{e})$. Als wirklicher Erzieher des Volkes hätte der Dichter zwar sein Repertoire stark einschränken müssen, doch wäre er so vom Nachahmer dritter Stufe zum "Hervorbringer" zweiter Stufe aufgestiegen freilich nicht mehr als Dichter, sondern als Erzieher. "Wir stellen also fest, dass von Homer an alle Dichter Nachahmer von Abbildern der menschlichen Tüchtigkeit sind und der anderen Dinge, von denen sie dichten, dass sie aber die Wahrheit nicht berühren. Es ist doch vielmehr so, wie wir vorhin vom Maler

PLATO, The electronic Journal of the International Plato Society, n 9, 2009.

http://gramata.univ-paris 1.fr/Plato

(c) All rights of reproduction of any form reserved. 
sagten: er macht etwas, das wie ein Schuster aussieht, ohne dass er selbst vom Schusterhandwerk etwas versteht, und er malt es für Leute, die auch nichts davon verstehen, sondern nur auf die Farben und auf die Umrisse schauen" (600 e 601a).

PLATO, The electronic Journal of the International Plato Society, n 9, 2009.

http://gramata.univ-paris 1.fr/Plato

(c) All rights of reproduction of any form reserved. 


\section{Noch einmal: bloße Meinung und nutzlos}

Das vierte Argument bringt eine weitere Dreiteilung, die die Korrelation von ontologischer und epistemologischer Abwertung von Dichtung und Malerei verdeutlichen soll. "Für jedes Ding gibt es drei Künste: die Verwendende, die Herstellende und die Nachahmende" (601 d). ${ }^{14}$ Der Maler malt Zügel und Zaum, hergestellt werden sie vom Sattler und vom Schmied. Wie aber beide Dinge beschaffen sein müssen, weiß weder der Maler noch der Schmied, sondern nur der, der mit ihnen umgeht, der Reiter. Dieses am Geschirr des Pferdes aufgezeigte Verhältnis gilt überall: "Tüchtigkeit und Schönheit und Richtigkeit jedes Gerätes und jedes Lebewesens und jeder Handlung beziehen sich doch auf nichts anderes als auf den Gebrauch, zu dem ein jedes verfertigt oder von Natur entstanden ist?" (idid.). Der Gebrauchende hat das Wissen davon, wie der Gegenstand, mit dem er umgeht, beschaffen sein muss. Deshalb erteilt er dem Handwerker, der den Gegenstand herstellt, Anweisungen, wie er ihn zu machen hat. ${ }^{15}$ Der von ihm unterwiesene Hersteller, der mit ihm zusammenarbeitet und auf ihn hört, hat zwar kein Wissen, aber "rechten Glauben" ( $\pi$ i $\tau \tau \iota \varsigma$ ò $\theta \dot{\eta})$. Der Nachahmer hingegen hat von den Dingen, die er erzeugt, weder Wissen, da er sie nicht anwendet, noch richtige Meinung, weil er nicht notwendig mit dem Wissenden zusammenarbeitet und von ihm keine Weisungen erhält (602 a). Ja, noch schlimmer: statt auf den Wissenden zu hören, stellt er die Dinge so dar, wie sie der unwissenden Menge schön erscheinen (602 b). Da der Nachahmer ohne Wissen um die Natur der Dinge noch um ihre Eignung im praktischen Gebrauch seine Kunst ausübt, ist diese im besten Falle "bloßes Spiel und kein Ernst" (ibid.).

14 Eine ähnliche, allerdings kompliziertere Einteilung trifft Sophistes 219: dort werden unterschieden $\kappa \tau \eta \tau \leftarrow \kappa \grave{~} \tau \dot{\varepsilon} \chi \nu \eta$, die "erwerbende" Kunst, d.h. Künste, die das benützen, was die Natur uns gibt (wie z.B. die Jagd oder die Fischerei), dann die $\pi \circ \eta \eta \tau \kappa \dot{\eta} \tau \dot{\varepsilon} \chi \nu \eta$, d.h. Künste, die herstellen, was in der Natur nicht vorkommt (von $\pi$ oin $\sigma$ เ ganz unplatonische unser Wort Poesie); diese "poietischen" Künste werden weiter unterteilt in solche Künste, die den Menschen unmittelbar nützen, und solche, die mittelbar nützen (z.B. durch Herstellung von Werkzeugen), und solche, die nachahmen und niemandem nützen: Rhetorik, Dichtung und Malerei. Dass die Nachahmung ( $\mu i \mu \eta \sigma ı)$ hier wie dort zu den $\tau \dot{\varepsilon} \chi \nu \alpha \iota$ gerechnet wird, bedeutet keine Anerkennung ihres $\tau \dot{\varepsilon} \chi \nu \eta$-Charakters; vielmehr wird hier die Ansicht der Verteidiger und Freunde der Sophisten und der Kunst aufgenommen, um sie in der Durchführung des Gedankens wie auch sonst umso schärfer wieder von ihr $\mathrm{zu}$ trennen. Die "Nachahmungskunst" ist Platon keine $\tau \dot{\varepsilon} \chi \sim \eta$ der Nachahmung, sondern vielmehr Nachahmung $\operatorname{der} \tau \dot{\varepsilon} \chi \nu \eta$.

15 Ähnlich Kratylos 390 b - c.

PLATO, The electronic Journal of the International Plato Society, n 9, 2009.

http://gramata.univ-paris1.fr/Plato

(c) All rights of reproduction of any form reserved. 
Dem ontologischen Abfall von der Idee über das Ding zum Bild des ersten Argumentes entspricht also hier im vierten Argument ein dreifacher Verfall des Wissens. Am besten kennt die Schönheit und Richtigkeit eines Dinges der dieses Gebrauchende. Er teilt sein Wissen dem Handwerker mit, so dass dieser, ohne das auf Erfahrung gegründete Wissen von der Natur des herzustellenden Gegenstandes zu haben, brauchbares Gerät fabrizieren kann. Da der Grad der Erkenntnis sich bei der Vermittlung von der obersten Stufe zur zweiten vermindert, hat der Handwerker keine Wissen ( $\dot{\varepsilon} \pi\llcorner\sigma \dot{\eta} \mu \eta)$ mehr, sondern nur noch eine rechte Meinung (ỏp $\theta \dot{\eta} \pi i \sigma \tau \iota \varsigma$ bzw. óp $\theta \dot{\eta} \delta$ $\left.\dot{o}^{\xi} \xi \alpha\right)$. Der auf der dritten Stufe stehende Nachahmer und seine Kunst haben hingegen keinen Bezug mehr zum praktischen Nutzen. Ohne diesen Bezug ist sie unnütz, bloßes Spiel. Sie steht auch zu keiner der beiden anderen $\tau \dot{\varepsilon} \chi \nu \alpha \iota$ in einem engen, in der Natur der Sache angelegten Zusammenhang, wie er zwischen der gebrauchenden und der herstellenden $\tau \dot{\varepsilon} \chi \nu \eta$ besteht. Und keine von diesen braucht den Nachahmer. Deshalb fällt auch kein Wort darüber, dass der Handwerker seinerseits die richtige Meinung, die er besitzt, (in einem durch die Weitergabe erneut getrübten Grad der Klarheit) an den Nachahmer weitergibt. Dieser muss sich sein Wissen von den Dingen selbst holen, erhält aber von allem nur die nutzlose sinnliche Erscheinung (598 b).

Welchen Grad der Erkenntnis der Nachahmer genauerhin erreicht, sagt uns das sogenannte Liniengleichnis vom Ende des 6. Buches (509 d - $511 \mathrm{e})$, an das hier gedacht werden muss. ${ }^{16}$ Das Gleichnis nimmt die Unterscheidung von

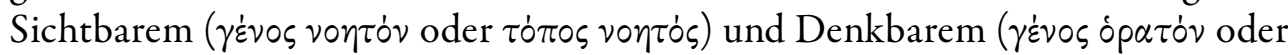

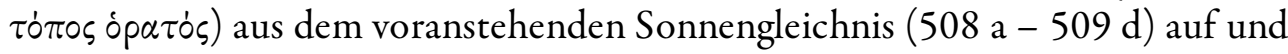
differenziert diese beiden Bereiche weiter aus. ${ }^{17}$ Das Sichtbare und das Denkbare

16 Zum Liniengleichnis u.a. UTERMÖHLEN 1967, KARASMANIS 1988, BORMANN 1987, 55ff., SMith 1996, Cludius 1998, Kersting 1999, 216ff., GERSON 2003, 148ff, v.a. 180ff., zuletzt DESJARDINS 2004, $55 \mathrm{ff}$.

17 Im sog. Sonnengleichnis wurde ausgeführt, dass das Gute, als die höchste Idee, "im Bereich des Denkbaren im Verhältnis zur Vernunft und zu den Gegenständen des Denkens" das ist, was "die Sonne im Bereich des Sichtbaren im Verhältnis zum Gesichtssinn und zum Sichtbaren" ist $(508 \mathrm{~b}-\mathrm{c})$. Zur Verdeutlichung weist Sokrates auf die vertraute Erfahrung hin, dass im Mondlicht die Gegenstände ihre Farben und scharfen Konturen verlieren, und vergleicht dann das Sehen bei Tageslicht mit der Betrachtung des Seienden durch die Vernunft und das Sehen bei Mondlicht mit der Betrachtung der Dinge der vergänglichen Welt durch die Sinne. Wenn die Seele "fest gerichtet ist auf das, worauf das Licht der Wahrheit und des Seienden fällt, dann erfasst und erkennt sie es und scheint im Besitz der Vernunft zu sein. Wenn sie aber auf das mit Finsternis Gemischte, das Entstehende und Vergehende schaut, dann fällt sie dem bloßen Meinen anheim, wird stumpfsinnig, wirft die Meinungen herüber und hinüber und macht

PLATO, The electronic Journal of the International Plato Society, n 9, 2009.

http://gramata.univ-paris $1 . \mathrm{fr} /$ Plato

(C) All rights of reproduction of any form reserved. 
sollen vorgestellte werden "wie eine in zwei ungleiche Abschnitte geteilte Linie". Jeder dieser Abschnitte soll wieder nach dem gleichen Verhältnis geteilt werden. ${ }^{18}$ Das Ergebnis ist eine Strecke mit den Abschnitten AB, BC, CD, DE. Es sollen sich verhalten $\mathrm{CB}$ zu $\mathrm{AC}$ wie $\mathrm{EB}$ zu DC und weiterhin $\mathrm{AC}$ zu CB wie $\mathrm{AD}$ zu DC und wie CE zu EB. Nach einer Drehung der Linie in die vertikale Richtung, werden dem obersten Abschnitt diejenigen Gegenstände zugeordnet, die "der Verstand selbst erfasst mit der Kraft der Dialektik". Der zweite Abschnitt von oben entspricht den $\dot{\pi} \circ 0 \dot{\varepsilon} \sigma \varepsilon ı \varsigma$, d.h. den Gegenständen der Mathematik und der ihr verwandten Wissenschaften. ${ }^{19}$ Die nächste Teilstrecke CD umfasst die ganze Welt der natürlichen Dinge, aber auch jede Art von "Erzeugnissen des

nunmehr den Eindruck, als sei sie aller Vernunft bar." (508 d). Die Parallelisierung von Erkenntnistheorie und Ontologie, von ontologischer Hierarchie und Erkenntnisgewinn ist der gemeinsame Nenner von Sonnen-, Linien- und Höhlengleichnis. Zur Idee des Guten RosS 1971, 39ff., FERBER 1984, SANTAS 1986, 96-114.

18 Die daraus resultierende Längengleichheit der Abschnitte BC und CD, die in jedem Fall gegeben ist, unabhängig davon, wie das Ausgangsverhältnis AC gewählt wurde, scheint keine Rolle zu spielen; sie schlägt sich jedenfalls nicht in der im Dialog folgenden Entfaltung des Gleichnisses nieder.

19 Das dialektische Denken der vónбıs unterscheidet sich von dem mathematischen Denken der

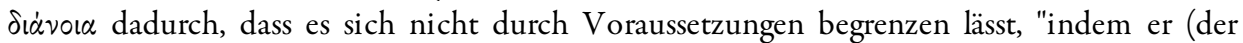
Verstand) die Voraussetzungen nicht als unbedingt Erstes und Oberstes, sondern in Wahrheit als bloße Voraussetzung, gleichsam als Stufen und Ausgangspunkte nimmt, damit der Verstand bis zum Voraussetzungslosen vordringend an den wirklichen Anfang des Ganzen gelange, und wenn er ihn erfasst hat, an alles sich halte, was mit ihm in Zusammenhang steht, und wieder zum Ende herabsteige, ohne irgendwie das sinnlich Wahrnehmbare dabei mit zu verwenden, sondern nur die Ideen selbst nach ihrem eigenen inneren Zusammenhang, und mit Ideen auch abschließe" (511 b - c). Die mathematische Erkenntnis ist hingegen in zweierlei Hinsicht an Voraussetzungen gebunden. Zum einen, weil sie anschauungsgebunden ist und die mathematischen Konstruktionen mit Hilfe empirischer Gegenstände sinnlich abbildet; zum anderen, weil sie sich durch axiomatische Setzung die Grundbegriffe und Lehrsätze vorgeben lässt und sie wie einen festen und gewissen Wissensanfang behandelt. Aus der Perspektive des Dialektikers sind diese Basissätze der Wissenschaft aber nicht unhinterfragbares und rechtfertigungsunbedürftiges Wissen, sondern Hypothesen, die zu untersuchen und ihrerseits auf ihre Voraussetzung hin zu befragen sind, bis im Allerhöchsten und Unerschütterlichen ihr Grund ausgemacht werden kann. Dass unter den Hypothesen der Dianoetiker letztlich die Annahme der Ideen verstanden werden darf, legt Phaidon $100 \mathrm{~b} f f$. nahe. Zur Zwischenstellung der Mathematik und der Zahlen zwischen Ideen und Konkreta bei Platon vgl. Aristoteles, Metaphysik 987 b 14ff.; dazu TÖPLITZ 1929-1931, BRENTLINGER 1963, ANNAS 1975, CHEN 1992, 215-227; zuletzt PRITCHARD 1995, 91-118; ferner GAISER 1963 und REALE 1993, 211-226 und 243-254 (im Lichte der "ungeschriebenen Lehre" im Sinne der Tübinger Schule).

PLATO, The electronic Journal of the International Plato Society, n 9, 2009.

http://gramata.univ-paris $1 . \mathrm{fr} /$ Plato

(C) All rights of reproduction of any form reserved. 
menschlichen Kunstfleißes" (510 a). Dem unterste, vierten Abschnitt schließlich werden die Abbilder der sich auf der dritten Stufe befindlichen Originale

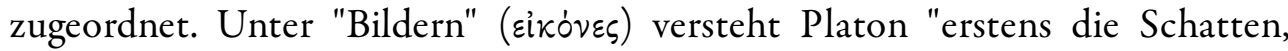
sodann die Spiegelbilder im Wasser und auf den Oberflächen dichter, glatter und glänzender Körper und alles Ähnliche", also auch die Produkte der Maler, die im ersten Argument unter diese "Phantasmen" ("Sehirrtümer") gereiht worden waren. Diesen vier Abschnitten werden sodann vier "Seelenzustände" zugeordnet: reine Vernunfttätigkeit (vónors) dem obersten, Verstandestätigkeit ( $\delta \dot{\alpha} \nu \circ \iota \alpha)$ dem zweiten, dem dritten Glauben (Fürwahrhalten; $\pi i \sigma \tau \iota \varsigma)$ und dem letzten die bloße Mutmaßung ( $\left.\boldsymbol{i}_{\kappa} \alpha \sigma i \alpha\right)$ (511 d - e). Die beiden unteren Abschnitte bilden zusammengenommen den Bereich der Meinung $(\delta \dot{o} \xi \alpha)$, die

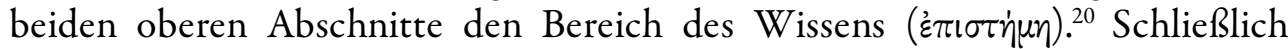
werden noch dem Bereich des Wissens das superiore Sein und dem Bereich der Meinung das inferiore Werden zugeordnet (534a): während die Verstandes- und Vernunfttätigkeit sich dem Sein (dem, "was ist") widmen und eben darum allein Erkenntnis erlangen, beschäftigen sich Vermuten und Glauben mit dem Werden (das Zusammengesetzte und Veränderliche, das "was gleichzeitig ist und nicht ist") und gelangen darum eben nicht über das auf das Sichtbare und sinnlich

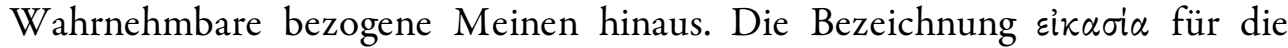
unterste Erkenntnisstufe rührt zweifellos von den 501 a genannten "Bildern"

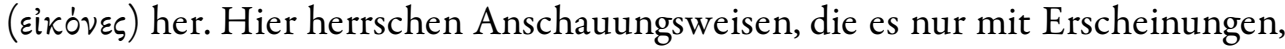
Phantasmen zu tun haben und über diese auch nicht hinauskommen. Während die mathematischen Hypothesen ein Transitum auf dem Weg zum reinen Denken der Ideen sein kann, führt von den Bildern kein Weg hinauf auf die Leiter der Erkenntnis. ${ }^{21}$ Das konkrete Objekt ist deshalb trotz seiner Defizienz gegenüber den Gegenständen der Mathematik und den Ideen seinem Abbild allemal vorzuziehen. Diesem im Liniengleichnis gezeichneten Zustand der

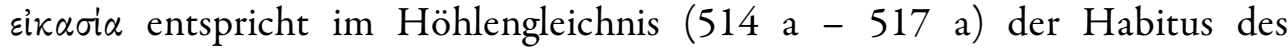

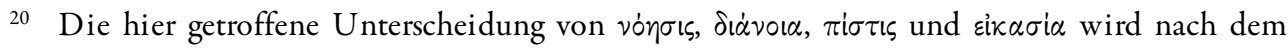
Höhlengleichnis noch einmal aufgenommen (533 e - 534 a). Im Unterschied zu $511 \mathrm{~d}$ - e ist

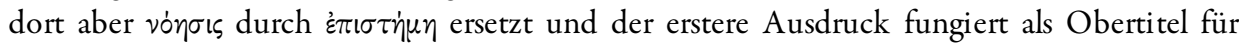

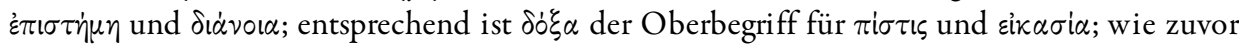
wird $\dot{\varepsilon} \pi \iota \tau \dot{\eta} \mu \eta$ der $\diamond \dot{\sigma} \sigma i \alpha$ und $\delta \dot{\xi} \xi \alpha$ der $\gamma^{\dot{\varepsilon} \nu} \varepsilon \sigma \iota \varsigma$ zugeordnet.

21 Wiederholt betont Platon, dass die Beschäftigung mit der Mathematik zum wahrhaft Seienden hinlenkt; vgl. beispielsweise aus dem Folgenden 523 a, 525 a, 527 b. Nichts dergleichen von dem Verhältnis zwischen Bild und Ding und diesen zu den Ideen.

PLATO, The electronic Journal of the International Plato Society, n 9, 2009.

http://gramata.univ-paris 1.fr/Plato

(C) All rights of reproduction of any form reserved. 
Höhlenbewohners, der im Dunkeln gefesselt es immer nur mit den undeutlichen Bildern der vom Feuer an die Wand geworfenen Schatten zu tun haben wird. ${ }^{22}$

\section{Argument: Für die niederen Instinkte geschaffen}

"Auf was für einen Teil des Menschen aber richtet sich die Wirkung, die ... dieses Nachahmen ... im dreifachen Abstand von der Wahrheit ... ausübt?" (602 c), lautet die Frage, die das fünfte Argument eröffnet, in dem das Verhältnis von Dichtung und Malerei zur Seele des Publikums untersucht wird. Dazu greift

22 Platon unterscheidet hier Wissen und Meinung deutlich anhand distinkter und unverwechselbarer Gegenstandsbereiche. Danach beschränkt sich Wissen auf wissbare Gegenstände und Meinung entsprechend auf meinbare Gegenstände. Vgl. 475 d - 480 b: Nachdem den "Schaulustigen" und "Hörbegierigen", den Träumenden, die "Weisheitsliebenden", die Wachenden, gegenübergestellt und ihnen die Meinung bzw. die Erkenntnis zugeordnet wurde (476 c - d ff.), heißt es: "Auf etwas anderes also hat seine regelrechte Beziehung das Meinen, auf etwas anderes hinwiederum das Wissen, jedes von beiden nach der besonderen Eigenart seines Vermögens." (477 b); "Jedes von beiden (Wissen, Meinung) bezieht sich also, da es etwas anderes vermag, seiner Natur nach auf etwas anderes." (478 a); "Wenn nun das Seiende durch Wissen erfassbar ist, muss dann nicht das durch Meinung Erfassbare etwas anderes sein als das Seiende?" (478 b); "...dass diese letzeren dasjenige über alles schätzen und lieben, was der Erkenntnis, jene dagegen nur das, was der Meinung zugänglich ist. ... Diejenigen also, die jegliches wirklich Seiende hochhalten, muss man doch Wahrheitsliebende (Philosophen), nicht aber Meinungsliebende nennen." (479 e - 480 a). Vgl. auch Timaios 27 e - 28 a; ferner Theätet $157 \mathrm{ff}$. und Protagoras $356 \mathrm{~d}$ f.. Trotzdem hat man versucht diese Zweiteilung der Welt in mundus intelligibilis und mundus sensibilis zu verwischen. Es handle sich bei vónбıs,

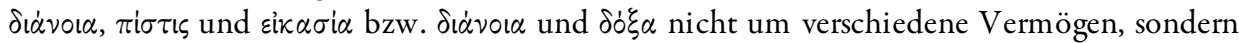
lediglich um unterschiedliche Zustände desselben Vermögens, i.e. um aufeinander aufbauende Erkenntnisweisen, die ein und dasselbe Seiende erfassen. So etwa EBERT 1974, FINE 1978 und 1990, ANNAS 1981, 190ff., SCHUBERT 1995, SZAIF 1998, $183 \mathrm{ff}$,, und PERL 1997. Dagegen zu Recht beispielsweise NeHAMAS 1975, KeTCHUM 1980, Ferber 1984; zuletzt GERSON 2003, 148ff., und GILL 2003, 38ff.. Zur platonischen Erkenntnistheorie im Allgemeinen ferner MORGAN 1983, GRAESER 1991, und SMITH 2000; vgl. auch die Verweise zum Liniengleichnis in Anm. 16. EBERT 1974, 73f., sich auf Proklos (In Platonis Rem

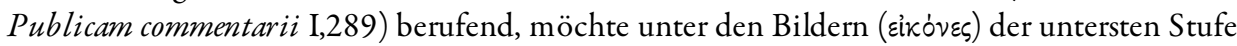
der $\varepsilon i k \alpha \sigma i \alpha(509$ e) ausschließlich Schatten- und Spiegelbilder und keinesfalls Bilder der Kunst verstanden wissen. Doch genau dies ist die Pointe. Der von EBERT veranschlagte enge Sprachgebrauch lässt sich für Platons Zeitgenossen nicht nachweisen und schon gar nicht für Platon selbst, der nicht nur den Begriff wiederholt auf die Produktionen der Kunst anwendet, sondern diese expressis verbis als Schatten- und Spiegelbilder bezeichnet (beispielsweise in Politeia 598 b, 599 a f., oder Sophistes 235 a - 236 c). Gemälde und Schatten sind eben von derselben Gattung.

PLATO, The electronic Journal of the International Plato Society, n 9, 2009.

http://gramata.univ-paris $1 . f r / P l a t o$

(c) All rights of reproduction of any form reserved. 
Platon vereinfachend auf die Psychologie des 4. Buches zurück, wo zwischen einem höheren, vernünftigen und einem niederen, begehrenden Seelenteil unterschieden worden war. ${ }^{23}$ Zunächst scheint die Argumentation aber abzuweichen. Dem Auge, heißt es, erscheinen dieselben Dinge je nach der Entfernung, aus der sie betrachtet werde, als groß oder klein. "Und dieselben Dinge erscheinen gebogen oder gerade, je nachdem wir sie im Wasser oder außerhalb betrachten. Oder sie erscheinen bald vertieft und bald erhaben, weil unser Blick durch die Farben irregeführt wird. Und diese ganze Verwirrung spielt sich offenbar in unserer Seele ab, und die Kunst der Schattenmalerei und die der Gaukler und viele andere mehr machen sich diese Schwäche unserer Natur zunutze und lassen es an keinem Blendwerk fehlen" (602 c - d). Das Auge, überhaupt die Sinnesorgane, seien ungeeignet, die wahre Beschaffenheit eines Gegenstandes zu bestimmen. Hierfür stehe dem Menschen die Wissenschaft des Messens, Zählens und Wägens zu Gebote, die zuverlässige, sich gleich bleibende Ergebnisse erziele. $^{24}$ Nun stehen die trügerische Sinneswahrnehmung und die ihr

23 Im 4. Buch waren genauerhin drei Seelenteile unterschieden worden: das Begehren

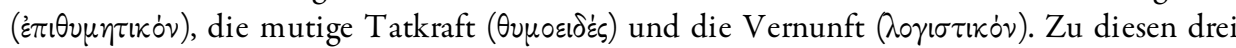
Teilen der Seele werden in Analogie gesetzt die drei Stände (Handwerker, Bauern und Kaufleute - nichtregierende Wächter - Philosophenkönige) und die drei Polisstufen (gesunde Polis - üppige Polis - Philosophen-Polis). Aus dieser Gliederung wird deutlich, dass die Seele wie die Gesellschaft eine Vielheit von Teilkräften ist, die in einem stets bedrohten Spannungsverhältnis zueinander stehen. Harmonie herrscht, wenn der mutvolle Tatendrang auf die Stimme der Vernunft hört, und wenn beide, Vernunft und Mut in Einheit, das Begehren vor dem Unmaß der Maßlosigkeit der Begierde bewahrt. Erst dann leistet jeder Seelenteil das Seine, und die Verfassung der Seele ist gut. Die Frage des 10. Buches ist also die Frage nach dem Beitrag der Kunst zu einer guten Verfassung der Seele und also der Gesellschaft. Auch die Rede von der Unsterblichkeit der Seele im sog. Er-Mythos am Ende des 10. Buches (613 e 621 d) greift auf die Unterteilung der Seele im 4. Buch zurück, aber auch auf das 7. Buch (518 ff), wo der vernünftige Teil der Seele etwas Göttliches und Unveränderliches genannt wird, im Gegensatz zu den anderen Teilen der Seele, die dem Körperlichen und also Vergänglichen verbunden sind. Wenn am Ende des 10. Buches von der Unsterblichkeit der "wahren Natur

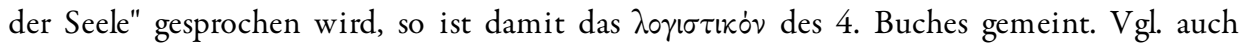
Phaidon 79 d ff. und Timaios 90 a. Dazu v.a. WoOdS 1987, LeSSES 1987, MiLler 1998, GERSON 2003, 99ff.; ferner WIND 1932; zur Analogie von Seele und Polis insbes. SAUNDERS 1962, Williams 1973, NeU 1971, PAPPAS 1995, 157ff., ANNAS 1981, 109ff., und HÖFFE 1997; zur Unsterblichkeit der Seele im 10. Buch der Politeia v.a. SHINER 1972, SZLEZÁK 1976, GERSON 1987.

24 Vgl. unten zu Philebos 50 ff.. Von der Messkunst als Korrektur bzw. Rettung vor der trügerischen Sinneswahrnehmung spricht Platon wiederholt, am eindringlichsten in Protagoras 356 c - 357 b: "Erscheinen eurem Gesicht die Größen in der Nähe größer, in der Ferne kleiner, oder nicht? ... Und das Dicke und die Menge ebenso? Und die gleichen Töne

PLATO, The electronic Journal of the International Plato Society, n 9, 2009.

http://gramata.univ-paris 1.fr/Plato

(C) All rights of reproduction of any form reserved. 
widersprechende wissenschaftlich ermittelte Realität mit je verschiedenen Kräften der menschlichen Seele in Verbindung. Die wissenschaftliche Erkenntnis beruhe nämlich auf dem "besten Teil der Seele", auf der Vernunft; die Welt der Erscheinungen hingegen spreche zum "Minderwertigen in uns". Die strikte Trennung der beiden Bereiche sieht Sokrates bestätigt durch das Prinzip, "dass ein und derselbe über dasselbe unmöglich Gegenteiliges meinen kann" (602 d). Deshalb kann die Vernunft als "der Teil der Seele, der auf Grund von Messungen urteilt", nicht empfänglich sein für die wechselnden Erscheinungen der sinnlichen Wahrnehmung. Folglich ist die Malerei und die nachahmende Kunst überhaupt, die es lediglich mit den Gegenständen, wie sie sinnlich wahrgenommen werden, zu tun hat, nicht nur "weit weg von der Wahrheit", sondern auch "weit weg von der Vernunft". "Die nachahmende Kunst ist also minderwertig, verkehrt mit Minderwertigen und gebiert Minderwertiges" (603 b), lautet das abschließende Verdikt.

Im weiteren Verlauf der Argumentation überträgt Platon nun diesen Befund auf die Dichtung. Auch die Dichtkunst paktiert mit der Wahrnehmung und der Sinnlichkeit und trägt so zur Verstärkung des seelischen Konfliktes zwischen Vernunft und Sinnlichkeit bei. Indem sie die Affekte und Emotionen anspricht, führt sie zum Umsturz der Vernunft und zum Aufruhr gegen die Gesetze. Der Mensch sei, schreibt Platon, wie bei der Bestimmung optischer Erscheinungen, so auch beim Handeln, verschiedenen Kräften seiner Seele ausgesetzt: einerseits der Vernunft, die beispielsweise gebiete, Schmerz gefasst zu ertragen, andererseits den Trieben und Leidenschaften, die vielmehr laute Klage über den Schmerz verlangten. Was uns dabei zum Widerstand auffordert, das ist "die Vernunft

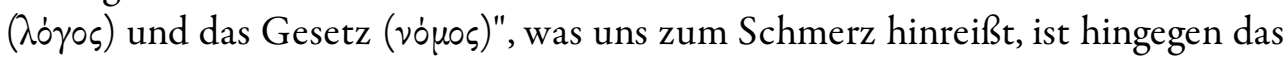
Gefühl $(\pi \dot{\alpha} \theta \circ \varsigma)$ allein. Dieses "gleichzeitige Auftreten entgegengesetzter Impulse in einem Menschen wegen derselben Sache" impliziert "zwei verschiedene

aus der Nähe stärker, aus der Ferne schwächer? ... Hinge nun eurer Wohlergehen davon ab, dass ihr die großen Entfernungen für euer Handeln wähltet, die kleinen aber miedet und unbeachtet ließet, worin müsstet ihr dann das Heil eueres Lebens finden? In der Messkunst oder in der Macht des Scheines? Oder würde uns die letztere nicht irre führen und zur Folge haben, dass wir oftmals die wahren Verhältnisse völlig verdrehen und dann Reue empfinden über unser Tun sowie über unsere Wahl des Großen und Kleinen, während die Messkunst dieses Trugbild seiner Macht entkleiden und durch klare Feststellung des wahren Tatbestandes unserer an dieser Wahrheit festhaltenden Seele zur Ruhe verhelfen und so zur Heilbringerin für unser Leben werden würde? Würden die Leute zugeben, dass uns bei dieser Annahme die Messkunst zum Glücke verhelfen würde oder etwa irgend eine andere Kunst?"; im Folgenden wird ein auf der Messkunst gegründetes Wissen der auf Sinneswahrnehmung basierenden bloßen Meinung gegenübergestellt.

PLATO, The electronic Journal of the International Plato Society, n 9, 2009.

http://gramata.univ-paris 1.fr/Plato

(C) All rights of reproduction of any form reserved. 
Elemente in seiner Natur" (604 b). Das eine, das Element der Vernunft, erlaubt uns ruhig zu bleiben, den Schmerz zu lindern und die Seele wieder aufzurichten, so dass dem Geschehenen seine wahre Bedeutung beigelegt und angemessene Konsequenzen gezogen werden können $(604 \mathrm{~b}-\mathrm{c})$. Das andere Element der Seele hingegen ist "unvernünftig und tatenlos und mit der Feigheit befreundet" und "zieht uns zu Erinnerungen an das Leiden und zu den Wehklagen hin und ist damit nicht zu sättigen" (604 d). Hinzu kommt, dass dieser niedere Teil der Seele um vieles leichter zu befriedigen ist als jener vernünftige. "Eben das, das Reizbare in uns, gibt reichlich Stoff zu Nachahmungen aller Art. Der besonnene und ruhige Charakter aber, der sich stets gleich bleibt, lässt sich nicht leicht nachahmen, und wenn er nachgeahmt wird, ist er nicht leicht zu verstehen, besonders nicht für eine festliche Volksversammlung und eine bunte Menschenmenge, wie sie sich im Theater zusammenfindet. Denn für sie ist das die Nachahmung eines Zustandes, der ihr fremd ist" (604 e). Die Dichtung kann also nicht nur den vernünftigen Teil der Seele nicht ansprechen, sie kann auch gar kein Interesse daran haben, wenn sie bei der Menge Beifall finden will. ${ }^{25}$ Dichter und Maler, der am Schluss des Argumentes dem Poeten wieder an die Seite gestellt wird, müssen also aus Platons Staat ausgeschlossen werden, denn sie stellen nicht nur her, was "im Vergleich mit der Wahrheit minderwertig" ist, sondern "regen den niederen Teil der Seele an und nähren ihn, und indem sie ihn stark machen, verderben sie den vernünftig überlegenden, genauso, wie wenn man

25 Die Abhängigkeit der Dichter und Maler, wie der Redner und Politiker, vom Geschmack und von den Meinungen der Menge und ihre Ausrichtung an ihr, kritisiert Platon häufig. Wer sich auf die Masse einlässt, macht diese zum Herren über sich und ist gezwungen zu tun, was jene lobt, also das darzustellen, was die Masse begreift und also einzig sehen und hören will. Beispielsweise Gorgias 502 b ff.: Die Dichter wagen es nicht, sich den Erwartungen des Publikums zu widersetzen und ihm Nützliches zu sagen, wenn es ihm unangenehm ist, sondern verlegen sich stattdessen darauf zu "schmeicheln", auch wenn sie dabei wissentlich Schlechtes sagen müssen. Sie tun es, weil Beifall und Anerkennung des Publikums ihre Erfüllung sind. Darin gleichen sie den Rednern (der "Volksrednerei", der "Redekunst ... vor den Versammlungen der freien Bürger"). Die Masse der Zuschauer übt aber ihren korrumpierenden Einfluss nicht nur auf die Dichter und Redner aus, indem sie diesen die Art ihrer Produktion vorschreibt, sie ist auch imstande, gute Menschen auf ihr Niveau herunterzuziehen. Von dieser Gefährdung (junger) philosophischer Naturen, wenn sie dem Einfluss der Massenreaktionen ausgesetzt werden, spricht Platon auch im 6. Buch der Politeia 492 a ff.. Zur gegenseitige Beeinflussung von Publikum und Dichter zum Schlechten auch Nomoi 658 e ff.; vgl. auch Ion 535 d. Dieser Abhängigkeit der Dichter, Maler und Redner wird stets kontrastierend die Freiheit des Philosophen gegenübergestellt. Ähnlich Theätet 172 c $173 \mathrm{c}$.

PLATO, The electronic Journal of the International Plato Society, n 9, 2009.

http://gramata.univ-paris 1.fr/Plato

(C) All rights of reproduction of any form reserved. 
in einer Stadt die groben Menschen mächtig macht und die Stadt in ihre Hand gibt, die feineren dagegen zugrunde richtet."

\section{Argum ent: Von verderblicher Wirkung für Seele und Gesellschaft}

"Aber noch haben wir nicht die schlimmste Anklage gegen diese Art von Kunst erhoben" (605 e), hebt der nächste Abschnitt an. Diese besteht darin, dass ihre Wirksamkeit, ihre Verführungskraft so groß ist, dass sie imstande ist, "sogar die Besten unter uns" (605 c) zu verderben. Platons letztes Argument handelt nocheinmal vertiefend von den moralischen Auswirkungen auf den vernünftigen Teil der Seele und der Gesellschaft. Dabei wandert der Akzent der $\mu$ i ganz von der produzierenden Nachahmung auf die rezipierende Nachahmung. Selbst vernünftige Leute, fährt Platon fort, die ihre eigenen Gefühle sonst zu beherrschen suchen, im Theater freuen sie sich über die Darstellung leidenschaftlicher Regungen, identifizieren sich mit diesen und lassen sich $\mathrm{zu}$ Mitgefühl, Gejammer oder Freude, oder gar zu Geschrei hinreißen (605 d - 606 d) ${ }^{26}$ Die größte Gefahr dabei liegt darin, "dass das Genießen des fremden

26 Dazu auch Mastrangelo \& HARRIS 1997. Bereits im 3. Buch (387 b ff.) hatte Platon von den Dichtern verlangt, keine Darstellung jammernder und klagender Helden und Götter zu geben; solche Darstellungen seien nicht nur nicht wahr, sondern würden Zurückhaltung und Selbstbeherrschung nehmen und statt dessen die Affekte wecken. Hier wie dort richtet sich Platon gegen eine Auffassung, die der Darstellung des leidenden Helden eine positive Wirkung auf das Publikum beimaß, insofern die Darstellung fremden Leids über eigene Sorgen hinwegtröste. Am deutlichsten ist diese Auffassung bei Timokles, Fragm. 6 (Poetae Comici Graeci, hrsg. R. Kassel \& C. Austin, Bd. 7, Berlin 1989, 758f.) ausgesprochen. Die Katharsislehre des Aristoteles ist bekannt. Platon sieht nicht Trost von der Dichtung ausgehen, sondern Weckung der Affekte, Stärkung des unvernünftigen Seelenteiles und damit den Umsturz der Ordnung in der Seele, woraus Unordnung und Ungerechtigkeit auch im Staat entstehen. Was Platon über die Erregung der Affekte durch die Dichtung sagt, stimmt übrigens inhaltlich mit der Beschreibung der Wirkung des $\lambda$ ó Sonderfalls in der Helena des Gorgias überein (Hermann Diels \& Walther KranZ, Die Fragmente der Vorsokratiker, 1. Aufl. Berlin 1903, n. 82 B 11,9). Im Gegensatz zu Platon sieht der Sophist aber in der Fähigkeit, durch Darstellung von fremdem Pathos die Affekte der Hörer zu wecken, die preiswürdige Macht des Logos. In Gorgias 501 d ff. lässt Platon die eine Zielsetzung der Dichtung, nämlich Freude zu spenden, mit einer anderen, auch für die Dichtung beanspruchten, nämlich zu nützen, konkurrieren. Beide Ziele schließen einander aus. Platon gründet seine Argumentation ähnlich wie Isokrates in der Rede an Nikokles II,4249, auf die empirisch erwiesene Tatsache, dass die Natur der meisten Menschen ihre Freude nicht am Nützlichen hat: Paränese und Belehrung werden bei der Menge kaum Freude hervorrufen. Homer und die Tragiker haben diese Natur der Menschen gut erkannt und ihnen

PLATO, The electronic Journal of the International Plato Society, n 9, 2009.

http://gramata.univ-paris $1 . \mathrm{fr} /$ Plato

(C) All rights of reproduction of any form reserved. 
Schicksals notwendig auf das eigene zurückwirkt. Wenn nämlich jemand dort die Wehleidigkeit großgezogen hat, dann ist es nicht leicht, sie bei den eigenen Leiden zu unterdrücken" (606 b). Die Dichtung weckt in der Seele des Zuschauers die Affekte, und indem der Zuschauer dies zulässt, nährt und stärkt er den unvernünftigen Teil seiner Seele, und zwar für alle Gelegenheiten. Mit anderen Worten: Die scheinbar unverbindliche, weil fremden Schicksalen geltende Reaktion auf das Bühnengeschehen ist folgenreich deshalb, weil sie unfähig macht, auf eigenes Schicksal weniger affektvoll zu reagieren (Rep.606 b). Das seelische Erleben, das der Dichter durch die Darstellung von fremdem Pathos dem Zuschauer vermittelt, erscheint Platon also deshalb so gefährlich, da die Emotionen, die durch die Illusion der Dichtung entfacht und eingeübt werden, sich notwendig auch dann in gleicher unkontrollierter Heftigkeit einstellen, wenn den Menschen selbst ein ähnliches Schicksal trifft wie das, das im Theater seine Affekte erregt hat. ${ }^{27}$ Das heißt, die von den Dichtern geweckten und genährten Affekte können beim Verlassen des Theaters nicht abgelegt werden, vielmehr werden sie habituell und strahlen auf das übrige Leben,

für Auge und Ohr gegeben, woran sie Freude haben.

27 Vgl. 395 c - d: "Wenn wir also an unserem ersten Satz festhalten, dass unsere Wächter, aller sonstigen Geschäfte ledig, die mit vollster Sachkenntnis ausgerüsteten Hüter der Freiheit der Stadt sein und kein anderes Geschäft betreiben sollen, so weit es nicht darauf Bezug hat, so dürfen sie offenbar nichts anderes tun oder nachahmen; wenn sie aber nachahmen, so müssen sie gleich von Kind auf die diesem ihrem Beruf entsprechenden Vorbilder nachahmen, also tapfere, besonnene, fromme, freie Männer und alles was dem gleicht, alles Unfreie aber weder tun noch es nachzuahmen geschickt sein und überhaupt nichts Hässliches, auf dass nicht aus der bloßen Nachahmung das wirkliche Sein als Frucht für sie hervorgehe. Oder hast du nicht gemerkt, dass die Nachahmungen, wenn sie von Jugend auf ununterbrochen fortgesetzt werden, zur Gewohnheit und (andern) Natur werden in Beziehung auf den Leib ebenso wie auf Rede- und Denkweise?" (Zum 3. Buch der Politeia im Folgenden.) Auch der Künstler selbst bleibt vom Charakter der Personen, die er nachahmend, sich in sie hineinversetzend, darstellt, nicht unberührt; auch er selbst wird von seinen Schöpfungen geformt. Hier wie dort

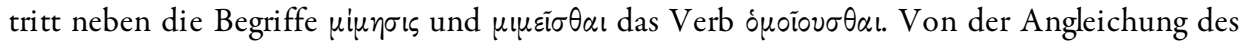
Charakters des Zuschauers an den Charakter des Gesehenen und Gehörten, spricht Platon auch ausführlich in der Erziehungslehre der Nomoi 655 c ff.; ferner in Ibid., 797 c. Als außerplatonisches Beispiel sei Plutarch, Vitae parallele, Solon 29, angeführt: "Nach der Aufführung (eines Stückes von Thespis) sprach er ihn an und fragte ihn, ob er sich nicht schäme, vor so vielen Hörern so große Unwahrheiten zu sagen. Als Thespis antwortete, ob es denn etwas Böses sei, im Scherz solche Dinge zu sagen und darzustellen, stieß Solon heftig mit seinem Stock auf die Erde und sagte: 'Wenn wir diesen Scherz so loben und ehren, dann werden wir ihn bald auch dort finden, wo es um ernste Dinge geht.'"; zit. nach Plutarch, Große Griechen und Römer, übers. Konrat Ziegler, Zürich 1979, 247.

PLATO, The electronic Journal of the International Plato Society, n 9, 2009.

http://gramata.univ-paris $1 . \mathrm{fr} /$ Plato

(C) All rights of reproduction of any form reserved. 
schließlich auf die ganze Gesellschaft aus. ${ }^{28}$ Zuerst findet man etwa einen Spaßmacher nur amüsant, dann verliert man den nötigen Ernst und wird selbst zum Possenreißer (606 c). Und so ist es auch mit allen anderen Leidenschaften und Gefühlen von Freude und Schmerz, die unsere Handlungen begleiten mögen. Auch auf sie wirkt sich ihre Nachahmung in derselben Weise aus: "Sie nährt und begießt das, was doch absterben sollte, und macht das zum Herrscher über uns, was doch beherrscht werden sollte, damit wir besser und glücklicher und nicht schlechter und unglücklicher werden" (606 d). Deshalb dürfen von der Dichtung nur Götterhymnen und Loblieder auf tüchtige Männer in Platons Staat aufgenommen werden. "Nimmst du aber die lustvolle Muse auf, ... dann werden in deiner Stadt Lust und Schmerz König sein statt des Gesetzes und der Vernunft" (607 a). ${ }^{29}$ In seinem Schlussurteil ruft Platon die Vorstellung eines Gerichtsverfahrens wach: Die Rechtmäßigkeit der bereits im 3. Buch ausgesprochenen Verurteilung der Dichter sei durch seine "Verteidigungsrede" bestätigt $(607$ b). Der "alte Streit zwischen Philosophie und Dichtung" sei entschieden: die Dichtung, und mit ihr die Malerei, werden zum Verlassen des Staates aufgefordert. Sie sollen aus dem Exil nur zurückkehren dürfen, "wenn sie einen vernünftigen Beweis dafür vorbringen können, dass sie in einer Stadt mit guten Gesetzen da sein müssen. ..., dass sie nicht nur Freude, sondern auch Nutzen bringen, für die Verfassung und für die menschliche Lebensführung" $(607 \mathrm{c}-\mathrm{d}) .^{30}$

28 NeHAMAS 1988 hat zu Recht hingewiesen auf die Nähe der von Platon kritisierten Wirkweise des antiken Theaters zu der Wirkweise der modernen Massenmedien und der Kritik Platons zu jener Kritik, wie sie etwa von Neil Postman, Jerry Mander oder George Gerbner \& Larry Gross in den 70er Jahren vorgetragen wurde. Die niederen Instinkte sind das Ziel der Massenmedien und unsere Sprache, unsere Reaktionen und Handlungen im wirklichen Leben ahmen Sprache, Reaktionen und Handlungen nach, wie sie uns in diesen vorgeführt werden. Nach Symposion 175 e soll das Griechische Theater ein Publikum von 30000 Zuschauern gefasst haben. Das mag übertrieben sein, trotzdem darf das griechische Drama als das Massenmedium der Antike bezeichnet werden.

29 Vgl. Philebos: Lust und Schmerz gehören dem Bereich des Werdens an (31 c ff., 42 c ff., 53 c ff.), also dem Bereich der bloßen Meinung (37 e ff.), also jener Erkenntnisart, die auf die sinnliche Wahrnehmung beschränkt bleibt und der jede wahre Erkenntnis wesenhaft verschlossen bleiben muss; wahre Erkenntnis ist die einzig reine Lust.

30 Sokrates gibt zu, dass er und seine Gesprächspartner ebenfalls dem Reiz der Dichtung ausgesetzt sind (607 c). Aber weder dies noch die Freundschaft und Achtung, die sie von Kindheit an für Homer als dem "erste Lehrer und Führer all der schönen Tragiker" (595 d; vgl. insbes. 606 e - 607 a) empfunden hatten, können in ihm die Verpflichtung zur Wahrheit aufheben (595 e, 607 c). In den Nomoi, das letzte Werk Platons, das weniger idealistisch von der

PLATO, The electronic Journal of the International Plato Society, n 9, 2009.

http://gramata.univ-paris 1.fr/Plato

(C) All rights of reproduction of any form reserved. 
Mit Ausnahme des letzten Abschnittes war der Dichtung stets die Malerei gleich betroffen an die Seite gestellt worden. Da das letzte Argument nur eine weitere Entfaltung des fünften Arguments darstellt, dürfen wir die gesamte Rede für die platonische Haltung gegenüber der Malerei in Anspruch nehmen. ${ }^{31}$ Sie lässt sich folgendermaßen zusammenfassen: Die Malerei ist ontologisch grundverkehrt gestellt. Sie ist es anfänglich schon, indem sie nicht das eigentliche, wahrhaft Seiende, die Ideen, im Blick hat, sondern nur das hier und jetzt kontingent Seiende, die konkreten Gegenstände der sinnlichen Wahrnehmung. Der Maler, wie auch der Bildhauer, zeigt nicht was jedes Ding an sich ist, sein Wesen, sondern führt uns lediglich ein bestimmtes einzelnes Ding vor Augen, das aber auch reichlich anders beschaffen sein könnte. Damit noch nicht genug, zeigt uns der Maler diesen ohnehin schon mit Zufälligkeit durchsetzten Gegenstand auch noch in einer zufälligen Erscheinungsweise, nämlich in der Weise, wie (nur) ihm

Verfassung des zweitbesten Staates handelt, wird wieder mit der Anwesenheit der Dichter gerechnet. Platon gesteht dort sogar zu, dass die Kunst nach Lust und Freude, die sie beim Publikum erzielt, beurteilt werden muss. Maßstab darf aber nicht der von der unzureichenden Bildung abhängige Beifall beliebiger Menschen sein, sondern das, was die Besten und ausreichend Erzogenen, letztlich das, was den Einen, der an Tugend und Wissen alle überragt, erfreut. Da eine derartige Einsicht von den Künstlern nicht zu erwarten ist, werden sie einem Gesetzgeber unterstellt, an dessen Vorgaben sie sich zu halten haben. D.h. nachdem man die Kunst doch nicht gut ausschließen kann, soll sie wenigstens einer rigorosen Kontrolle durch die Philosophen unterstellt werden; s. v.a. 659 a ff.; dazu SAUNDERS 1992.

31 KARDAUN 1993, vertritt die Ansicht, Platon führe die Malerei ausschließlich zur besseren Illustration der Verurteilung der Dichtung an, woraus sich aber keineswegs auch nur auf eine Abneigung Platons gegenüber der Malerei schließen lasse. Diese Ansicht wird durch ihre Wiederholung (KARDAUN 1997 und 2000) nicht weniger unsinnig. NEHAMAS 1982 wiederum gesteht zwar zu, dass Platon kein Freund der Malerei ist, er habe aber nur die Dichtung aus dem Staat verbannt, denn nur dieser werde der eine Verbannung allein rechtfertigende Vorwurf einer die Moral verderbenden Wirkung gemacht, während die Malerei als "bloßes Spiel und kein Ernst" (602 b) diese Würdigung gar nicht erfährt. Diese Argumentation übersieht seltsamerweise, (1.) dass innerhalb des 5. Arguments, das hinsichtlich der verderblichen Wirkung der Künste mit dem 6. Argument eine Einheit bildet, diese Wirkung zunächst an der Malerei aufgezeigt wird, (2.) dass in 603 b - c die Analogie von Malerei und Dichtung hinsichtlich ihrer die Moral verderbenden Wirkung ausdrücklich betont wird, und (3.) dass bereits am Übergang vom 5. zum 6. Argument (605 a - b) folgerichtig Dichtung und Malerei gemeinsam aus dem Staat ausgeschlossen werden, bevor das 6. Argument das bereits im 5. Argument gesagte hinsichtlich seiner gesellschaftlichen Konsequenzen an Hand der Dichtung weiter entfaltet. Dichtung und Malerei werden also zweimal zu einem Zeitpunkt korreliert, zu dem laut NEHAMAS von der Malerei nicht mehr die Rede sein soll.

PLATO, The electronic Journal of the International Plato Society, n 9, 2009.

http://gramata.univ-paris 1.fr/Plato

(C) All rights of reproduction of any form reserved. 
der Gegenstand gerade (nur jetzt) erscheint, also in einem willkürlich gewählten oder nicht gewählten Blickwinkel und in momentaner Beleuchtung; kurz, nicht wie er an sich ist, sondern nur wie er uns erscheint. Diese Kunst ist als Nachahmung einer Nachahmung unüberbrückbar fern von Wahrheit und Wissen, ontologisch und daher auch epistemologisch wertlos und unnütz, aber auch schädlich, weil sie uns drei Stufen unter der Wahrheit zu fesseln und heimisch zu machen sucht. Sie hält uns aber nicht nur fest, sondern verdirbt uns weiter, nämlich dadurch, dass sie nicht die Vernunft, sondern den niederen Teil der Seele mit ihren Affekten und Gefühlen anspricht. Dadurch ist sie verderblich und gefährlich zunächst für den individuellen Charakter und das individuelle Seelenheil, über das Individuum aber schließlich auch für die menschliche Gemeinschaft insgesamt. So stellt die Malerei genau diejenige Situation her, die für den Philosophen die Grundsituation der Verkehrung ist, aus der er die Menschen zu befreien sucht. Die Malerei knüpft die Fesseln, die er löst, je wieder neu. Deshalb muss die Kunst aus dem platonischen Idealstaat ausgeschlossen werden. An ihre Stelle tritt die Philosophie allein.

Deutlicher könnte die Verurteilung aller Kunst nicht ausgesprochen sein. Und trotzdem hat man immer wieder versucht sie zu entkräften oder gar zu widerlegen, entweder mit der Absicht die Kunst vor Platon zu retten oder umgekehrt Platon vor der Verurteilung der Kunst. Dabei hat man auf vermeintliche Widersprüche zwischen dem 10. und dem 3. Buch der Politeia hingewiesen (1.), einen Wandel im platonischen Verständnis des Begriffes der uirnors postuliert, sowie auf Stellen des platonischen Korpus verwiesen, an welchen der Philosoph der Kunst einen direkten Zugang zu der Welt der Ideen zugestehen soll (2.), oder wo er von der göttlichen Inspiriertheit des Künstlers spricht (3.), sowie auf jene zahlreichen Stellen, die vom Schönen handeln (4.). Schließlich habe Platon auch nicht alle Kunst verurteilt, sondern nur eine gewisse zeitgenössische Strömung der Kunst (5.), oder, allgemeiner, nur die illusionistische Kunst im Gegensatz zu einer abstrakten (6.). Ich werde mich im Folgenden jedem einzelnen dieser Argumente ausführlicher zuwenden und auf ihren Gehalt prüfen.

\section{Widerspruch im Staat?}

$\mathrm{Zu}$ Beginn des 10. Buches lobt Sokrates die Art und Weise, in der er in den vorangegangenen Büchern den idealen Staat eingerichtet hat; ganz besonders treffe das zu für die Bestimmungen über die Dichtung, nämlich, "dass wir sie auf

PLATO, The electronic Journal of the International Plato Society, n 9, 2009.

http://gramata.univ-paris 1.fr/Plato

(c) All rights of reproduction of any form reserved. 
keinen Fall zulassen wollen, soweit sie nachahmende Kunst ist" (595 a). Diese Bemerkung scheint sich auf eine Stelle des 3. Buch der Politeia (398 a) zurückzubeziehen, an der bereits vom Ausschluss der Dichter aus der Stadt die Rede gewesen war.

In diesem 3. Buch sowie am Ende des 2. Buches war im Rahmen der Darstellung der Erziehung der zukünftigen Wächter die Rolle der Kunst, insbesondere aber der Dichtung, bereits behandelt worden. Da junge Menschen zu allererst durch Nachahmung lernen, hieß es dort, gehört die Auswahl und Kontrolle der Gegenstände, mit denen sie Umgang haben, zu den vorrangigsten Aufgaben der Erziehung im idealen Staate. Den wichtigsten Zugang zu Beispielen und Vorbilder hatten junge Menschen aber durch die Dichtung, die in der Erziehung der Griechen die erste Rolle spielte. Wenn also das Angebot an Modellen im Interesse der Erziehung kontrolliert werden soll, dann muss an erster Stelle die diese Vorbilder und Beispiele weitgehend zur Verfügung stellende Dichtung untersucht und der Kontrolle unterzogen werden. ${ }^{32}$

In der nun folgenden Analyse unterscheidet Platon zunächst $\lambda \dot{o} \gamma \circ \varsigma$ und $\lambda \dot{\varepsilon} \xi 1 \zeta$, Inhalt und Form der Dichtung (392 c). Was den Inhalt angeht (376 e - 392 c), so werden an erster Stelle die Vorstellungen von den Göttern als falsch kritisiert, wie sie die Werke Homers, Hesiods und anderer vermitteln (377 e - 383 c): Heranwachsende sollen sich als Entschuldigung nicht mehr auf die Untaten der Götter gegen ihre Eltern berufen können, wenn sie sich ungebührlich gegenüber ihren eigenen Eltern betragen (Platon nennt Chronos und Zeus als Beispiele). Die Götter sind vielmehr uneingeschränkt gut und somit Ursache allein von Gutem, von Schlechtem aber niemals. Götter sind, zweitens, wesenhaft stets sich selbst gleich, einfach und unwandelbar und geben auch nicht durch Träume und Erscheinungen vor, wandelbar zu sein. Niemals täuschen, betrügen oder verzaubern sie die Menschen. Ähnliches gelte für Helden und bedeutende historische Persönlichkeiten. ${ }^{33}$ Sodann befasst sich Platon mit der von den

32 Die Einsicht, dass der Umgang mit Werken der Kunst (Malerei und Skulptur werden ausdrücklich angeführt) die gleiche formende oder verformende Wirkung hat wie der zwischenmenschliche Verkehr, hat auch Aristoteles veranlasst, der Jugend den Kontakt mit gewissen Kunstgattungen und -inhalten vor Erreichung eines bestimmten Alters zu verbieten (Politik 1336 a f.; vgl. 1340 a).

33 Dass die Dichter falsche Götter lehren, behauptete schon Hesiod (Theogonie 27); vgl. Solon (Fragment 21), Pindar (Olympische Oden I,28f.), Heraklit (HERMANN Diels \& WaLTHER KRANZ, Die Fragmente der Vorsokratiker, 1. Aufl. Berlin 1903, n. 22 A 22f., n. 22 B 40.42, n. 22 B 56f.). Berühmt die Kritik des Xenophanes (Ibid., n. 21 B 10-16), der die Götter der Dichter für naive Selbstprojektionen der Menschen von einst erklärte. Wahrscheinlich richtete

PLATO, The electronic Journal of the International Plato Society, n 9, 2009.

http://gramata.univ-paris 1.fr/Plato

(C) All rights of reproduction of any form reserved. 
Dichtern überlieferten Hadesmythologie (386 a - 387 c): Die Darstellung der Schrecken der Unterwelt werden verboten, weil sie dem Mut und der Opferbereitschaft der Soldaten abträglich seien. Weiters beanstandet er, dass die Dichtung Götter und Helden über den Tod eines Geliebten oder Freundes wehklagen lassen, dergleichen rufe Verweichlichung hervor (387 d - 392 a). Auch die Szenen homerischen Gelächters werden verurteilt. Überhaupt lasse das Verhalten der Helden Homers vielerlei zu wünschen übrig: Sie sind

sich bereits seine Kritik der Götterdarstellungen bei Homer und Hesiod, insofern sie den Göttern alle möglichen Schandtaten angehängt haben, gegen eine demoralisierende Wirkung solcher Darstellungen. Die Argumentation, dass den Menschen der angeblich von den Göttern begangene Diebstahl, Ehebruch und Betrug, zur Legitimierung ihres eigenen Tuns dient, finden wir jedenfalls in späteren Zeiten öfters. Bei Aristophanes (Wolken 1076ff.) beispielsweise will der ungerechte Logos einen ertappten Ehebrecher mit dem Hinweis auf Zeus verteidigen: auch der Göttervater hat Ehebruch begangen; wie könnte aber ein Sterblicher glauben, gegenüber solchen Versuchungen standhafter als ein Gott zu sein? An einer anderen Stelle (Wolken 902ff.) erinnert der ungerechte Logos, gegenüber dem Glauben des gerechten Logos, dass bei den Göttern Recht und Gerechtigkeit herrsche, an Zeus, der seinen Vater gefesselt hat: das hätte er nicht ohne Schaden tun können, wenn es unter den Göttern Recht gäbe. Euripides (Hippolytos 451ff.) lässt die Amme der Phaidra ganz ähnlich argumentieren: Die Liebschaften der Götter sollen ihre Bedenken ausräumen; sie solle nicht stärker als die Götter sein wollen, denn das wäre Hybris. Dabei beruft die Amme sich ausdrücklich auf die Werke der Dichter. Wer sich mit ihnen befasst, hat die passenden Beispiele zur Entschuldigung seiner Handlungsweise stets parat. Auch Isokrates (Busiris XI,38ff.) beklagt die Blasphemien der Dichter: Was sie über die Götter erzählen, würde kein Mensch von seinem Feind zu behaupten wagen. Ihre Darstellungen von göttlichen Schandtaten dienen den Leuten als Grundlage ihrer Verteidigung; sie geben ihnen Beispiele zur Hand, auf die sie sich zur Entschuldigung und Rechtfertigung des eigenen Tuns berufen können. Ja, sie führen den Leuten, die Schlechtes tun wollen, viele neue Möglichkeiten erst zu, denn, indem sie den Menschen zeigen wie es gemacht wird, bringen sie diese überhaupt erst auf dumme Gedanken und locken so zu weiteren Übertretungen. Platon weist in der Politeia auf die gleichen beiden Punkte hin wie Isokrates: Die Dichter erleichtern die Schlechtigkeit, indem sie zeigen, wie es gemacht wird, und sie liefern gleich die Entschuldigung dazu: denn wenn die Götter es tun, kann der Mensch es ruhig nachmachen. D.h., jeder wird mit sich Nachsicht haben, wenn er schlecht ist, da er überzeugt wurde, dass auch die Götter und Heroen dergleichen tun und getan haben. Vgl. Euthyphron 5 e f.: der namengebende Dialogpartner beruft sich zur Rechtfertigung seines Vorgehens auf die gleichen Erzählungen von Zeus wie der ungerechte Logos bei Aristophanes; oder Nomoi 941 b: keiner dürfe sich von den Dichtern und anderen Mythenerzählern täuschen und sich einreden lassen, er täte, wenn er raubt und Gewalt anwendet, nichts Verwerfliches, sondern das, was die Götter selbst tun. Zu der Ablehnung der Darstellung jammernder und klagender Helden und Götter, der andernorts eine positive Wirkung, nämlich der Trost eigenen Leidens, zugeschrieben wurde, vgl. den Komiker Timokles, Fragm. 6 (Poetae Comici Graeci, hrsg. R. Kassel \& C. Austin, Bd. 7, Berlin 1989, 758f.).

PLATO, The electronic Journal of the International Plato Society, n 9, 2009.

http://gramata.univ-paris 1.fr/Plato

(C) All rights of reproduction of any form reserved. 
unbeherrscht, bestechlich, habgierig, aufsässig und grausam. Was schließlich die Darstellung von Menschen betrifft, so sei darauf zu achten, dass ihnen Glück und Unglück ihrem moralischen Verhalten entsprechend zufällt; Ungerechtigkeit darf sich auch in der Literatur nicht lohnen (392 a - 392 c). Viele Inhalte der Dichtung sind also nicht wahr und bergen deshalb die Gefahr der negativen Beeinflussung der Jugend, in deren Entwicklung die Nachahmung von Vorbildern eine entscheidende (und unvermeidliche) Rolle spielt. Die Inhalte der Dichtung sind deshalb von einer Zensur nach tugendethischen Kriterien zu reinigen. ${ }^{34}$

Noch gefährlicher als die Inhalte der Dichtung sei aber die Form, in der diese präsentiert werden (392 c ff.). Zunächst werden drei Arten der Darstellung von Personen unterschieden: (1.) die einfache oder narrative, (2.) die nachahmende und (3.) die aus Erzählung und Nachahmung gemischte Darstellung. Zuvor war

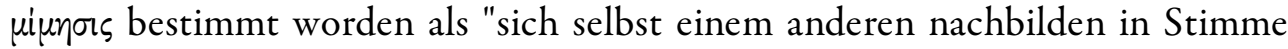
oder Gebärde, das heißt doch den darstellen, dem man sich nachbildet" (393 c). Nach den genannten Arten der Darstellung teilt Platon sodann die Dichtungen und mythischen Erzählungen in drei Gruppen ein; das heißt, wie weit ein literarischer Text mimetisch ist, wird zum Unterscheidungsmerkmal verschiedener Arten von Dichtung: Die dramatische Dichtung der Tragödie und der Komödie ist ganz mimetisch. Die zweite Kategorie, vertreten durch den Dithyrambos, ist gekennzeichnet durch das völlige Fehlen mimetischer Elemente. Ihre Darstellungsform ist der Bericht, die $\dot{\alpha} \pi \alpha \gamma \gamma \varepsilon \lambda i \alpha$ des Dichters. In der dritten Gruppe, zu der das Epos und anderes gehören, wechseln beide Formen. Das bei der zweiten und der dritten Darstellungsweise beteiligte Element der Nachahmung hält Platon für pädagogisch gefährlich: Es verführt die Rezipienten von Dichtung mehr als die erzählende indirekte Darstellung von Personen dazu, sich mit der literarischen Figur zu identifizieren, ihr nachzueifern und sie dadurch nachzuahmen. Es wird überlegt, ob es nicht das Beste sei, gleich die gesamte

34 Nicht viel besser als der Dichtung ergeht es der Musik (398 c ff.). Platon unterscheidet drei Komponenten: Text, Tonart und Rhythmus. Für den Text gelten dieselben Maßstäbe wie für die Dichtung; Tonart und Rhythmus müssen zu ihm passen. Alle an das Pathos apellierende Tonarten werden deshalb ausgeschlossen. Es verbleiben die dorische und phrygische, die aufrüttelnd und mild ("gewaltsam und zwanglos") wirken sollen und sich für die Erziehung tapferer Wächter am Besten zu eignen scheinen. Diesen Einschränkungen sollen schließlich auch die Auswahl der Instrumente und ihre Bauart Rechnung tragen. Die Flöte wird als zu vielseitig verbannt zugunsten der Kithara und der Leier für die Stadt, der Hirtenpfeife für ländliche Gebiete. Auch die Rhythmen sollen ausgelesen werden, doch wird ihre Diskussion mangels Sachkompetenz der Gesprächspartner vertagt.

PLATO, The electronic Journal of the International Plato Society, n 9, 2009.

http://gramata.univ-paris 1.fr/Plato

(c) All rights of reproduction of any form reserved. 
Dichtung aus dem Staate auszuschließen (394 d). Doch scheint sich Sokrates vorerst mit der milderen Maßnahme ihrer rigorosen Kontrolle zufrieden zu geben. Dabei wird an ein früheres Ergebnis des Gesprächs erinnert, wonach jeder einzelne jeweils nur eine Tätigkeit gut und erfolgreich ausüben könne (370 b). ${ }^{35}$ Hinsichtlich der Nachahmung wird die Bestätigung dieses Satzes der Dichtung selbst entnommen (395 a): Die Praxis zeige nämlich, dass nicht einmal einander so eng verwandte Gattungen der mimetischen Dichtung, wie Tragödie und Komödie, von einem Dichter gleich gut gehandhabt werden können. Die gleiche, enge Spezialisierung sei auch bei Rhapsode und Schauspieler, ihrerseits Nachahmer, nötig (395 a). Wie die Dichter nicht in der Lage sind "vielerlei schön darzustellen ( $\mu \mu \varepsilon \tilde{\tau} \sigma \alpha \iota) "$ (395 b), so sind auch die Wächter nicht in der Lage, viele verschiedene Dinge zum Besten des Staates zu gestalten. Deshalb müssen sich die Dichter auf eine Darstellungsform, die Wächter auf ihre Aufgaben im Staat beschränken; nur durch die Bereitschaft zur Arbeitsteilung und zur Konzentration auf ihre Pflichten können sie diese optimal erfüllen. Von früher Kindheit an sollen sie deshalb nur das nachahmen, was ihnen zur Erfüllung ihrer Aufgaben nutzt, alles andere aber unterlassen. Da überdies die Gefahr besteht, dass Identifikation und Nachahmung den Charakter der nachahmenden Personen im Sinne des Vorbildes beeinflussen, darf jeder nur das positive Vorbild nachahmen, das zu der ihm eigenen Aufgabe im Staate gehört. So sollen nur tapfere, besonnene, fromme und edle Männer, nicht aber Weichlinge, Wahnsinnige und schlechte Männer nachgeahmt werden (395 c - d). Als die diesen Inhalten und erzieherischen Zielen einzig angemessene Form der Darstellung wird sodann die reine Erzählung und der Bericht bestimmt, die, wenn sie auf nachahmenswerte Charaktere treffen, aber nur dann, in einen nachahmenden und so die nachahmende Rezeption provozierenden Modus wechseln dürfen $(396 \mathrm{c}-\mathrm{e})$.

Wir haben es hier also mit einem deutlichen Wechsel in der Argumentation zu tun. In 394 b - d schien für die Wahl der für den idealen Staat geeigneten Dichtung zur Verfügung zu stehen: eine erzählende Dichtung, eine nachahmende Dichtung und eine Dichtung, die aus einer Mischung von Erzählung und Nachahmung besteht. Am Ende der Argumentation stehen wir hingegen vor der Wahl zwischen einer Dichtung, die hautsächlich erzählend ist, aber die Nachahmung guter Menschen und guter Handlungen erlaubt, einer Dichtung, die uneingeschränkt nachahmt, und einer Dichtung, die eine Mischung beider darstellt; und es ist allein die erste Form, die für den idealen Staat zugelassen wird.

35 Vgl. auch $420 \mathrm{cff}$.

PLATO, The electronic Journal of the International Plato Society, n 9, 2009.

http://gramata.univ-paris 1.fr/Plato

(C) All rights of reproduction of any form reserved. 
Somit scheint tatsächlich ein Widerspruch zum 10. Buch zu bestehen, zu dessen Beginn gesagt wird, dass alle Dichtung, sofern mimetisch, ausgeschlossen worden sei.

Dieser scheinbare Gegensatz zwischen dem 3. und dem 10. Buch der Politeia wurde von vielen Kommentatoren dazu benutzt, die in Letzterem ausgesprochene harsche Verurteilung der Kunst abzuschwächen oder gar als unplatonisch auszuschließen. ${ }^{36}$ Tatsächlich lässt sich diese Spannung nicht ganz auflösen, doch ist darauf zu bestehen, dass sich die Aussagen der beiden Bücher keineswegs grundsätzlich widersprechen und das 3. Buch deshalb auch nicht dazu benutzt werden kann, die Aussage des 10. Buches zu entschärfen. ${ }^{37}$

Zunächst ist darauf hinzuweisen, dass es Platon an der früheren Stelle vor allem um die $A r t$ der Darstellung geht $(\lambda \dot{\varepsilon} \xi$ I $)$ und nichts dem entgegensteht, dass auch eine nicht-mimetische Darstellungsform qua Kunst mimetisch ist. Dann findet eine Verschiebung des Gedankenganges statt: $\mu$ i $\mu \eta \sigma \varsigma s$ und seine Ableitungen, die bisher streng technische Bezeichnungen für Darstellungsformen gewesen sind, werden plötzlich inhaltlich-ethisch bewertet; die Darstellungsform wird mit dem dargestellten Inhalt konfrontiert. Dazu muss jedoch erst der Status des Dargestellten selbst geklärt werden. Das soll die platonische Ideenlehre leisten. Diese wird aber erst in den folgenden Büchern dargelegt. Mit anderen Worten, der Maßstab für die ethische Entscheidung darüber, was dargestellt werden darf, muss erst noch gefunden werden. Die früheren Darlegungen zu Dichtung und Kunst im 2. und 3. Buch konnten also nur präliminarischen Charakter besitzen,

36 Das 10. Buch der Politeia wurde bezeichnet als "digression" (NeTTleship 1901, 340), "retrospect" (ADAM 1963 [1902], 384), "appendix" (SHOREY 1935, lxi), "coda" (CROMBIE 1962, 143) u.ä., oder als "unverbindliche Veranschaulichung eines philosophischen Gedankens, welche andere Aspekte der Kunst nicht ausschließt" (WEHRLI 1957, 45). Wenig hilfreich auch die Ansicht, Platon habe sich in der Hitze des Gefechtes mit dem größten Feind der Philosophie weniger als sonst um die Konsistenz seiner Argumentation gekümmert (CORNFORD 1945, 321f., und CROSS \& WOOZLEY 1964, 287), er habe sich überhaupt nie um Konsistenz bemüht (MELBERG 1995, 12f.), sein Unvermögen sich von seiner alten Liebe zur Kunst zu lösen habe zu unausgeglichenen und irrationalen Schlägen gegen diese geführt (ELSE 1986, 3ff.). Ernstzunehmender die Warnung von FUHRMANN 1992, 72, dass die Schriften Platons als Dialoge dialektisch angelegt sind und also Probleme erörtern und Denkmodelle vorführen, die sich nicht immer um innere Stimmigkeit bemühen und auch nicht immer erkennen lassen, wie der Autor selbst zu ihnen steht; vgl. ROOCHNIK 2003 , allerdings mit zweifelhaften Schlussfolgerungen.

37 Eine konsequente Weiterführung der im 3. Buch angelegten Gedanken im 10. Buch haben vertreten u.a. COLLINGWOOD 1925, TIMMERMANN 1998, und v.a. NeHAMAS 1982 und 1988.

PLATO, The electronic Journal of the International Plato Society, n 9, 2009.

http://gramata.univ-paris 1.fr/Plato

(C) All rights of reproduction of any form reserved. 
wie sie denn auch im Rahmen der Überlegungen zum ebenfalls vorläufigen Wächterstaat stehen. Im 10. Buch dagegen wird vor dem Hintergrund der elaborierten philosophischen und psychologischen Theorien der mittleren Bücher das Thema Kunst abschließend behandelt. Die beiden Diskussionen stimmen darin überein, dass bestimmte, moralisch vorbildliche Kunst im Idealstaat erlaubt sein soll; in Letzterer tritt jedoch eine Verschärfung ein, weil nun das wahre Wesen der Kunst erkannt ist und sich den moralischen Gründen ontologische und epistemologische beigesellt haben. Nun, da der mimetische Charakter aller Kunst offenliegt, wird der Staat noch radikaler gesäubert.

Hinzu kommt, dass innerhalb dieser Radikalisierung eine zweifache Verschiebung der Argumentation zu beobachten ist. Galt die Aufmerksamkeit Platons zunächst vor allem der Nachahmung des Dargestellten in der Seele des Lesers und Hörers, so richtet sie sich jetzt auf den Nachahmungscharakter der Darstellung selbst. Ging es also erst um den mimetischen Charakter der Kunstrezeption, so geht es nun um den mimetischen Charakter der Kunstproduktion. Alle Dichtung ist nachahmend, wenn man sie von ihrem Objekt her betrachtet. Mit anderen Worten: Während im 2. und 3. Buch das Dargestellte selbst zunächst nur nach seinem Wahrheitsgehalt und seiner tugendethischen Eignung für die mimetische Kunstrezeption betrachtet wurde, so geht es nun im 10. Buch um den Nachahmungscharakter des Dargestellten selbst.

Mit dieser Verschiebung von der Kunstrezeption zu der Kunstproduktion geht eine weitere Verschiebung einher, nämlich von der Erziehung des Wächternachwuchses zu der Kontrolle aller Bürger. Ging es im 3. Buch ausdrücklich um die erste Phase der Erziehung der jungen Wächter (401 a - 402 a), also um die Erziehung von Kindern, die der verstandesmäßigen Dialektik noch nicht fähig sind (402 a: "wenn der Verstand noch nicht eingesetzt hat"), so geht es im 10. Buch um die mündigen Bürger des Idealstaates. ${ }^{38}$ Nachahmung ist immer schädlich, sobald die Vernunft eingesetzt hat; hier erfüllt sie keine Funktion mehr, sie wird durch die höher stehende Vernunfttätigkeit abgelöst. Unter dieser neuen Hinsicht wird im 10. Buch die Kunst aus dem Staat ganz ausgeschlossen.

Die Diskussion der verschiedenen Bücher unterscheidet sich also deutlich und auf legitime Weise: Der zweite kritische Gang des 10. Buches ist keine bloße Repetition des bereits gesagten, sondern eine Erweiterung und Vertiefung der bisherigen Kunstkritik. Was schließlich die Aussage in 595 a betrifft, dass alle

38 Auch Aristoteles (Poetik 1448 b 5-9) sagt, dass Nachahmung ein natürliches Mittel des Lernens ist und dass Menschen "zuallererst durch Nachahmung lernen"; doch findet sich bei ihm nicht die platonische Beschränkung auf die Kindheit.

PLATO, The electronic Journal of the International Plato Society, n 9, 2009.

http://gramata.univ-paris 1.fr/Plato

(c) All rights of reproduction of any form reserved. 


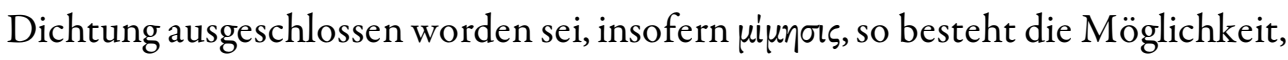
dass diese Bemerkung sich gar nicht auf die Behandlung der Dichtung im 3. Buch zurückbezieht, sondern auf die Unterlassung jeglicher Erwähnung der Kunst in der vorangegengengen Beschreibung des idealen Staates in Buch $4-9 .{ }^{39}$

\section{Gute Mimesis?}

Wenn die hier von uns vertretene Ansicht zutrifft, dass die Behandlung der Kunst im 3. und im 10. Buch keinen Widerspruch enthält, es sich vielmehr um zwei verschiedene Argumentationsgegenstände handelt, die konsistente Stufen einer einheitlichen Beweisführung darstellen, dann verliert eine historisch höchst bedeutende Interpretation ihre Textgrundlage: Immer wieder hat man versucht, Platon eine Art idealistische Kunst vertreten zu lassen, bei welcher der nachahmende Künstler nicht auf die Sinnesgegenstände beschränkt bleibt, sondern in direkter Verbindung mit der Welt der Ideen Werke schafft, die ein geeigneteres Transitum im Aufstieg zu den Urbildern der Dinge darstellen als alle nicht durch eine solche Kunst verwandelten Gegenstände der sinnlichen Wahrnehmung.

Ausgehend von der Annahme eines Widerspruchs zwischen 3. und 10. Buch, hat man versucht Platons Kritik der Kunst durch einen entsprechenden

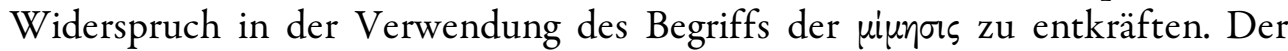
Philosoph habe nämlich "Nachahmung" in einem zweifachen Sinne verwendet, in einem guten und in einem schlechten. Und dieser Differenzierung von guter und schlechter Nachahmung folge eine Unterscheidung zwischen einem guten und einem schlechten Künstler, nämlich einem unwissenden und einem wissenden. Gute Mimesis verlange also, dass nicht nur das Modell, das nachgeahmt wird, gut ist, vielmehr muss auch der Künstler selbst gut sein und die Prinzipien des Guten und Schönen verstehen. Eine diesen Forderungen entsprechende Kunst sei fähig, die Welt der Ideen direkt oder zumindest unverfälschter zur Anschauung zu bringen als alle anderen Gegenstände der sinnlichen Wahrnehmung. ${ }^{40}$

39 Vgl. NEHAMAS 1999, 254ff..

40 Siehe v.a. TATE 1928 und 1932; zuvor bereits ganz ähnlich ADAM 1963 (1902), Bd. 2, 385; und GREENE 1918; die Unterscheidung zwischen gutem und schlechtem Maler bereits bei SARTORIUS 1895, v.a. 143f.; im Anschluss an TATE: GRUBE 1935, CROSS \& WOOZLEY 1964, v.a. 277ff., OATES 1972, HALl 1974, KARELIS 1976; ähnlich MENZA 1972, 132 und 161f., NeHAMAS 1982, BelfiORE 1984, 126ff., FerRari 1989, WiEgmaNn 1990, ASMIS 1992, v.a. 349 ff., LOSSAU 1993, 19, BÜTTNER 2000, 170ff.; für eine idealistische Kunst bei Platon auch

PLATO, The electronic Journal of the International Plato Society, n 9, 2009.

http://gramata.univ-paris 1.fr/Plato

(C) All rights of reproduction of any form reserved. 
Zur Stützung dieser Argumentation hat man auf verschiedene Stellen des platonischen Korpus verwiesen, an welchen der Philosoph die Annahme einer die Ideen reflektierenden Malerei vorauszusetzen scheint, allen voran auf drei Stellen der Politeia selbst.

Im 5. Buch (472 d) fragt Platon, ob es recht wäre, von einem Maler, der mit all seiner Kunst ein Bild des denkbar schönsten Menschen geschaffen hat, den Nachweis zu verlangen, dass es einen solchen Menschen auch tatsächlich geben kann. Das wäre - so die Antwort - ein Missverstehen der Kunst, denn was der Maler intendiert, ist etwas, das es in der Sinneswirklichkeit der Welt gar nicht zu geben braucht, ja gar nicht geben kann, nämlich ein "Paradigma" dessen, wie der schönste Mensch aussehen könnte. ${ }^{41}$ Daraus wird gefolgert, Platon habe die

BUNDY 1927, LODGE 1947, 221f., VERDENIUS 1949, GREY 1952, SCHWEITZER 1953a, 45ff., WEHRLI 1957, FlasCH 1965, 270, GALlOP 1965, SÖRBOM 1966, 133ff., WAGNER 1969, v.a. 241ff., POLLITT 1974, 47, GOLDEN 1975, KeUls 1978a, Halliwell 2000, va. 104ff., Halliwell 2002, v.a. 127ff., FIGAL 2000, STEINER 2001, 74 ff.; vgl. auch GOMBRICH 2002, $107 \mathrm{ff}$. Nach OSBORNE 1987 greife Platon nicht die Kunst selbst an, sondern nur eine bestimmte Theorie der Kunst; nach KARDAUN 1993 und 2000, nicht die Kunst, sondern nur die Künstler. Auf den scheinbaren Widerspruch zwischen 2. und 3. Buch und dem 10. Buch hat übrigens bereits Proklos hingewiesen (Commentarius in Republicam Platonis I, 197: "Denn dass der, der die ganze (sc. Literatur) für mimetisch hält, dieses (sc. 'sofern sie mimetisch ist') hinzusetzt, ist überflüssig.") und davon seine Revision des platonischen Kunsturteils ausgehen lassen; letztlich kommt er zu der Unterscheidung von drei Arten der Dichtung: inspirierte, didaktische und mimetische, die wiederum unterteilt wird in "eikastische" und "phantastische"; allein Letztere habe Platon abgelehnt. Dazu SHEPPARD 1980 und BÜTTNER 2000, 330ff.; zur Dichtungstheorie des Proklos und der Spätantike allgemein v.a. BERNARD 1990.

41 Die Vorstellung, die Natur in ihrem Abbild durch die Kombination verschiedener Modelle zu verbessern, wird bei Cicero (De inventione II,1) und Plinius (Naturalis historia 35,64) mit der sog. Zeuxislegende verbunden: Zeuxis habe, beauftragt ein Bild der Helena für den Heratempel in Kroton (bzw. Agrigent, nach Plinius) auszuführen, die fünft schönsten Jungfrauen der Stadt ausgewählt, von denen jede einen besonderen körperlichen Vorzug besaß, jedoch keine sämtliche in sich vereinte, um deren schönsten Körperteile zu einer idealen Figur zusammenzufügen. Vgl. Quintilian, Institutio oratoria XII,10,7. Auf die nur von Späteren berichtete Entstehungsgeschichte des Helenabildes von Zeuxis scheint bereits Sokrates in den Memorabilien des Xenophon (III,10,1-8) anzuspielen. In einem ersten Versuch vom Schönen des Einzeldinges zu abstrahieren, schlägt Sokrates vor: "da man nicht leicht einem untadelig schönen Menschen begegnet, so nehmt ihr das Schöne von jedem und bildet so einen völlig schönen Körper." Doch dieser Versuch einer empirischen Begrenzung des Schönen wird sofort wieder fallen gelassen. Die Verknüpfung zufälliger Einzelschönheiten führt nur zu einer in der Natur möglichen Schönheit, nicht zu dem wahrhaft Schönen. Erst bei Plotin (Enneaden $\mathrm{V}, 8,1)$ wird das Motiv in eine idealistische Theorie der Kunst inkorporiert. Die

PLATO, The electronic Journal of the International Plato Society, n 9, 2009.

http://gramata.univ-paris 1.fr/Plato

(C) All rights of reproduction of any form reserved. 
Existenz einer idealistischen Kunst im Sinne einer die Ideen nachahmenden Kunst anerkannt. Doch wird hier unser moderner Begriff des Idealen mit dem platonischen Begriff der Idee verwechselt. Und von uiunors ist an dieser Stelle gar nicht die Rede. Gedacht ist an ein Gemälde, in welchem der Maler hervorragende Einzelzüge verschiedener Menschen zu einem Bild "vollkommener" Schönheit zusammenstellt. Gewonnen hat er damit immer erst das denkbar schönste Aussehen eines Menschen. Das aber hat noch nichts mit der platonischen Welt der Ideen zu tun, vielmehr bleibt es notwendigerweise an der Oberfläche der sinnlichen Erscheinung haften. Sokrates erwähnt den Maler an dieser Stelle übrigens nur als Bei-spiel. Mit dem Hinweis auf den Künstler, von dem niemand den Nachweis verlangen wird, dass es einen solchen Menschen idealer Schönheit auch wirklich gibt, wehrt der Philosoph seine Gesprächspartner ab, die von ihm zu wissen verlangen, ob der von ihm entworfene Staat auch möglich ist.

Schwerer wiegen da schon die beiden anderen Stellen der Politeia. Zu Beginn des 6. Buches $(484 \mathrm{~d})$ verweist Platon, gefragt, wer die Gesetzgeber und die Staatslenker des besten Staates sein sollen, auf die Philosophen, denn diese besäßen wie die Künstler die Fähigkeit, jedes Einzelne in seinem Wesen zu erkennen; sie trügen ein deutliches "Paradigma", ein Urbild aller Dinge, in ihrer Seele. "So wie es die Maler tun, die auf das Wahrste blickend sich immer wieder diesem zuwenden und sich anstrengen, auf das genaueste zu beobachten, so haben auch sie (die Philosophen) die Kraft, die Sitten und Gesetze im Hinblick auf das Schöne, das Gerechte und das Gute zu stiften und über die schon bestehenden Gesetze zu wachen" (ibid.). An anderer Stelle (500 e - 501 c) werden die Philosophen schlichtweg Maler genannt, welche die beste Stadt "nach dem göttlichen Musterbild" entwerfen. ${ }^{42}$ Der Widerspruch zu der im 10. Buch ausgesprochenen Positionierung der Kunst und des Künstlers "in dreifacher Entfernung von der Wahrheit" (597 e) sei eingestanden, doch lassen sich durch vereinzelte und kurze Stellen, an denen es nicht um die Kunst selbst geht, sondern Platon sich ihrer als Instrument und Illustration zur Verdeutlichung anderer Aussagegegenstände bedient, nicht jene Textpassagen des 10. Buches ausstechen, deren Argumentationen ausführlich und ausschließlich von der Kunst selbst handeln und zu einer begründeten Verurteilung dieser führen. Ein solches

Zeuxislegende findet in der Renaissance und später zahlreiche Verwendung, und zwar sowohl in ihrer neuplatonisch-idealistischen als auch in ihrer aristotelisch-empirischen Gewandung; dazu noch immer lesenswert PANOFSKY 1993 (1924), v.a. 24ff.; vgl. BARKAN 2000. Zu Plotins Auffassung von der Kunst und vom Schönen, neben den einschlägigen Einführungen zur antiken Ästhetik, BOURBON Di Petrella 1956, SCHÖNDORF 1974, GUIDELLI 1999.

42 Vgl. Timaios $19 \mathrm{~b}$ - c, wo sich Platon auf den Staat als ein Gemälde zurückbezieht.

PLATO, The electronic Journal of the International Plato Society, n 9, 2009.

http://gramata.univ-paris 1.fr/Plato

(C) All rights of reproduction of any form reserved. 
Vorgehen verrät mehr über die Wünsche der Interpreten als über die Absichten Platons.

Das platonische Universum ist in allen seinen Bereichen durchzogen von einer hierarchischen Struktur der Seinsebenen und sein ganzes philosophisches System gründet in dem Prinzip des Abfalls tiefergestufter Entitäten gegenüber dem Sein einer höheren Entität. Alle diese tiefergestuften Entitäten sind $\mu \mu \dot{\eta} \mu \alpha \tau \alpha$

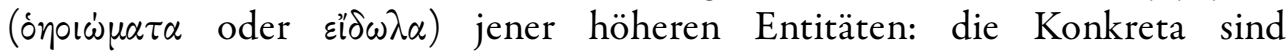
Nachahmungen der Ideen und die Abbilder der Konkreta wiederum Nachahmungen dieser. Es trifft zwar zu, dass diese Stufung nicht nur unter dem Zeichen der Defizienz der niedrigeren gegenüber der höheren Stufe steht, sondern auch positiv betrachtet werden kann, weshalb das Verhältnis der sinnenfälligen Dingen zu dem washeitlichen Sein, den Ideen, von Platon nicht nur als Nachahmung, Abbild oder Ähnlichkeit, sondern auch durch den Begriff der Teilhabe ( $\left.\mu_{\varepsilon} \theta \varepsilon \xi \xi \varsigma\right)$ umschrieben wird. Zwar kennen die Ideen selbst keinen sinnlichen Ausdruck und sind letztlich nur dem Logos und der dianoetischen Erkenntnis zugänglich. Dennoch partizipieren die Dinge an der Ideenwelt insofern, als die Ideen ihre urbildlichen Formen und Ursachen sind. Und durch diese Teilhabe an den Ideen sind die sinnenfälligen Dinge diesseitige Repräsentanten der Ideen, die imstande sind über sich hinaus in das transzendente Bereich zu verweisen und hierdurch den Menschen zu der Erkenntnis der Ideen selbst anzuleiten und den platonischen Aufschwung der Seele auszulösen. So wird der Sinneswahrnehmung doch auch heuristischer Wert zuerkannt; sie bleibt als eine Durchgangsstufe im Bau der werdenden Erkenntnis unentbehrlich und dem wahren Wissen verbunden. ${ }^{43}$ Dies trifft aber keineswegs für das Verhältnis der künstlerischen Produktionen zu den Dingen als ihren Urbildern zu, geschweige denn für das Verhältnis von Kunstwerken und Ideenwelt. Wie auch aus unserem Gang durch das 10. Buch der Politeia zu ersehen war und sich im Liniengleichnis bestätigt hatte, lässt sich zwar das Verhältnis zwischen Konkreta und Ideen unter dem positiven Blickwinkel der Anteilhabe betrachten, an keiner Stelle aber wird den Produktionen der Künstler eine vergleichbare Funktion zugeschrieben, weder dort noch in einem der anderen der platonischen Dialoge. Sie sind ja nicht mehr Mimesis der Ideen, sondern nur noch Nachahmungen von Nachahmungen und als solche nicht nur gar fern der Wahrheit, sondern und vor allem auch heuristische wertlos. Denn wozu sollte ich mich den Abbildern der Dinge zuwenden, wenn mir auch die den

43 Siehe beispielsweise Politeia 516 a - c (Höhlengleichnis) oder Symposion 210 a - 212 a (Rede der Diotima über die Stufenfolge der Liebe).

PLATO, The electronic Journal of the International Plato Society, n 9, 2009.

http://gramata.univ-paris 1.fr/Plato

(C) All rights of reproduction of any form reserved. 
Ideen näher stehenden Originale zur Verfügung stehen? (599a - b). Und sollte einmal ein Künstler denkend Einsicht in die Ideen gewonnen haben, dann hört er notwendigerweise auf Künstler zu sein und wird Philosoph. Mit anderen Worten, die Forderung an den Künstler, die Ideen selbst nachzuahmen, ist eine logische Unmöglichkeit, denn um sie zu erfüllen, müsste er aufhören Künstler zu sein. Als Künstler würde er die erkannte Idee wieder zu einem sowohl gegenüber der erkannten Idee als auch gegenüber ihrem sinnlich wahrnehmbaren Abbild defizienten und deshalb wertlosen Sinnentrug verwässern. Der philosophische Künstler wie der Philosoph als Künstler stellt innerhalb des platonischen Systems eine contradictio in terminis dar. Die Vorstellung, die Kunst könne die Ideen vollkommener wiedergeben als die Natur und der Künstler müsse dazu nur auf die in seiner Seele aufbewahrten oder durch Übung gewonnenen Ideen blicken, ist nicht platonische, sondern nach- und insbesondere neuplatonische Lehre. ${ }^{44}$

44 Erstmals bezeugt durch Cicero (Orator II,8-10, vgl. II,18f.); vgl. u.a. Seneca (Epistulae morales ad Lucilius 58,18-21 und 65,7-10) und Dion Chrysostomos (Oratio 12,55-61); der locus classicus dann bei Plotin (Enneaden V,8,1). Die Verlagerung der Idee aus dem transzendenten Bereich ins Innere des Künstlers ist vorbereitet bei Xenophon (Symposion 4,21) und Aristoteles (Metaphysik 988 a 4, 1032 a 32 - b 1). Dadurch dringt erstmals ein subjektiver Faktor in die Kunstbetrachtung ein; erst jetzt können Einbildungskraft ( $\phi \alpha \nu \tau \alpha \sigma i \alpha)$ und schöpferisches Vermögen des Künstlers gewürdigt werden (beispielsweise bei Dion Chrysostomos, Oratio 12, oder Philostrat der Ältere, Leben des Apollonius von Tyana), bis hin zum Kunstwerk als Spiegel der großen Künstlerseele in der Schrift des Pseudo-Longinus, Über das Erhabene (1. Jh. n. Chr.). Neben den einschlägigen Einführungen zur antiken Ästhetik, s. auch PANOFSKY 1924. Vgl. auch die bei SCHLIKKER 1940, 68ff., beschriebene gleichzeitige Ablösung der (objektiven) Symmetrie durch die (subjektive) Eurythmie (bis zu ihrer bekannten Definition bei Vitruv, De architectura I,2, als "venusta species, commodusque in compositionibus membrorum aspectus"); oder die Rangablöse der Symmetrie des Kunstwerkes durch die Phantasie des Künstlers von Philostrat dem Älteren zu Philostrat dem

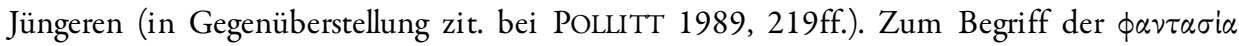
SCHWEITZER 1934, WATSON 1988, Fowler 1989, Silverman 1991. Für eine moderne philosophische Variante neuplatonischer Kunstinterpretation s. HEIDEGGER 1960 (auch HeIDEgGer 1947 und 1961), sowie GADAMER 1960, 87ff.; zu Letzterem vgl. KRIEGER 1967; für eine naturwissenschaftlich-neurophysiologische Variante s. ZEKI 1999, v.a. $37 \mathrm{ff}$. ("The neurology of the Platonic ideal"). Zeugnisse einer "platonisierenden" Auffassung der Kunst der Moderne auf Seiten ihrer Produzenten finden sich allerorts; beispielsweise bei Henri Matisse (z.B. Notes d'un peintre, 1908; zit. in CHARLes Harrison \& PAUL WOOD (Hg.), Kunsttheorie im 20. Jahrhundert, Stuttgart 1998, Bd. 1, 96); vgl. insbes. die Charakterisierung des Kubismus durch den Kunstkritiker JACQUE RIVIÈRE in Sur les tendances actuelles de la peinture, 1912 (zit. ebd., 228f.). $\mathrm{Zu}$ platonisch-neuplatonischen Strömungen in der Kunst der Moderne zuletzt HENDRIX 2004, insbes. 175ff. (Cezanne) und 203ff. (Kubismus); vgl. AleXandrakis 2002, Hendrix \& DE Girolami Cheney 2002

PLATO, The electronic Journal of the International Plato Society, n 9, 2009.

http://gramata.univ-paris 1.fr/Plato

(C) All rights of reproduction of any form reserved. 


\section{Göttlich inspirierte Kunst?}

Um zu zeigen, dass Platon ein Freund der Kunst gewesen ist oder ihr gar die Rolle zugeschrieben hat, die Ideenwelt in ausgezeichneter Weise zu reflektieren, wurde insbesondere auch darauf verwiesen, dass er doch namentlich im Ion und im Phaidros die göttliche Inspiriertheit des Künstlers eindrücklich vertreten habe. ${ }^{45}$ Dort fände Platon "die rettende Lösung einer unmittelbaren Verknüpfung des Künstlers mit der Ideenwelt, durch die er der Schranke der Realitätsschichten entgehen kann." ${ }^{46}$ Eine sorgfältige Durchsicht jener Stellen, die von der $\mu \alpha v i \alpha$, dem ekstatischen Erfüllt- und Besessensein der Künstler handeln, zeigt jedoch, dass Platon die alte Ansicht von der göttlichen Inspiriertheit der Künstler nicht zu ihrem Lob, sondern vielmehr zur Entlarvung ihre Unwissenheit verwendet. ${ }^{47}$ Wieder ist es das Ziel des Philosophen, das Ansehen, das die Dichter und andere Künstler in der Öffentlichkeit genießen, und ihren eigenen Dünkel als ungebührlich zu erweisen (und auf die Philosophie zu übertragen).

Diesem Ansinnen begegnen wir erstmals in der Apologie $(22$ a - c). Ein Orakelspruch hatte Sokrates zum weisesten aller Menschen erklärt. Der Philosoph macht sich auf, die Richtigkeit des Spruches zu prüfen. Nachdem er zunächst die Politiker und die Handwerker befragt hat, widerfährt ihm bei den Dichtern erstaunliches: Wie er feststellen muss, verstanden sie selbst nicht so gut über ihre Werke zu reden wie zufällig anwesende Dritte. Sokrates schließt daraus, "dass ihre Werke nicht Früchte der Weisheit sind, sondern einer gewissen natürlichen Anlage und einer Begeisterung, wie sie sich bei den Wahrsagern und Orakelsängern findet. Denn auch diese sagen vielerlei Schönes, haben aber von dem eigentlichen Sinn dessen, was sie sagen, keine Ahnung. In ähnlicher Geistesverfassung befinden sich auch die Dichter" (22 c). In verwandter Weise spielt der Schluss des Menon (99 b - d) das Wissen gegen die Intuition aus:

und 2004 .

45 Beinahe alle in Anm. 40 angeführten Autoren verweisen zur Stützung ihrer These einer von Platon gebilligten guten (idealistischen) Kunst auf die Stellen des Ion und des Phaedrus; s. beispielsweise VERDENIUS 1949, 4ff., OATES 1972, 49ff., WIEGMANN 1990), $115 \mathrm{ff}$. , BÜTTNER 2000, 255ff.; ergänze VERDENIUS 1943 und 1944.

46 WAGNER 1969, 239.

47 Die kritische Stoßrichtung der Rede von der Inspiriertheit der Dichter haben gesehen TigerstedT 1969, DALFEN 1974, 77ff., WOODRUFF 1982; v.a. aber MURRAY 1992 und FUHRMANN 1992, 77ff.; ferner ASMIS 1992.

PLATO, The electronic Journal of the International Plato Society, n 9, 2009. http://gramata.univ-paris 1.fr/Plato

(C) All rights of reproduction of any form reserved. 
Gottbegeisterte Seher, Dichter und Politiker, heißt es dort, vermögen zwar Wahres zu künden oder Richtiges zu tun; hierbei werden sie jedoch nicht von wirklicher Einsicht, sondern nur von einer zutreffenden Meinung oder gar vom Zufall geleitet.

Die Stellen des Ion und des Phaidros vermitteln ein komplexeres Bild, ziehen aber dieselben Schlüsse. Im Dialog mit dem Rhapsoden Ion dehnt Sokrates den Zustand des "Wahnsinns" auf Darsteller und Zuhörer aus (533 c - 536 d).$^{48}$ In erster Linie geht es um den Rhapsoden, den Interpreten von Dichtung und Mittler zwischen epischem Dichter und Publikum, doch im Verlauf des Dialogs spricht Sokrates auch über den Dichter selbst und schließlich auch vom Publikum, weil alle, die an der Dichtung teilhaben, von derselben göttlichen Kraft getrieben werden: Die Muse erfüllt erst den Dichter mit ihrer Begeisterung, dann auch den Rhapsoden und schließlich die Hörer, wie ein Magnet nicht nur selbst eiserne Ringe anzieht, sondern diese Fähigkeit auch auf diese überträgt, sodass sie weitere Ringe anziehen und eine Kette bilden. Doch keines der Glieder besitzt $\tau \dot{\varepsilon} \chi \nu \eta$, denn keiner hat ein Wissen davon, was er tut. ${ }^{49} \mathrm{Im}$ Falle des Rhapsoden erweise dies seine Einseitigkeit: Die Interpreten der Dichter können - ihrer eigenen Aussage zufolge - jeder immer nur einen Dichter auslegen, also entspringt ihre Fähigkeit nicht dem Wissen, denn wer etwas weiß, der versteht sich nicht nur auf etwas Vereinzeltes, wie keiner Arzt genannt werden kann, der nur einen einzigen Menschen heilen kann (531 a ff.). Im Gegensatz zur $\tau \dot{\varepsilon} \chi \nu \eta$, die auf verschiedene Gegenstände angewandt werden kann, ist die Inspiration des Rhapsoden wie die des Dichters einseitig und nicht kontrollierbar. Somit wird den Dichtern auch im Ion Vernunft und Wissen abgesprochen. Jedenfalls ist die Weisheit ihrer Kunst mit der von Platon gelehrten Weisheit der Philosophen nicht zu vergleichen.

Im Phaidros (244 a - 245 a) unterscheidet Platon vier Arten der $\mu \alpha v i \alpha$, des Wahnsinns: die Entrücktheit der Propheten und Wahrsager, die Begeisterung der Priester, den Enthusiasmus der Dichter und die Besessenheit der Liebenden. ${ }^{50}$ Von der Dichtkunst wird verlautet, sie sei eine $\mu \alpha v i \alpha$, die von den Musen ausgehe;

48 Zum Dialog Ion im Besonderen auch FLASHAR 1958 und CARABBA 1998; ferner BeCKER 1993; zuletzt FIGAL 2000 und VÖHLER 2004.

49 Das Thema des Unwissens taucht erstmals auf in 532 c 6 und wird dann regelmäßig wiederholt: 533 d, 536 c, 536 d, 542 (Schluss); die Begriffe $\tau \dot{\varepsilon} \chi \nu \eta$ und $\dot{\varepsilon} \pi \imath \tau \dot{\eta} \mu \eta$ erweisen sich im Ion als austauschbar.

50 Entrückung, Begeisterung, Enthusiasmus, Besessenheit, Verzückung oder Raserei, Variationen des mit "Wahnsinn" nur unzureichend wiedergegebene Wortes $\mu \alpha v i \alpha$.

PLATO, The electronic Journal of the International Plato Society, n 9, 2009.

http://gramata.univ-paris 1.fr/Plato

(C) All rights of reproduction of any form reserved. 
sie ergreife die reine und zarte Seele, erwecke sie und begeistere sie zu Liedern und anderen Werken, und indem sie die Taten der Vorfahren feiere, erziehe sie die Nachkommen. "Wer aber ohne den Wahnsinn der Musen an die Pforte der Dichtkunst gelangt, in der Meinung, dass bloße Fertigkeit ( $\tau \dot{\varepsilon} \chi \nu \eta)$ ihn zum Dichter mache, der ist ungeweiht, und seine verstandesmäßigen Werke werden von den Werken des Wahnsinns in den Schatten gestellt" (245 a). Die Dichtkunst erscheint hier als direktes Sprachrohr göttlicher Wahrheiten. Doch darf nicht übersehen werden, dass der Ton dieser Passagen "leicht, ironisch und spielerisch"51 ist. So deutet Platon mehrfach auf den inspirierten Zustand des Sokrates hin; ${ }^{52}$ er lässt ihn sich uncharakteristisch und seltsam benehmen, legt ihm abgegriffene Phrasen in den Mund und deutet mehrmals darauf hin, dass Sokrates nicht verantwortlich sei für das, was er sage. Das heißt, auch im Falle des Sokrates, des vortrefflichsten aller Philosophen, hat Inspiriertheit einen Mangel an Wissen und wahrer Einsicht zur Folge. In der späteren Rangordnung der Seelen und ihrer Lebensformen $(248 \mathrm{~d}-\mathrm{e})$ erhält deshalb der Philosoph den ersten Rang, während der Inbegriff der Inspiriertheit, der Dichter, "gemeinsam

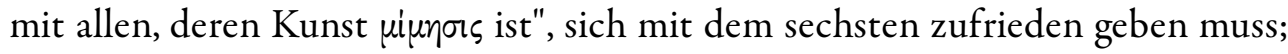
gleichzeitig der letzte Platz innerhalb der vier zuvor als göttlich inspiriert bezeichneten Gruppen. Neben dem Philosophen werden dem Dichter vorgezogen: der gerechte und tüchtige König, gefolgt vom guten Politiker, dem Familienvater und dem Geschäftsmann, an vierter Stelle der Athlet und der Arzt, an fünfter der Prophet und der Priester. Unter dem Dichter stehen nur noch der Handwerker und der Bauer, der Sophist und andere Demagogen, sowie, an letzter Stelle, der Tyrann. ${ }^{53}$ Was sich hier schon deutlich spiegelt, die Entgegensetzung von künstlerischer und philosophischer Betätigung, wird zum Schluss des Dialoges nocheinmal eigens expliziert und als Ergebnis der Diskussion festgehalten: Wer seine Reden, Gesetzeswerke und andere Texte "im Besitz des Wissens um die Wahrheit der Sache" verfasst hat und also fähig ist über den Inhalt des Geschriebenen und seine Implikationen vernünftig zu argumentieren,

51 ROWE 1986, 10.

$52235 \mathrm{~d}, 238 \mathrm{c}-\mathrm{d}, 241$ e, 257 a, 262 d, $263 \mathrm{~d}$.

53 Man hat in der an erster Stelle gereihten Seele des "Freundes der Weisheit und der Schönheit und Dieners der Musen und des Eros" die des göttlich inspirierten Dichters im Gegensatz zu der des bloß handwerklichen Dichters erkennen wollen (mit Verweis auf diese Unterscheidung in 245 a; beispielsweise VICAIRE 1960, 53f., MÜLlER 1971, 27, WIEGMANN 1990, 120, oder TATARKIEWICZ 2003 (1976), 140ff.), doch die vorangegangenen wie nachfolgenden Ausführungen zeigen, dass es sich dabei nur um die Philosophen handeln kann, die deutlich als die wahren Dichter vorgeführt werden.

PLATO, The electronic Journal of the International Plato Society, n 9, 2009.

http://gramata.univ-paris 1.fr/Plato

(C) All rights of reproduction of any form reserved. 
ein solcher dürfe weder Redner, noch Politiker, noch Dichter genannt werden, sondern verdiene allein als "Philosoph", als Freund der Weisheit, bezeichnet zu werden. Dichter aber solle heißen, wer nichts Besseres vorzuweisen habe als das in langer Mühe erarbeitete Werk (278 b - e). Der Dialog Phaidros enthält somit keineswegs die gesuchte Rehabilitation der Kunst; vielmehr bekräftigt er das Verdammungsurteil, das Platon Zeit seines Lebens über sie verhängt hat und das sich bereits deutlich in den besprochenen Stellen der Apologie, des Menon und des Ion ausgesprochen hatte. Es ist der Mangel an Wissen und Einsicht in die wahre Natur der Dinge, die Platon den Künstlern zum Vorwurf macht. ${ }^{54}$ Die Dichter seien deshalb durch die Philosophen als "erste Lehrer und Führer" (Politeia 595 d) zu ersetzen.

\section{Schöne Kunst?}

Zur weiteren Stützung der Ansicht, Platon hätte für eine Art idealistische Kunst plädiert, wurde auf jene zahlreichen Stellen verwiesen, an denen der Philosoph von der Schönheit handelt. Aus ihnen sei zu schließen, dass die Kunst einen ausgezeichneten Zugriff auf die Idee der Schönheit habe. ${ }^{55}$ Tatsächlich spricht Platon immer wieder von sinnenfälliger Schönheit und nennt auch bald diesen

54 Dass der Künstler über kein Wissen verfüge und man ihn deshalb über nichts befragen könne, vertritt auch Protagoras 347 e - 348 a, Phaidros 265 b, Hippias Minor 365 c - d, Politeia 382 e, 598 d - e, 599 a ff., Timaios 72 a, Nomoi 682 a, 719 b, 801 b - c. Vgl. Phaidros 274 e - 276 a, wo die Schrift in der Gegenüberstellung mit der Lehre im dialektischen platonischen Dialog ähnliche Vorwürfe treffen: Sie fördere die Vergesslichkeit, ihre Trennbarkeit vom Autor entziehe sie seiner Kontrolle, und vor allem: keine Fragen könnten an sie gerichtet werden; darin sei sie der Malerei verwandt $(275 \mathrm{~d})$. Verglichen mit dem "lebendigen und beseelten Wort des Wissenden" werde sie deshalb mit Recht als ein bloßes Nachbild bezeichnet (276 a). Dazu noch immer unübertroffen HAVELOCK 1963; vgl. LENTZ 1989; zu dem etwa zu Platons Zeit stattfindenden Übergang von Oralität zu Literalität im antiken Griechenland im Allgemeinen v.a. THOMAS 1992 und WORTHINGTON \& FOLEY 2002; über die Antike hinausgehend die klassische Studie ONG 2002 (1986).

55 Auch auf die Schönheit der Kunst berufen sich beinahe alle in Anm. 40 genannten Autoren, beispielsweise HaLliwell 2000, 113, und HaLliwell 2002, 141; oder WiegmanN 1990, 118ff.; ferner GRASSI 1980 (1962), 109ff.; in diesem Zusammenhang auch zu erwähnen CASSIRER 1923, der zu recht die platonische Antithese von sinnenfälliger Schönheit und abstrakter Idee des absolut Schönen betont, dabei aber eine Korrelation von immer schärfer werdender Verurteilung der Kunst und fortschreitender Vertiefung seiner Vorstellung von der Schönheit annimmt: "Je höher er daher die Idee der Schönheit rückt, um so tiefer sinkt für ihn jetzt die Schale der nachbildenden Kunst herab." (21).

PLATO, The electronic Journal of the International Plato Society, n 9, 2009.

http://gramata.univ-paris 1.fr/Plato

(C) All rights of reproduction of any form reserved. 
bald jenen Gegenstand der sinnlichen Wahrnehmung "schön". So ist von der Schönheit der Farben ebenso wie von der Schönheit der Formen die Rede. ${ }^{56}$ Auch hebt Platon den Gesichtssinn aus den übrigen Sinneswerkzeugen als das edelste hervor; an anderer Stelle wird die Sehkraft als das klarste und schärfste unter den Wahrnehmungsorganen gepriesen. ${ }^{57}$ Eros als der schönste Gott erscheint in zartem Körper, anmutiger Haltung und blühenden Farben und Düften. ${ }^{58} \mathrm{Im}$ Timaios wird der Kosmos wiederholt als schön gepriesen, insofern in ihm Ebenmaß und Proportion herrschen. ${ }^{59} \mathrm{Ja}$, sogar Kunstwerke werden vereinzelt als schön bezeichnet. So wird etwa Phidias genannt als Künstler, "der so ausgezeichnet schöne Werke geschaffen hat." ${ }^{60}$ Und dennoch, wo Platon ausführlich vom Schönen spricht, kommt das Kunstwerk nicht vor, und umgekehrt, wo von der Kunst eigentlich gehandelt wird, also im 10. Buch der Politeia, dort wird ihren Werken kein einziges Mal die Eigenschaft der Schönheit zuerkannt. Dieser Umstand verlangt nach einer Erklärung.

Zunächst ist darauf hinzuweisen, dass der griechische Begriff der Schönheit ( $\kappa \alpha \lambda o$ ó, $\kappa \alpha \lambda o$ o $)$ nicht mit unserem modernen, auf ästhetische Aspekte verengten Begriff zu verwechseln ist. Formen, Farben, Melodien bildeten für die Griechen nur einen, und für Platon nur einen untergeordneten Ausschnitt aus dem Bereich des Schönen. Dieser umfasste nicht nur das, was Auge und Ohr ergötzt, sondern auch alle anderen angenehmen Dinge, wie etwa eine gute Speise oder ein guter Wein. Weiters, alles Nützliche, Taugliche, Brauchbare, sodass Gegenstände als schön bezeichnet werden, insofern sie der Erfüllung ihres Zweckes entsprechend gefertigt und verfasst sind. ${ }^{61}$ Schließlich stand den Griechen das Schöne in enger

56 Beispielsweise Gorgias 465 b, Philebos 51 c, 53 a - b, Nomoi 668 e - 669 a.

57 Politeia $507 \mathrm{c}-508 \mathrm{~d}$ bzw. Phaidros $250 \mathrm{c}-\mathrm{d}$.

58 Symposion 196 a.

59 Timaios $31 \mathrm{~b}$ ff..

60 Meno $91 \mathrm{~d}$; allerdings geht es an dieser Stelle nicht um den Bildhauer, sondern darum, die unverschämten Verdienste eines pseudo-weisen Sophisten anzuprangern, nämlich, "dass der einzige Protagoras mit dieser seiner Weisheit mehr Geld verdient als Phidias, dem man so überaus herrliche Werke verdankt, und als zehn Bildhauer sonst." Vgl. Timaios 19 b, sowie Politeia 420 c - 421 b und Kratylos 429 a - b. An den beiden letztgenannten Stellen ist bereits angedeutet, dass die Schönheit der Kunstwerke keine ästhetische ist, sondern von Angemessenheit und Wahrhaftigkeit, von ihrer Nützlichkeit und ihrem sittlichem Gehalt bestimmt wird; davon im Folgenden.

61 Beispielsweise Xenophon, Memorabilia X,9, Sokrates im Gespräch mit dem Panzerschmied Pistias: Die Schönheit eines Panzers habe nichts mit seinen Proportionen, dem Wert seines Materials, oder dem Reichtum seiner Verzierungen zu tun, sondern wird allein von der Frage

PLATO, The electronic Journal of the International Plato Society, n 9, 2009.

http://gramata.univ-paris 1.fr/Plato

(C) All rights of reproduction of any form reserved. 
Wechselbeziehung zur moralischen Kategorie des Guten ( $\alpha \gamma \alpha \theta \dot{o} \varsigma, \alpha \gamma \alpha \theta \dot{o} \nu)$, sodass etwa gute Eigenschaften oder gerechte Handlungen "schön" genannt werden. Gut und schön erscheinen oft geradezu austauschbar. ${ }^{62}$

All diese Facetten der antiken Schönheit sind auch in den platonischen Dialogen präsent. So heißt es etwa in Politeia $457 \mathrm{a}-\mathrm{b}$, innerhalb der Diskussion der Erziehung der Frauen zum Wächterdienst für den idealen Staat, dass alles Nützliche schön und alles Schädliche hässlich sei. Wenn auch die Frauen zum Wächterdienst erzogen werden sollen, dann muss ihnen dieselbe Erziehung zu teil werden wie den Männern: "Also bleibt den Frauen der Wächter nichts anderes übrig als sich zu entkleiden - da ja statt des Gewandes die Tugend ihre Hülle bilden wird - und sich zu beteiligen am Krieg und dem sonstigen Wachdienst für die Stadt und auf jede andere Tätigkeit verzichten. ... Der Mann aber, der über entkleidete Frauen lacht, die bei diesen Übungen nur das Beste im Auge haben, pflückt von seinem Lachen eine unreife Weisheitsfrucht und hat wie es scheint keine Ahnung davon, worüber er lacht und was er tut. Denn das ist und bleibt doch der schönste Spruch, dass das Nützliche schön ist und das Schädliche hässlich." ${ }^{63}$ Nackte Frauen, die sich für ihre Aufgabe im Wächterstaat körperlich ertüchtigen und sich deshalb entkleiden, können keinesfalls lächerlich sein, vielmehr sind sie immer schön, insofern ihr Handeln seinen Zweck erfüllt.

Beispiele für die ethisch-moralische Seite der Schönheit finden sich in beinahe allen platonischen Dialogen. In den Nomoi $(654$ b - 655 c) etwa lesen wir, dass der richtig erzogene und also bessere Mensch notwendigerweise schöner tanzt und singt als der weniger oder falsch erzogene und also schlechtere Mensch, auch wenn Letzterer sich durch Naturveranlagung oder durch Übung besser zu

bestimmt, wie gut er an den Körper, für den er bestimmt ist, angepasst und also für die Tätigkeit, für die er bestimmt ist, geeignet ist. An seiner Schönheit ändert also nichts, dass der zu schützende Körper selbst hässlich ist, etwa kleinwüchsig oder krummbeinig etc. (auch diese Hässlichkeit des Körpers ließe sich wieder unter dem Aspekt der Nützlichkeit und Eignung betrachten). In diesem Sinne kann ein Mistkübel als schön gelten, wenn er seinem Zweck entspricht, etc.. Ein goldenes Schild hingegen kann niemals schön sein, denn Gold ist kein für ein Schild geeignetes Material, macht es doch dieses zu schwer und also untauglich, d.h. hässlich.

62 Diese Verbindung des ethisch Schönen mit dem anschaulich Schönen spiegelt sich in der seit Herodot literarisch ausgeprägten Fügung $\kappa \alpha \lambda$ ò $\kappa \alpha \grave{~} \alpha \gamma \alpha \theta \dot{c} \varsigma$ und der späteren Wortprägung der $\kappa \alpha \lambda \circ \kappa \dot{\alpha} \gamma \alpha \theta i \alpha$ wieder; so nannte man etwa den vollendeten Edelmann $\kappa \alpha \lambda \circ \kappa \dot{\alpha} \gamma \alpha \theta \dot{o} \varsigma$ : schön und gut. Zur Kalokagathia Melber 1935, BOURriot 1995 und Petrochilos 2002; ferner ROSCALLA 2004.

63 Von der Schönheit des Nützlichen ist in den platonischen Dialogen öfters die Rede, beispielsweise in Protagoras 358 b, oder Gorgias $474 \mathrm{~d}-475$ a.

PLATO, The electronic Journal of the International Plato Society, n 9, 2009.

http://gramata.univ-paris 1.fr/Plato

(C) All rights of reproduction of any form reserved. 
bewegen versteht oder eine vollere und sicherere Stimme besitzt. Der Wohlerzogene singt und tanzt schöner, weil nur er durch seine in der Erziehung gewonnene

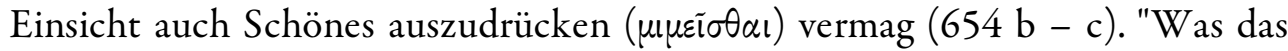
Gebärdenspiel und die Sangesweise des Feigen oder Tapferen anlangt", fährt Platon fort, "so ist die des Tapferen schön, die des Feigen dagegen hässlich, und das ist auch die richtige Bezeichnung dafür. Und um uns über alles dies nicht in lange Erörterungen einzulassen, so gelte ein für alle Mal folgendes: alle Körperstellungen und Tonweisen ohne Ausnahme, die Ausdruck von Seelen- oder Körpertüchtigkeit sind, sei es unmittelbar oder mittelbar durch bildliche Nachahmung [also auch Malerei und Skulptur!], sind schön, mit denen dagegen, die Ausdruck des Gegenteils sind, steht es umgekehrt" $(655 \mathrm{~b}-\mathrm{c})$. Entsprechend war bereits im 3. Buch der Politeia (400 d ff.) als schön "die wahrhaft treffliche und wohlbeschaffene sittliche Gesinnung" genannt worden und an die Malerei und die anderen Nachahmungskünste die Forderung ergangen, nur diese darzustellen. An einer späteren Stelle der Nomoi (668 b ff.) wiederum heißt es, dass man, um die Schönheit der Künste beurteilen zu können, neben dem Wesen des dargestellten Gegenstandes und der Richtigkeit seiner Darstellung auch über ihren sittlichen Wert Bescheid wissen müsse. ${ }^{64}$ Schließlich (859 e - 860 a) geht Platon befremdlicher-, aber konsequenterweise so weit Leiden schön zu nennen, wenn sie eine gerechte Ursache haben. Schön sei deshalb beispielsweise der Tod des Tempelräubers und jedes anderen Feindes der gesetzlichen Ordnung. Ähnlich im Alkibiades (115 a - 116 d), wo derjenige schön genannt wird, der im Krieg seinem Kameraden zu Hilfe eilt und dabei verwundet oder gar getötet wird. Die edle Absicht mache den Handelnden und das aus der Handlung folgende Übel schön, denn "wer gerecht handelt, handelt notwendig schön" und "gut und schön sind ein und dasselbe".65

Diese hier angesprochene Identität von Gutem und Schönen findet sich an zahlreichen Stellen des platonischen Korpus vorausgesetzt, beispielsweise im Symposion (201 c), wo von Eros, dem Gott der Liebe, gesagt wird, dass er, wenn er des Schönen ermangelt und es deshalb erstrebt, er zugleich des Guten ermangelt und deshalb begehrt, denn das Schöne und das Gute seien identisch. ${ }^{66}$ Entsprechend verlautet es mit Blick auf unsere eigene irdische (rechte) Liebe:

64 Vgl. Politeia 420 c - 421 b, sowie Sophistes 266 d ff., wo die Unterscheidung von richtiger ( $\varepsilon i \kappa \alpha \tau \kappa \dot{\eta})$ und verfälschender Kunst ( $\phi \alpha \nu \tau \alpha \sigma \tau \iota \kappa \dot{\eta} \tau \dot{\varepsilon} \chi \nu \eta)$ ebenfalls an einer Statue exemplifiziert wird.

65 Dass Gerechtigkeit schön mache, behauptet auch Menexenos 246 e.

66 Dies die Ausgangsthese der nun folgenden Rede der Diotima (201 d ff.).

PLATO, The electronic Journal of the International Plato Society, n 9, 2009.

http://gramata.univ-paris 1.fr/Plato

(C) All rights of reproduction of any form reserved. 
"Wer das Schöne liebt, worum ist ihm bei dieser Liebe zu tun? ..., dass ihm das Gute zuteil wird" (204 d - e). ${ }^{67}$ Deshalb kann (beziehungsweise soll) es dem Liebenden letztlich nie um die äußerliche, körperliche Schönheit gehen, sondern immer nur um die innere, seelische, die allein gut sein kann. Auf diese innere Güte hin ist die schöne Erscheinung zu transzendieren. ${ }^{68}$ Die Schönheit der Seele ist "die wahrhaft treffliche und wohlbeschaffene sittliche Gesinnung" (Politeia 400 e), mit einem Wort Tugend (444 e). Zu ihrem Besitz führen schöne Lebensziele (ibid.). Die größte Schönheit aber ist die Einheit von innerer und äußerer Schönheit (402 d), ${ }^{69}$ wobei die äußere, körperliche Schönheit der inneren, seelischen Schönheit folgt, niemals umgekehrt (403 d).$^{70}$ Wer die Schönheit des Körpers mehr liebt als die der Seele wird deshalb ein "Feind der Kunst und der Schönheit" genannt $(403 \mathrm{~b}-\mathrm{c}) .^{71}$ In diesem Sinne schließt der Dialog Phaidros

67 Vgl. Menon 77 a - 79 c, v.a. 77 b. Von der Identität von Schön und Gut spricht Platon auch in Protagoras 358 b, Charmides 158 e - 161 a, Lysis 216 d, Theätet 157 d, Politeia 509 a (Sonnengleichnis, Idee des Guten), Timaios 87 c, u.ö.; in Phaidros 246 e und Philebos 65 a die Trias von Wahrheit, Güte und Schönheit.

68 In 215 a - b sagt Sokrates von sich selbst, sein Äußeres gleiche den hässlichen Silenen, doch wenn man es "aufklappe", so erblicke man im Inneren Götterbilder. Vgl. Gorgias 523 a - 526 c: während sich irdische Richter durch schöne Leiber bestechen ließen, beurteile das Totengericht die Verstorbenen nach ihrer wahren Beschaffenheit, nach ihrer seelischen Schönheit oder Hässlichkeit.

69 "Wo also treffliche Seeleneigenschaften und ihnen entsprechende und mit ihnen zusammenstimmende äußere Erscheinung sich paaren, beide von einerlei Gepräge, da bietet sich das schönste Schauspiel für den, der zu schauen fähig ist." Vgl. Timaios 87 c - 88 c: "Alles Gute nun ist schön, und was schön ist, das entbehrt nicht des richtigen Maßes. Demnach darf auch ein lebendes Wesen, wenn man ihm Schönheit zusprechen soll, des Ebenmaßes nicht entbehren. ... Denn für Gesundheit und Krankheit, wie auch für Tugend und Laster ist kein Ebenmaß und kein Missverhältnis wichtiger als das unmittelbar zwischen Seele und Körper selbst bestehende. ...." Vom rechten Maß als dem Tugendhaften, Schönen und Wahren spricht Platon auch in Gorgias 506 e, Philebos 64 d - 66 b, Politeia 486 d, Politikos 284 b - e, Nomoi 668 e, u.ö.; Sophistes 228 a fügt zur positiven These die negative hinzu: "hässlich ist das, dem das Maß fehlt".

70 Vgl. Nomoi 728 e. Für ein außerplatonisches Beispiel s. etwa Plutarch, Pro pulchritudine 2: "Die Wohlgestalt des Körpers ist das Werk der Seele, die dem Körper den Glanz und die Ehre der Wohlgestalt leiht."

71 "Ein Feind der Musen- und der Schönheit": $\mu$ ov $\sigma \alpha$ meint meist die Kunst der Musik (z.B. Laches 180 d, Gorgias 449 d, Symposion $187 \mathrm{a}$ - b, Philebos 17 b - c), kann aber auch die Dichtkunst (z.B. Symposion 196 e), die Kunst der Malerei (Politeia 601 b), oder - wie wohl an dieser Stelle - die Kunst im Allgemeinen bedeuten (vgl. z.B. Symposion 196 e).

PLATO, The electronic Journal of the International Plato Society, n 9, 2009.

http://gramata.univ-paris $1 . \mathrm{fr} /$ Plato

(C) All rights of reproduction of any form reserved. 
(279 c) mit einer Anrufung der Götter, sie mögen Sokrates innere Schönheit verleihen.

In jenen vier platonischen Dialogen, wo vom Schönen ausführlich gehandelt wird, dem Hippias Maior, der Politeia, dem Symposion und dem Phaidros, tritt neben dieses ethische Moment ein ontologisches und, damit verbunden, ein epistemologisches. Das Schöne erweist sich dort als Bezeichnung eines Verhältnisses des Erkennens und des Begehrens, beziehungsweise deren Erfüllung in der vollen Entsprechung zu ihrem Gegenstand, der Wahrheit, die als das Schönste bezeichnet wird. Im Folgenden werde ich mich diesen vier Dialogen eingehender zuwenden.

"Was ist das Schöne?", lautet die Frage, die im Hippias Maior den gesamten Dialog leitet. Sie wird von Sokrates an den berühmten, gerade in Athen angekommenen Redner Hippias gerichtet, der sich doch bestens auf die Beantwortung der Frage verstehen müsste. Seine Antworten zeigen aber, dass er noch nicht einmal die Fragestellung begriffen hat. Ein schönes Mädchen sei schön, auch Gold sei schön, verlauten seine ersten Versuche. Doch, so Sokrates, dann wäre das Schöne ebenso ein schönes Pferd, eine schöne Lyra oder ein schöner Topf, und so fort. Alles Dinge, auf die des Heraklit Ausspruch vom Affen Anwendung findet: der schönste Affe sei, gegen den Menschen gehalten, hässlich, und selbst das schönste Mädchen wird, neben eine Göttin gestellt, nicht mehr schön erscheinen. Sokrates habe aber nicht gefragt, was schön und hässlich sei, gemeint war vielmehr das Schöne an sich, das Wesen der Schönheit, also dasjenige, durch dessen Hinzutreten alle schönen Einzeldinge ihre Schönheit erst erhalten (289 d). Der nun folgende dritte Vorschlag des Hippias, das Schöne sei "reich, gesund und geehrt von Hellenen, in vorgerückten Jahren nach schöner Bestattung der gestorbenen eigenen Eltern von seinen eigenen Nachkommen schön und stattlich begraben zu werden", untermauert nur noch einmal des Sophisten Unverständnis und wird keiner ausführlichen Antwort mehr gewürdigt (293 c). Derart als Gesprächspartner disqualifiziert, übernimmt Sokrates selbst die Rolle des Antworten vorschlagenden. Das Schöne sei das Geziemende oder

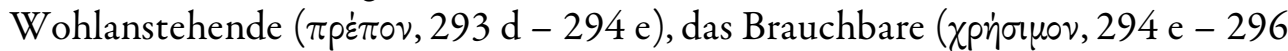

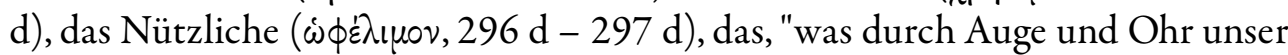
Wohlgefallen erregt" (297 d - 304 a). Doch alle diese traditionellen Auffassungen vom Schönen erweisen sich in ihrer jeweiligen Diskussion als unzureichend. Setzen wir etwa das Schöne mit dem Nützlichen, dem zur Erfüllung eines guten Zweckes Taugliche, gleich, so stoßen wir auf eine neue Ungereimtheit, denn dadurch wird das Schöne in ein ursächliches Verhältnis zu dem Guten gebracht. In diesem Falle müsste, da Ursache und Wirkung wohl von

PLATO, The electronic Journal of the International Plato Society, n 9, 2009.

http://gramata.univ-paris 1.fr/Plato

(c) All rights of reproduction of any form reserved. 
einander zu scheiden sind, das $\kappa \alpha \lambda o^{\prime} v$ etwas anderes sein als das $a \gamma \alpha \theta \dot{\nu} v$. Diese Trennung des Schönen von dem Guten wäre aber etwas ganz Unerhörtes. Der Dialog endet letztlich ohne explizite Antwort und mit der Feststellung "schwierig ist das Schöne" (304 e). Und die implizite Antwort? Was der Hippias Maior leisten soll, ist, neben der Inanspruchnahme des Guten im Schönen, die Vorbereitung der Erkenntnis des Chorismos zwischen den schönen Einzeldingen und partikulären Erlebnissen auf der einen Seite und dem Schönen selbst auf der anderen Seite. Denn was vom Beginn der Auseinandersetzung an immer wieder den verschiedenen Definitionsvorschlägen als ein Unerreichbares

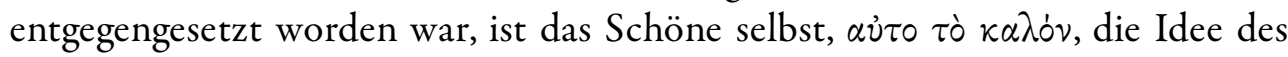
Schönen. ${ }^{72}$

In der Politeia kehrt dieser Chorismos von irdischen Schönheiten und transzendenter Schönheit wieder, nun werden aber auch dessen Erkenntnis und

72 Phaidon 65 d - 66 a: "...ein Schönes an sich und ein Gutes an sich. ... Hast du jemals etwas dergleichen mit den Augen gesehen? ... Oder hast du durch irgendeine andere Sinneswahrnehmung es erfasst? ... Wird nicht der von uns der wahren Erkenntnis eines jeden Dinges am nächsten kommen, der es sich am strengsten und schärfsten zur Aufgabe macht durch reines Denken das eigentliche Wesen des betrachteten Gegenstandes zu erforschen? ... Wird das nicht auf denjenigen zutreffen, der am meisten mit dem bloßen Verstand an ein jedes herantritt, ohne das Gesicht zum Gehilfen des reinen Denkens zu machen oder irgendeine andere Sinneswahrnehmung zur Begleiterin des überlegenden Verstandes zu machen, der also mit ausschließlicher Verwendung des reinen Denkvermögens ein jegliches Seiende rein für sich zu erfassen sucht, möglichst unabhängig von Auge und Ohr und überhaupt von allem Körperlichen als einer störenden Beigabe, die durch ihre Einmischung die Seele nicht in den Besitz der Wahrheit und Vernunfterkenntnis gelangen lässt?"; Phaidon $100 \mathrm{~d}$ - e: "...wenn mir jemand als Grund dafür, dass irgend etwas schön ist, entweder die blühende Farbe oder die Gestalt oder sonst etwas Derartiges angibt, so lasse ich mich auf all das von vornherein gar nicht ein - denn alles andere verwirrt mich nur - und halte mich schlicht und einfach und vielleicht einfältig daran, dass nichts anderes es schön macht als die Gegenwart oder Gemeinschaft oder wie immer man auch dies Verhältnis der Zusammengehörigkeit bezeichnen will - jenes Urschönen. Denn über die Art dieses Beisammenseins will ich keine weiteren Versicherungen geben, sondern beschränke mich auf die Behauptung, dass alles Schöne durch das Schöne schön wird."; Politeia, beispielsweise 507 b: "Wir behaupten, dass es eine Vielheit von schönen Dingen und von guten Dingen und so von jeder Art von Dingen gibt, wie wir sie denn auch in der Rede unterscheiden. ... Und auch, dass es ein Schönes an sich und ein Gutes an sich gebe und so bei allem, was wir eben als Vielheit setzten; und indem wir nun umgekehrt das viele Einzelne einer Idee als der Einheit für jede Klasse des Vielen unterordnen, benennen wir es nach seinem wirklichen Wesen als dem Ding an sich. ... Und von den ersteren sagen wir, dass sie gesehen aber nicht gedacht werden, von den Ideen aber, dass sie gedacht aber nicht gesehen werden."; Symposion, bes. 210 a - 212 a, im Folgenden.

PLATO, The electronic Journal of the International Plato Society, n 9, 2009.

http://gramata.univ-paris $1 . \mathrm{fr} /$ Plato

(C) All rights of reproduction of any form reserved. 
ihr Grund als schön bezeichnet. ${ }^{73}$ So heißt es im 6. Buch (508 e - 509 a), die

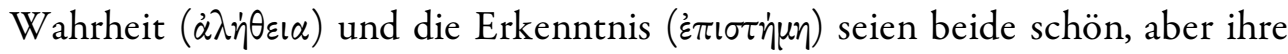

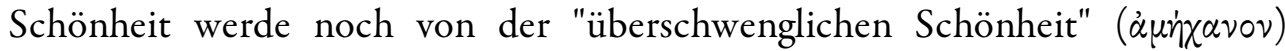
desjenigen übertroffen, das nicht nur die Erkennbarkeit des Seienden, sondern das Seiende selbst hervorbringt.$^{74}$ Dieses Schönste ist die Idee des Guten, die, wie die Sonne im Bereich des Sichtbaren das Sichtbare sichtbar werden lässt und Grund seines Werdens und Wachsens ist, im intelligiblen Bereich der Ideen der erster Grund ihres Seins und erster Ermöglichungsgrund ihrer Erkenntnis ist. ${ }^{75}$ Hier ist das Schöne also nicht nur ontologisch konnotiert, sondern auch epistemologisch. Ontologisch, insofern das Wort ein Optimum an Sein und das, was in größter Seinsfülle erscheint, bezeichnet. Epistemologisch, insofern Wahrheit und Erkenntnis mit der Schönheit in eins gesetzt werden und als schön

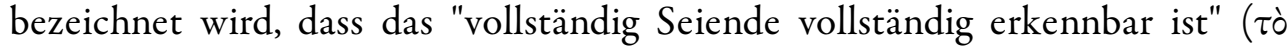
$\pi \alpha \nu \tau \varepsilon \lambda \tilde{\omega} \varsigma$ oैv $\pi \alpha \nu \tau \varepsilon \lambda \tilde{\omega} \varsigma \gamma \nu \omega \sigma \tau o \dot{\nu}, 477$ a). Das Schöne ist hier also ein Entsprechen oder eine Übereinstimmung zwischen Erkennen und Sein und das Schönste die Erkenntnis der Idee des Guten, die der "größte Gegenstand der Erkenntnis" ( $\mu \dot{\varepsilon} \gamma ı \sigma \tau \nu \mu \dot{\alpha} \theta \eta \mu \alpha, 505$ a) genannt wird. Diesem Erkennen, das dem höchsten Sein entspricht, wird hier - wie später im 10. Buch und andernorts - ein bloßes Meinen entgegengesetzt, das weder auf das Sein noch auf das Nichtsein, sondern auf das bezogen ist, was zwischen beiden liegt, nämlich das unendliche irdische Bereich des Werdens und Vergehens. ${ }^{76}$ Verglichen mit der Erkenntnis der Episteme ist das Erkennen der Meinung ein nur scheinbares Übereinstimmen von Erkennen und Sein. Bezüglich des Schönen bedeutet dies: Was in einer Hinsicht schön ist, ist in anderer Hinsicht hässlich. Während sich der Philosoph um die Erkenntnis des Schönen selbst bemühe, lasse die Meinung der Menge der Schaulustigen nur diese defiziente Vielheit des Schönen gelten und spreche dem wahren Schönen der Erkenntnis die Existenz ab (479 b - 480 a). ${ }^{77}$ An dieser Stelle

73 Ich folge im Folgenden TAURECK 1981.

74 Vgl. Kratylos 416 b - e, wo Sokrates auf die Frage seines Dialogpartners nach dem Schönen erwidert, dass zuallererst der Verstand schön zu nennen sei, "welcher die Dinge hervorbringt, die wir zum Ausdruck unserer Freude an ihnen als schön bezeichnen."; der genauere Sinn dieser Stelle bleibt aber dunkel.

75 Die Trias von Wahrheit, Güte und Schönheit in Phaidros 246 e und Philebos 65 a.

76 Vgl. Theätet 157 d, wo das immer gleichbleibende wahre Sein in der Entgegensetzung zum Werdenden als schön und gut bezeichnet wird.

77476 b: "Auf der einen Seite stehen für sich die Schaulustigen und Liebhaber von Künsten und Vertreter der praktischen Berufe, auf der anderen hinwiederum diejenigen, auf die unsere Erörterung hinwies, die man mit Recht Weisheitsliebende nennen kann. ... Die

PLATO, The electronic Journal of the International Plato Society, n 9, 2009.

http://gramata.univ-paris 1.fr/Plato

(c) All rights of reproduction of any form reserved. 
setzt Platons erste Aburteilung der Kunst ein. Von Schönheit ist dann konsistenterweise nicht mehr die Rede. Als Mimesis der Mimesis sind Werke der Kunst ontologisch defizient und epistemologisch nutzlos. Insofern das Schöne ein Verhältnis der philosophischen Erkenntnis und ihre Erfüllung in der Übereinstimmung mit ihrem Erkenntnisgegenstand bezeichnet, kann kein Kunstwerk schön sein. Ja, insofern sich die philosophische Erkenntnis überhaupt keines sinnlich Wahrnehmbaren in ihrem dialektischen Gang bedient (511 b c), muss aus den Ausführungen in der Politeia sogar die uns befremdliche Folgerung gezogen werden, dass das Schöne nicht nur in Kunstwerken nicht, sondern überhaupt nicht sinnlich erscheint. Das sinnlich Wahrnehmbare mag höchstens insofern als schön bezeichnet werden als es dem wahren Schönen und den anderen Ideen strukturell ähnlich ist. Reine Klänge, reine Farben und geometrische Formen seien deshalb schön (Philebos 51 c - 53 c). Reines Weiß beispielsweise sei schön, weil die reine Farbe einfach und unabhängig von anderen Beimischungen ist und so dem einfachen und eigenständigen absoluten Sein ähnelt. Mit anderen Worten: Es ist schön, insofern es dem Philosophen ein Vorstellungsmuster für die Einartigkeit und Unwandelbarkeit seiner Idee des Guten gibt. ${ }^{78}$

Hörbegierigen und Schaulustigen schwärmen für schöne Stimmen und Farben und Gestalten und alles, was die Kunst uns dergleichen herstellt, aber das Wesen des Schönen selbst zu schauen und sich daran zu erfreuen ist ihr Geist nicht fähig. ... Diejenigen aber, welche imstande sind sich dem Schönen selbst zuzuwenden und es rein für sich zu schauen, sind die nicht seltene Ausnahmen?" Der Schaulustige hat es allein mit dem Vielen, das schön ist, zu tun; der Philosoph erkennt das Schöne selbst und verwechselt nicht das Viele, das schön ist, mit ihm. Der Gegensatz von Philosoph und "den Schaulustigen" wird verglichen mit dem gegensätzlichen Zustand von Wachendem und Träumendem (476 c). Erkenntnis und bloße Meinung werden nochmals einander gegenübergestellt (476 d ff.). In 479 a kehrt Sokrates erneut zur Diskussion des Schönen zurück: "Dieses also vorausgesetzt mag mir nun - so werde ich sagen - jener Biedermann Rede und Antwort stehen, der ein schönes an sich und eine sich in der nämlichen Beziehung stets gleich bleibende Form der Schönheit selbst nicht anerkennt, wohl aber an vielerlei Schönes glaubt, jener Schaulustige, der durchaus nichts davon wissen will, wenn man das Schöne für Eines erklärt und das Gerechte usw. Unter diesem vielerlei Schönen ... findet sich da irgendetwas, was nicht auch hässlich erscheinen wird? Und unter dem Gerechten, was nicht auch ungerecht? Und unter dem Heiligen, was nicht auch unheilig? ... Von denen also, die nur vielerlei Schönes schauen, das Schöne selbst aber nicht erblicken und auch nicht imstande sind einem anderen, der den Weg dazu weiß zu folgen, und nur vielerlei Gerechtes, das Gerechte selbst aber nicht, und so durchweg, werden wir behaupten, dass sie von allem nur eine Meinung haben, aber keinerlei Wissen von dem, was sie meinen."; vgl. 538 d; ferner Enthydemos 301 a, sowie Phaidon 65 d.

78 Vgl. auch 58 a. Im Philebos begegnen wir auch der Gegenüberstellung von Philosophen und

PLATO, The electronic Journal of the International Plato Society, n 9, 2009.

http://gramata.univ-paris 1.fr/Plato

(C) All rights of reproduction of any form reserved. 
Im Dialog Phaidros scheint Platon zunächst zu einer ganz anderen Sicht anzuheben: Das Schöne ist hier dasjenige, welches in den sinnlichen Bereich am stärksten hineinstrahlt. Jede Seele hat, ehe sie ihren Lebensweg begann, an einem übersinnlichen Ort das Seiende an sich geschaut. Die Schönheit - im Unterschied zur Gerechtigkeit, der Besonnenheit und den anderen Ideen - hatte schon dort einen "besonderen Glanz" (250 b). Und auch hier auf Erden wird sie "mit dem klarsten unserer Organe erfasst als die am klarsten strahlende" (250 d). "Nur der Schönheit ist dies zuteil geworden, uns das Hervorleuchtendste und das Liebreizendste zu sein" (ibid.). Das Schöne wird also zunächst als das $\dot{\varepsilon} \kappa \phi \alpha \nu \dot{\varepsilon} \sigma \tau \alpha \tau \circ \nu$, als das für unsere sinnliche Wahrnehmung hier und jetzt am stärksten Leuchtende, ja sogar als die einzig sinnlich wahrnehmbare Idee bestimmt. Damit ist aber das in der Politeia ausgesprochene Verständnis des Schönen als erkenntnishaftes Übereinstimmen nicht mehr vereinbar, denn dort war das Schöne wesenhaft unsinnlich. Im Phaidros hingegen sagt Platon ausdrücklich, dass einzig und allein das Schöne in den Bereich des Sichtbaren hineinleuchten könne, während andere unsinnliche Wesenheiten, wie beispielsweise die Gerechtigkeit, in keiner Weise anschaulich werden.

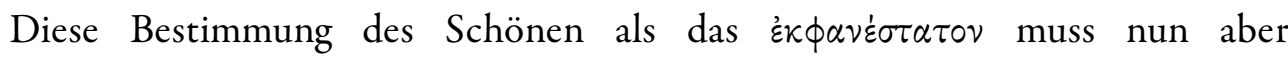
zusammengedacht werden mit der zweiten Bestimmung, die ihm Platon zur Seite

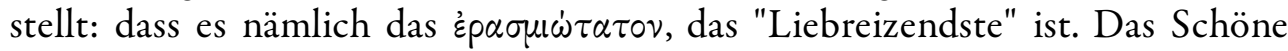
steht also in einem Verhältnis des Liebens und Begehrens. Jemand erblickt ein schönes Antlitz oder einen schönen Leib und ist außer sich vor Entzücken. Was ihm, dem Entzückten, dabei geschieht, weiß er zunächst nicht (250 a - b, 255 d). Nicht sein Erkenntnisvermögen ist also zunächst erregt, sondern sein Begehren. Was mit diesem Verhältnis des Begehrens gemeint sein könnte, darüber gibt das Symposion genaueren Aufschluss. Dort belehrt Diotima Sokrates, dass es außer dem Zwischensein der $\delta \dot{o} \xi \alpha$ - zwischen Wissen und Nichtwissen - noch ein anderes $\mu \varepsilon \tau \alpha \xi \dot{\nu}$ gebe, nämlich zwischen schön (und gut) und hässlich (und böse) (202 a - b), das einem Sein zwischen Mangel ( $\pi \varepsilon v i \alpha)$ und Überfluss ( $\pi$ ópos) entspricht (203 b). Dieses Zwischensein ist, beziehungsweise löst aus ein Streben und ein Begehren, das von Platon Eros genannt wird. Der Begehrende strebt nach dem Überfluss, dem Schönen, letztlich nach dem Guten, das er nicht hat, und das unsterbliches Dasein ist (207 d). Damit hat sich die Frage nach dem Wesen des sinnlich erscheinenden Schönen offenbar auf die Frage verlagert, wie das Gute gewollt wird. Jetzt ist das Schöne letztlich die Übereinstimmung des Begehrens mit dem Begehrten oder die Angemessenheit des Begehrens gegenüber dem

den Vielen wieder. Zum Philebos ausführlicher im Folgenden.

PLATO, The electronic Journal of the International Plato Society, n 9, 2009.

http://gramata.univ-paris 1.fr/Plato

(C) All rights of reproduction of any form reserved. 
Guten. Welche Funktion aber füllen in diesem Verhältnis des Begehrens die konkreten sinnenfälligen schönen Körper und Antlitze aus, von denen im Phaidros wie im Symposion so oft die Rede ist?

Wenn die Seele hier auf Erden einen schönen Körper erblickt, dann wird sie erinnert an jenen Glanz, den sie in der Präexistenz geschaut hat, und verfällt in $\mu \alpha \nu i \alpha$. Dieses Entzücken am schönen Antlitz und Körper führt zur Liebe und zur Freundschaft, findet ihre wahre Erfüllung aber keineswegs in der körperlichen Befriedigung, sondern führt - recht vollzogen - weiter vom Sinnlichen zum Ethischen und schließlich zur Erkenntnis. Wer den richtigen Weg bis zur höchsten Form der Liebe einschlägt, wird deshalb - wie Platon Diotima ausführen lässt - folgende Stufen steigen $(210 a-212$ a): In der Jugend wird er einen schönen Körper lieben, der in ihm den Sinn für das Schöne weckt. Dann aber wird er erkennen, dass die Schönheit an allen Körpern ein und dieselbe ist. Er wird also nicht mehr nur einen schönen Körper lieben, sondern alle. Außerdem wird er der seelischen Schönheit einen höheren Rang zuerkennen als der leiblichen Schönheit. Hiernach wird er auf das Schöne im tätigen Leben und in den Sitten achten und erkennen, dass derartige Erscheinungsformen des Schönen alle miteinander verwandt sind. Die auf dieser Stufe der Liebe gewonnene Einsicht veranlasst ihn, dem körperlich Schönen noch geringeren Wert beizumessen. Nach der Erkenntnis des Schönen im tätigen Leben soll er eine weitere Stufe aufwärts geführt werden: zur Erkenntnis der Schönheit der Wissenschaften. Wieder darf er nicht am Einzelnen haften bleiben; dann wird er zur höchsten Wissenschaft gelangen: dem Wissen von einem einzigen Schönen, das ihn erkennen lässt: Dieses Schöne ist unwandelbar, es entsteht und vergeht nicht, es wird nicht größer noch kleiner, noch mehr noch weniger, es ist jedem Wechsel und jeder Veränderung enthoben, es ist nicht zu bestimmter Zeit, an bestimmten Orten und in bestimmtem Verhältnis und für gewisse Personen schön und hässlich, es ist nicht ein wahrnehmbares Einzelnes, es ist keine Rede, kein Gedanke und auch keine Wissenschaft, es ist überhaupt in keinem anderen, sondern es ist rein für sich immer "eingestaltig". Dieses Schöne ist gemäß dem Symposion die nicht sinnenfällige, die eingestaltige, absolut einfache, und unveränderliche Seinsheit, durch die alles "schön" genannte das ist, was es ist, nämlich schön; das Schöne an sich, die Idee des Schönen, als Seins- und Erkenntnisgrund alles vielen "Schönen". Alles Schöne in den Wissenschaften, im Bereich der Praxis, in den Künsten und im Bereich des Körperlichen ist nur deshalb schön, weil es an diesem Schönen selbst Anteil hat. Andererseits ist der stufenweise Fortschritt in der Erkenntnis des Schönen nur möglich aufgrund der

PLATO, The electronic Journal of the International Plato Society, n 9, 2009.

http://gramata.univ-paris 1.fr/Plato

(C) All rights of reproduction of any form reserved. 
kontinuierlichen $\mu \dot{\varepsilon} \theta \varepsilon \xi ı$, der Teilhabe am Schönen selbst, die freilich auf jeder Stufe im Vergleich zur höheren Stufe geringer ist.

Der Eros, das eigentliche Thema des Dialogs, erweist sich also letztlich als das Streben nach Erkenntnis des Schönen an sich, des Schönen selbst, der Idee des Schönen, dessen wodurch alles andere schön ist. Aufgrund der Identifikation des Schönen mit dem Guten (204 e) ist Eros aber auch das Verlangen nach Erkenntnis des Guten. Der Zusammenhang zwischen Eros und Schönem ist also nur zu Beginn ein ästhetischer, dann aber ein ethischer und schließlich ein epistemologischer. Der Prozess wird ausgelöst durch die Schönheit eines Körpers oder eines Antlitzes, diese sind aber nur Widerspiegelung oder Ausdruck und also Hinweis auf die Schönheit der Seele; die Seele wiederum ist nur schön wenn sie gut ist, und gut ist der Mensch nur, wenn er erkennt. Letztlich geht es also auch hier, wie auch schon zuvor in der Politeia, um ein Verhältnis des Erkennens. ${ }^{79}$ Auch das Verhältnis des Begehrens ist nur dann schön, wenn es zur Erkenntnis führt. Folglich hat die Paideia die Aufgabe, die Schönheit des Begehrens in Schönheit des Erkennens zu verwandeln. Erst die Erkenntnis des Schönen selbst bringt wahrhafte Tugend und damit dauernden Besitz des Guten und Schönen, letztlich Unsterblichkeit der Seele.

Wie wir gesehen haben, kommt es allein der Schönheit zu, diesen Aufstieg der Seele auszulösen und zwischen Sinnlichem und Geistigem, zwischen Irdischem und Transzendentem zu vermitteln. Nun hat man gemeint, die schöne Kunst müsse hier doch in besonderer Weise geeignet sein, den Menschen auf diesen Erkenntnisweg zu bringen, und Plotin und seine Nachfolger haben der Kunst auch tatsächlich diese Funktion zugeschrieben. Platon jedoch spricht weder in der Politeia noch im Phaidros oder im Symposion von der Kunst, die trotz aller Rede vom Schönen keiner einzigen Erwähnung gewürdigt wird. Die Kunst kann im platonischen System an der bevorzugten Stellung des Schönen keinen Anteil haben, zum einen, weil sie, wie das 10. Buch der Politeia ausführt, ontologisch defizient und also epistemologisch wertlos ist, zum anderen, weil ein Kunstwerk keine Seele besitzt und es deshalb der für den Erkenntnisweg wesentlichen Stufe der ethischen Schönheit entbehrt. An dieser Stelle sei nocheinmal an jene Passage des Kratylos (432) erinnert, an der Sokrates feststellt, dass wenn ein Gott einen Mensch dem Kratylos nachbilde nicht nur "nach Farbe und Gestalt wie die Maler", sondern "auch das ganze Innere genau dem deinigen angleichend

79 Die Idee des Schönen im Symposion dürfte identisch sein mit der Idee des Guten in der Politeia, wenngleich im Gastmahl vom Schönen nicht gesagt wird, was in der Politeia vom Guten ausgesagt wird, nämlich dass es Seins- und Erkenntnisgrund der anderen Ideen sei.

PLATO, The electronic Journal of the International Plato Society, n 9, 2009.

http://gramata.univ-paris 1.fr/Plato

(C) All rights of reproduction of any form reserved. 
darstellte und alle Besonderheiten von Weichheit und Wärme völlig entsprechend wiedergäbe, ebenso Bewegung, Seele und Vernunft ganz wie bei dir in sein Werk hineinlegte", dann hätten wir es nicht mehr mit einem Bild des Kratylos, sondern mit einem zweiten Kratylos zu tun, denn ein Bild könne "Bewegung, Seele und Vernunft" nicht nachbilden. ${ }^{80}$ Ein Kunstwerk kann deshalb niemals den Aufschwung der Seele auslösen; ein von ihm ausgelöstes Begehren beruht wesenhaft auf Trug und ist leer; im besten der Fälle führt es zu nichts, wahrscheinlich aber zum Verderb der Seele.

Zusammenfassend lässt sich festhalten, dass Platon nie Kunst mit Schönheit und auch nie Schönheit mit Kunst gemeinsam dachte. Weder im 3. noch im 10. Buch der Politeia, denjenigen Stellen, wo er ausführlich von der Kunst handelt, wird auch nur ein einziges Mal der Begriff des Schönen auf ein Werk der Kunst positiv angewandt. Schönheit ist dem Philosophen vor allem ein Equivalent des Wahren und des Guten und Bezeichnung der Übereinstimmung des Denkens und Verhaltens mit diesen. Deshalb sah Platon durch die Verbannung der Kunst aus seinem idealen Staat diesen auch keineswegs der Schönheit beraubt. Nicht nur sorgt sich Platon um die Schönheit jedes einzelnen Bürgers durch selektive Heiratspolitik, er tut auch alles dafür sicherzustellen, dass die Bürger seines Idealstaates in der schönsten Umgebung aufwachsen. Das Bedürfnis seiner Bürger nach Schönheit sah er durch die Institutionen und das Leben der idealen Stadt ausreichend befriedigt. Der platonische Staat ist schön, insofern er zur Erfüllung seines Zweckes bestens eingerichtet ist, er von gerechten Politikern geleitet wird, und gute Menschen erzeugt, nicht zuletzt durch eine philosophische Erziehung, die zur höchsten Seinsfülle in der Erkenntnis führt.

\section{Nur gegen die zeitgenössische Kunst?}

All den Schwierigkeiten der vorangegangenen Fragen kann man entgehen und dennoch das Ziel erreichen, wenn man behauptet, Platons kunstkritische Äußerungen zielten nur auf die zeitgenössische Kunstpraxis, keineswegs aber beträfen sie die Kunst schlechthin, sodass Raum bleibe für eine Wertschätzung einer zur Gegenwart alternativen Kunst, auch wenn Platon sich dahingehend nicht unmissverständlich geäußert habe. ${ }^{81}$ Eine ganze Reihe von Kommentatoren

80 Vgl. Hippokrates, De victu I,21: Bildhauer stellen eine $\mu$ i $\mu \eta \sigma ı$ des menschlichen Körpers her, "mit Ausnahme der Seele"; ferner Xenophon, Memorabilia III,10.

81 Neben den im Folgenden genannten Autoren s. auch WEBSTER 1939, 138ff. und 174ff., Glaser 1940, 33ff., Broos 1948, BianCHI BANDINELli 1955 und 1968, 426f., HyMAN

PLATO, The electronic Journal of the International Plato Society, n 9, 2009.

http://gramata.univ-paris $1 . \mathrm{fr} /$ Plato

(c) All rights of reproduction of any form reserved. 
hat auch versucht näher zu bestimmen, welche Künstler oder welche Kunstrichtung der Philosoph genauerhin im Visier gehabt und welcher er hingegen den Vorzug gegeben hätte.

Nach SCHUHL (1933) sei Platon in einer weite Kreise erfassenden Querelle des Anciens et des Modernes auf der Seite einer archaisierenden Maler- und Bildhauerschule einer neuartigen Illusionsmalerei gegenüber gestanden. ${ }^{82} \mathrm{Im}$ selben Jahr vertrat STEVEN die Ansicht, Platon habe sich zwar gegen eine illusionistische Malweise gewandt, habe dabei aber nicht die Kunst seiner Reifezeit, sondern vielmehr die seiner Jugend abgelehnt. In den platonischen Dialogen fänden sich Zeugnisse für eine "Verurteilung der Athenischen Kunst des späten 5. Jahrhundert" und eine "Hochschätzung der Pelopponesischen Kunst des frühen 4. Jahrhundert", genauerhin der Sikyonischen Malerschule, deren Gründer und erster Führer Pamphilos großen Wert auf Mathematik und Geometrie gelegt und einen auf diese gegründeten Zeichenunterricht in das allgemeine Curriculum aufgenommen habe; ihr Einfluss spiegle sich wider in dem linearen, die Umrisse betonenden Stil der attischen Vasen seit 370 v. Chr.. Diese Schule einer linearen Malerei auf mathematischer Grundlage hätte Platons Anhängerschaft gefunden und ihm die Grundlage zur Verfügung gestellt, von der aus er seinen Angriff auf die alte Illusionsmalerei führte. ${ }^{83}$ SCHWEITZER (1953) wiederum, in Umkehrung der These von STEVENS, vertrat die Ansicht, dass die Schule illusionistischer Malerei, gegen die sich Platon im 10. Buch der Politeia

1989, 84ff., CHILDS 1994.

82 SCHUHL 1933. Die These von der Existenz einer archaisierenden Schule im frühen 4. Jh. v. Chr. wurde von WEBSTER 1934 und HACK 1935 sofort in Frage gestellt und fand zunächst keine Nachfolge; was SCHUHL nicht davon abgehalten hat sie 1952 zu wiederholen (SCHUHL 1952). Ganz ähnlich aber noch BRUNO 1977, 31ff., der in Anwendung Wölfflinscher Terminologie einen Widerstreit der Geschmäcker unter den Zeitgenossen Platons erkennen zu können meinte, nämlich zwischen archaisierender Betonung von Form und Linie auf der einen Seite und modernem Kolorismus und Schattierung der Farben auf der anderen Seite, wobei erstere Richtung mit dem Namen Parrhasios, letztere mit Zeuxis in Verbindung gestellt worden sei; Platon sei als Exponent eines abstrakten philosophischen Idealismus naturgemäß auf Seiten der Konservativen gestanden. Für ein früheres Beispiel einer ganz ähnlichen Anwendung Wölfflinscher "Grundbegriffe" auf die Kunst der Antike s. RODENWALDT 1916.

83 STEVEN 1933. Zustimmend WEBSTER 1934 und 1952; eine Nähe von platonischem Denken und Sikyonischer Malerschule hatte vor STEVEN bereits PFUHL 1923, Bd. 2, 729, vermutet, aber nicht weiter verfolgt. Unser Wissen von der Sikyonischen Malerschule beschränkt sich auf kurze Erwähnungen bei Plinius (Naturalis Historia 35,75-77), Plutarch (Leben des Aratos von Sikyon 12,5-13,1) und Quintilian (Institutio oratoria 12,10,1-10). Daraus lässt sich kein klares Bild oder jedes gewinnen.

PLATO, The electronic Journal of the International Plato Society, n 9, 2009.

http://gramata.univ-paris 1.fr/Plato

(C) All rights of reproduction of any form reserved. 
wende, gerade jene Sikyonische Malerschule gewesen sei. $^{84}$ Eine genaue Durchsicht aller platonischen Aussagen zur Kunst bei gleichzeitiger Beachtung ihrer Chronologie zeige einen Wandel von einer positiven zu einer negativen Haltung, ein Wechsel, der nicht durch eine Entwicklung im platonischen Denken selbst, sondern nur durch einen äußeren Einfluss erklärt werden könne. Der Auslöser sei in der neuen (raum)perspektivischen Malweise des Pamphilos und seiner Schule zu suchen. ${ }^{85}$ Platon habe sich aber zu seiner Ablehnung der zeitgenössischen Kunstentwicklung nicht nur durch die Raumperspektive allein herausgefordert gesehen, sondern ebensosehr durch die neuen Inhalte und Sinngehalte, die durch sie aussagbar geworden waren. ${ }^{86}$ Gleichzeitig mit der Einführung perspektivischer Mittel sei nämlich die Kunst von dem politisch verordneten kultischen Bereich in das private Bereich ausgezogen, was nicht nur eine Individualisierung und Konkretisierung auf Seiten des Dargestellten, sondern auch eine neue Haltung der Empathie auf Seiten des Rezipienten zur Folge gehabt hätte; eine Entwicklung, die sich etwa an den Veränderungen in den Darstellungen der reich überlieferten attischen Grabreliefs, insbesondere aber am Aufkommen des Individualportraits hier und andernorts ablesen lasse. Während SCHWEITZER unentschieden ließ, ob hier die Funktion der Form gefolgt sei oder, umgekehrt, die Form der Funktion, plädierte MORENO (196465) entschieden für Letzteres: Platons Verwerfung der Kunst sei eine Reaktion auf den neuen Realismus als Ausdruck neuer gesellschaftlicher und persönlicher Freiheiten im Gefolge einer neuen politischen und vor allem wirtschaftlichen Lage nach den beiden großen Kriegen. ${ }^{87}$ TATARKIEWICZ (1963) begnügte sich wieder mit Kunst- und Geistesgeschichte: Im Athen Platons habe es zwei radikal entgegengesetzte und sich bekämpfende philosophische Strömungen und diesen Denkschulen entsprechende Kunsttheorien gegeben: die eine, die von dorischen Lehrern von außen nach Athen gebrachte pythagoräische, habe, entsprechend ihres kosmozentrischen Weltbildes, eine objektive Ordnung und Harmonie und deren Ausdruck in zahlenmäßigen Proportionen, kurz Wahrheit, hochgehalten; die andere, die zur gleichen Zeit in Athen selbst von ionischen Denkern, allen voran den Sophisten und insbesondere Gorgias entwickelt worden war, habe hingegen, entsprechend ihres anthropozentrischen Weltbildes, die Realität der

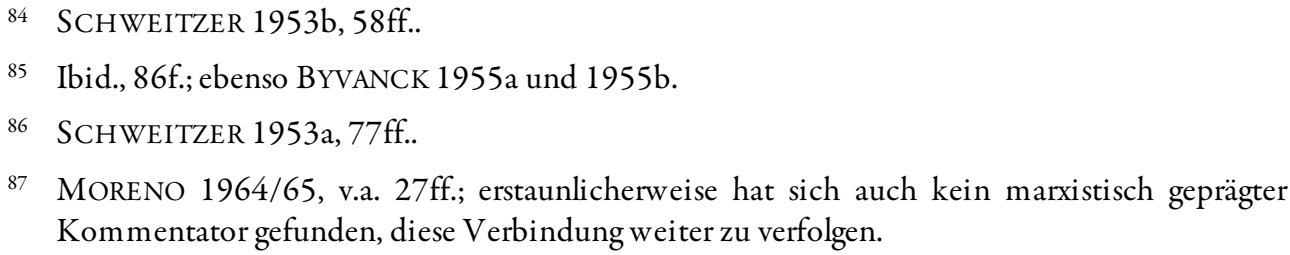

PLATO, The electronic Journal of the International Plato Society, n 9, 2009.

http://gramata.univ-paris 1.fr/Plato

(c) All rights of reproduction of any form reserved. 
menschlichen Wahrnehmung und Perspektive, kurz Illusion, gefeiert. Platons Dialoge ließen nicht nur klar erkennen, dass er von der pythagoräischen Philosophie beeinflusst war, sondern auch, dass er einer diesen pythagoräischen Lehren entsprechenden Ästhetik zum Sieg über den sophistischen Subjektivismus verhelfen wollte. ${ }^{88}$ DEMAND (1975) beschwörte nocheinmal das Phantom der Sikyonischen Malerschule: Platons Bemerkungen zur Malerei fielen deutlich in zwei Gruppen: eine frühere der Zuneigung und eine spätere der Abneigung. Und auch der Bruch lasse sich genau verorten, nämlich mitten in der Politeia, zwischen dem 3. und dem 10. Buch. ${ }^{89}$ Die Punktualität dieses Meinungsumschwungs könne nur durch ein äußeres Ereignis erklärt werden, nämlich durch die Sikyonische Malerschule und deren "Einführung einer neuen und extremen Form des Illusionismus in die Athenische Szene." Die Maler dieser Schule hätten nämlich nicht nur, wie bereits SCHWEITZER angenommen hatte, raumperspektivische Mittel in die Malerei eingeführt, sondern erstmals "die ganze Bandbreite illusionistischer Techniken" angewendet. ${ }^{90}$ Nach KeUls (1978) wiederum könne man der Sikyonischen Malerschule gar keine illusionistischen Innovationen zuschreiben; vielmehr läge das entscheidende Merkmal dieser Schule darin, dass in ihr, und durch ihren Einfluss auch andernorts, die Malerei in das allgemeine Curriculum aufgenommen worden war. ${ }^{91}$ Die Verwendung einer auf Mathematik gegründeten Malerei in der schulischen Erziehung habe Platons zweifache Ablehnung hervorrufen müssen, hatte er doch selber den Nutzen von Mathematik und Geometrie für die Erziehung betont, aber die Malerei von dieser radikal ausgeschlossen. CHILDS (1994) schließlich sah in den Stellungnahmen Platons zur Kunst eine präzise Beschreibung der Entwicklung der Kunst im 4. Jahrhundert hin zu einer neuen Innerlichkeit und Spiritualität, die sich als Mittel eines radikalen Illusionismus bediente, der die Verformung der realen Welt verfolgte. ${ }^{92}$ Diese Entwicklung habe Platon keineswegs abgelehnt, vielmehr den neuen Status des Bildes als ein Ausdrucksmittel überindividueller Werte begrüßt und durch göttliche Inspiration erklärt.

88 TATARKIEWICZ, 1963. Ähnlich, aber weniger antithetisch TATARKIEWICZ 2003 (1976), $281 \mathrm{ff}$. und $320 \mathrm{ff}$. .

89 DEMAND 1975), 17 ff..

90 Ibid, $19 f$.

91 Keuls 1978b, v.a. 139ff.. Vgl. oben Anm. 83, sowie Aristoteles, Politik 1337 b, wo dieser berichtet, dass von manchen Schulen die Malerei den traditionellen Fächern der Grammatik, Musik und Gymnastik hinzugefügt worden sei, ohne aber einen Einfluss der Sikyonischen Schule auf diese Entwicklung zu erwähnen.

92 CHILDS 1994.

PLATO, The electronic Journal of the International Plato Society, n 9, 2009.

http://gramata.univ-paris $1 . \mathrm{fr} /$ Plato

(c) All rights of reproduction of any form reserved. 
Wir müssen und können an dieser Stelle auf eine ausführliche Diskussion dieser Stellungnahmen und der Quellen, auf die sie sich berufen, verzichten und erlauben uns sie mit einer groben Bewegung zur Seite zu schieben: Weder die vereinzelten und kurzen platonischen Erwähnungen einzelner Künstler, ${ }^{93}$ noch die spärlichen und oft aus viel späterer Zeit stammenden anderen Quellen, noch die erhaltenen Kunstwerke, lassen es weder zu ein genaueres und verlässliches Bild eines bestimmten Malers oder gar einer bestimmten Maler-Schule zu gewinnen, noch Platon auf eine Ablehnung oder Vorliebe der einen oder anderen festzulegen. ${ }^{94}$

93 Polygnot wird erwähnt in Ion 532 e, in Gorgias 448 b sein Bruder; Zeuxis wird in Gorgias 453 c genannt und ist vielleicht mit dem in Protagoras $318 \mathrm{~b}$ angeführten Zeuxippus von Heraklea gemeint; der berühmte Kanon des Polyklet wird nicht genannt, in Protagoras 328 c wird lediglich bemerkt, dass die Kunst seiner Söhne um vieles geringer sei als die des Vaters; in Protagoras $311 \mathrm{c}$ werden Polyklet und Phidias gemeinsam genannt, als berühmte Bildhauer, die Schüler gegen Bezahlung unterrichtet hätten; ein explizites Lob erhält allein und ausgerechnet Phidias, "der so ausgezeichnet schöne Werke hinterlassen hat" (Menon $91 \mathrm{~d}$ ).

94 Diese Unmöglichkeit spiegelt sich sprechend in der Literatur, wenn in der Entgegensetzung eines linearen, monochromen und eines malerischen, koloristischen Stils für beide Seiten dieselben Künstler in Anspruch genommen werden. So wird beispielsweise Parrhasios, der sich sonst meist in ersterer Kategorie wiederfindet, von STEVEN 1933, 153f., für Letztere reklamiert. Selbst Phidias muss die Seiten wechseln, wenn er von SCHWEITZER 1953a, 16 und 86, als ein von Platon gelobter Vertreter eines archaischen Skulpturenstils angeführt wird. Ein ähnliches Schicksal ereilte bisweilen Poliklet, je nach dem, ob der Ausdruck "quadratus" bei Plinius in abwertender oder lobender Weise auf ihn bezogen wird; dazu unten Anm. 114. (Zur Annahme einer antiken Auseinandersetzung "Linie/Form versus Farbe" insbesondere BRUNO 1977, $31 \mathrm{ff} ., 67 \mathrm{ff}$ und 95ff.; ferner KEULS 1978b, 91ff.; der Widerstreit wird seit HelbIG 1867 meist mit dem Gegensatz von Parrhasios versus Zeuxis gleichgesetzt; vgl. GSCHWANTLER 1975.) Neuere Kommentatoren haben deshalb auch darauf verzichtet, Platons Vorlieben oder Abneigungen mit einzelnen Künstlern oder gar Schulen zu identifizieren, und vorgezogen sich darauf $\mathrm{zu}$ beschränken, einen gewissen allgemein verbreiteten Illusionismus für Platons Verurteilung der zeitgenössischen Malerei verantwortlich zu machen. Die Tendenz ist freilich dieselbe geblieben, nämlich die Kunst vor Platon zu retten, beziehungsweise Platon vor seiner Verurteilung der Kunst. KEULS 1978b, 118, hat trotz irriger Schlussfolgerungen zu Recht darauf hingewiesen, dass die sich in den Begriffen der $\sigma \kappa \eta v o \gamma p \alpha \phi i \alpha$ und der $\sigma \kappa \iota \alpha \gamma p \alpha \phi i \alpha$ spiegelnden illusionistischen Neuerungen in der Maltechnik der Platon vorangehenden Generation zugeschrieben werden müssen und also allein deshalb die Vorstellung aufgegeben werden muss, Platon habe sich gegen die Erfindung illusionistischer Techniken zur Zeit seines eigenen Schaffens gewandt. Dasselbe gilt übrigens auch für die Dichtung, gegen die sich Platon wendet: erstes Ziel seines Angriffs bilden die großen epischen und dramatischen Dichtungen des 5. Jh., und nicht jene des 4. Jh.; angesprochen sind u.a. Hesiod und Aischylos, v.a. aber Homer, der "erste Lehrer und Führer all der schönen Tragiker" (595 d; vgl. insbes. 606 e - 607 a). Wie die Kritik an der Malerei, so ist

PLATO, The electronic Journal of the International Plato Society, n 9, 2009.

http://gramata.univ-paris 1.fr/Plato

(C) All rights of reproduction of any form reserved. 


\section{Bühnen- und Schattenmalerei}

Sowenig man einzelne Künstler oder Schulen als diejenigen identifizieren kann, die Platons Kritik der Kunst provoziert haben, so ist dennoch klar, wogegen er sich im Allgemeinen und im Besonderen richtet: Gegen alle Kunst, insofern sie wesenhaft nicht mehr zu sein vermag als bloße Nachahmung der Wirklichkeit wie sie unseren Sinnen erscheint, sowie gegen die zeitgenössische Malerei als Höhepunkt dieser Illusion der sinnlich erfahrbaren Welt. Das macht nicht nur eine Lesung des 10. Buches der Politeia unmissverständlich klar, sondern zeigt sich auch deutlich an Platons Verwendung der Begriffe oknvorpaфia und okı $\alpha$ p $\alpha \phi i \alpha .^{95}$

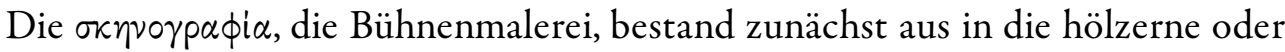
steinerne Theaterarchitektur gesetzte Tafelbilder, etwa mit illusionistischen Ausblicken in die Landschaft; später dürfte sie auch großflächig größere Teile oder gar die gesamte Theaterarchitektur ersetzt haben, indem sie deren Architekturteile, in anderen Fällen konkrete, den dargestellten Stücken entsprechende Orte, durch Architekturelemente in perspektivischer Verkürzung und in Ausrichtung auf den Blickpunkt der Zuschauer wohl mehr andeutete als tatsächlich illusionierte, ähnlich den Architekturdarstellungen der erhaltenen römischen Wandmalereien in den Villen Kampaniens und Roms.

Die okı $\gamma p \alpha \phi i \alpha$, wörtlich "Schattenmalerei", war eine Technik, die offenbar die Plastizität der dargestellten Figuren und Gegenstände durch das Abschattieren verschiedener Farbtöne verfolgte; sie wurde wohl nicht zuletzt in der Bühnenmalerei angewandt. ${ }^{96}$ Nun dient der Begriff okı $\gamma p \alpha \phi i \alpha$ Platon als Bezeichnung

auch die an der Dichtung von ganz grundsätzlicher Art. Die Mahnung CoLLINGWOODS 1925, 169, dass der metaphysische Charakter der platonischen Kunstkritik eine Vorliebe für einen bestimmten Stil ausschließe ("...it would show the greatest ineptitude in him that he should pick a quarrel with art as a whole on metaphysical grounds when he really wanted to quarrell with contemporary art on aesthetic grounds"), blieb unerhört, übrigens auch von ihm selbst (CollingWoOD 1960 [1938], 49: "What Plato wanted to do ... was to put the clock back and revert from the amusement art of the Greek decadence to the magical art of the archaic period and the fifth century").

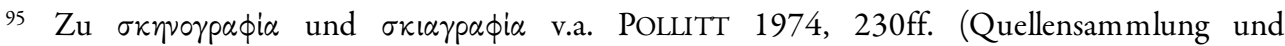
Kommentar), TRIMPI 1978, ROUVERET 1989, 65ff. und 106ff.; ferner DEMAND 1975, 5ff., und KEULS 1978 b und 1975, allerdings mit unzulässigen Schlussfolgerungen.

96 Die Einführung der Technik der "Schattenmalerei" wurde von der späteren Geschichtsschreibung mit dem Namen Apollodoros verbunden (Athen, spätes 5. Jh.), dem man deshalb den

PLATO, The electronic Journal of the International Plato Society, n 9, 2009.

http://gramata.univ-paris 1.fr/Plato

(c) All rights of reproduction of any form reserved. 
alles Unklaren, Unechten und Betrügerischen; sie scheint ihm die Quintessenz aller trügerischen Wahrnehmung. In den Nomoi (663 c) beispielsweise vergleicht Platon die unklare Vorstellung, die die unwissende Menge von Gerechtigkeit und Ungerechtigkeit hat, mit der trügerischen Wahrnehmung einer "Schattenmalerei". Im Phaidon (69 a - b) ist das Streben nach Tugend ohne Einsicht wie eine

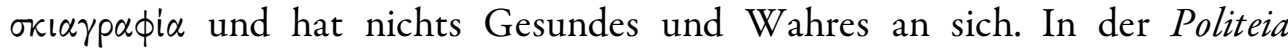
wiederum steht "schattierte Lust" für unechte, nicht gereinigte Lust (583 b, 586 b), wie "okı $\alpha$ p $\alpha$ фi $\alpha$ der Tugend" für falsche, vorgetäuschte Tugend (365 c): so wie in der Schattenmalerei der Bühnenskene eine gemalte Fassade ein reales Haus suggeriert, sich aber im Trug erschöpft, so kann ein schlechter Mensch, wenn er geschickt genug ist, den Anschein von Tugendhaftigkeit erwecken, ohne tatsächlich tugendhaft zu sein. Bei einer Aufzählung optischer Täuschungen im 10. Buch der Politeia $(602 \mathrm{c}-\mathrm{d})$ führt Platon auch den Umstand an, dass uns Gegenstände oft entgegen ihrem wahren Sein als konvex oder konkav erscheinen, weil die ihnen durch den Maler gegebenen Farben uns täuschen, und dass allen Gauklern voran die Kunst der Schattenmaler sich diese Schwäche unserer Natur zunutze mache. ${ }^{97}$ An mehreren anderen Stellen spricht Platon davon, dass die

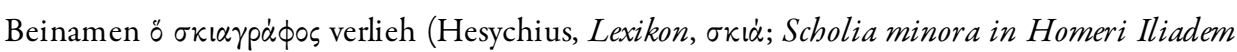
X,265; zit. bei POLLITT 1974, 238 bzw. 250). Das griechische Wort $\sigma \kappa \iota \alpha \gamma p \alpha \phi i \alpha$ wurde wohl zu Recht mit dem lateinischen "lumen et umbrae" identifiziert; Quellen bei POLLITT 1974, 399f.. Plinius (Naturalis historia 35,29) und Quintilian (Institutio oratoria 12,10,4) bzw. deren Quellen, betrachten die Erfindung von "lumen et umbrae" als Geburt der echten Malerei, im Gegensatz zur alten zeichnerisch-linearen Kunst. Plinius (35,60f.) verbindet zwar den Begriff nicht mit Apollodoros, berichtet aber, dieser sei der erste gewesen, der es unternommen hätte, die "äußere Erscheinung" darzustellen (primus species exprimere; zu "species" POLLITT 1974, 436ff.), sein Werk sei das erste gewesen, das "die Augen festhielt" (teneat oculos); er habe die Türen zur Kunst geöffnet, durch die dann Zeuxis geschritten sei. Nach Quintilian hingegen habe Zeuxis die theoretische Grundlage der Malerei mit "lumen et umbrae" gelegt; die Maler des frühen fünften Jahrhundert, Polygnotus und Agloaphon, hätten dagegen noch einen archaischen Stil mit "simplex color" vertreten; vgl. Plutarch (De Gloria Atheniensium 2, ferner Moralia 346 a). Den Kontrast zu der früheren Malweise stellt auch Dionysios von Halikarnass (De Isaeo 4, 1. Jh. v. Chr.) heraus: "In ancient painting the scheme of colouring was simple and presented no variety in the tones; but the line was rendered with exquisite perfection, thus lending to these early works a singular grace. This purity of droughtsmanship was gradually lost; its place was taken by a learned technique, by the differentiation of light and shade, by the full resources of the rich colouring to which the works of the later artists owe their strength."; zit. nach RiCHTER 1970, 61). Vgl. Aristoteles, Poetik 1450 b: "Wenn jemand blindlings Farben aufträgt, und seien sie noch so schön, dann vermag er nicht ebenso zu gefallen, wie wenn er eine klare Um risszeichnung herstellt."

97 Vgl. die Verwendung des verwandten Begriffes à $\pi \circ$ xpaiveเv in Politeia 586 b - c, und in Nomoi 769 a - b, wo Platon sich missbilligend über die schier endlose Zeit und Mühen

PLATO, The electronic Journal of the International Plato Society, n 9, 2009.

http://gramata.univ-paris $1 . f r / P l a t o$

(C) All rights of reproduction of any form reserved. 
"Schattenmalerei" von einer gewissen Distanz aus betrachtet werden müsse, um ein stimmiges Bild zu erhalten, während sie von der Nähe betrachtet unverständlich bleibe, dass also ihr Betrug einen unwissenden, flüchtigen Blick verlange, einer genaueren Betrachtung aber keineswegs standhalte. ${ }^{98}$ Deshalb zögen die betrügerischen "Schattenmaler" auch ein Publikum aus Kindern und unwissenden Erwachsenen vor, dem sie ihre Gemälde nur in gewissem Abstand vorführen (Sophistes $234 \mathrm{~b}$ - c und Politeia $598 \mathrm{c}$ ). Im Theätet (208 e) ist die Rede von einer Argumentation, die wie eine okı $\gamma$ paфia zunächst Sinn zu machen scheint, sich aber bei näherer Betrachtung als trügerisch erweist. ${ }^{99}$ Kritias (107 a e) vergleicht die aus Unwissenheit ungenaue mündliche Rede von "himmlischen und göttlichen Dingen" mit einer in "Schattenmalerei" gegebenen Landschaft und Atmosphäre eines Gemäldes. An einer weiteren Stelle der Politeia (523 b) unterscheidet Sokrates zwischen sinnlicher Wahrnehmung, die zu keiner weiteren Untersuchung durch die Vernunft anregt, weil sie für die Beurteilung

verwundert, die die Maler beim "Auftragen und Abschattieren der Farbe" aufbringen. Auf den Einwurf seines Gesprächspartners Kleinias, dass er sich mit der Malerei noch nie beschäftigt habe, erhält dieser als Antwort, dass er dadurch auch nichts versäumt hätte. Eine ähnliche Verwendung des Begriffs $\sigma \kappa ı$ p $\alpha$ фi $\alpha$ bei Aristoteles, Metaphysik 1024 b: "Das Falsche wird in einer Bedeutung ein falscher Sachverhalt genannt, und dies einmal dadurch, dass etwas nicht zusammen besteht oder nicht zusammen bestehen kann... Zum anderen heißen falsch solche Dinge, welche zwar etwas seiendes sind, aber in deren Natur es liegt, entweder nicht zu erscheinen, wie sie sind, oder als das, was sie nicht sind, z.B. Schattenmalerei, Traum; denn diese sind zwar etwas, aber nicht das, dessen Vorstellung sie erwecken. Dinge also heißen falsch in diesen beiden Bedeutungen, entweder weil sie nicht sind, oder weil die von ihnen hervorgerufene Vorstellung die Vorstellung eines Nicht-seienden ist." Später wird auch der Begriff $\sigma \kappa \eta v o \gamma p a \phi i \alpha$ in solch pejorativer Weise verwendet beispielsweise von Polybius (Historiae XII,28a: der Unterschied zwischen Geschichtsschreibung und epideiktischer Rede sei wie der "zwischen einem wirklichen, solide gebauten und wohnlich eingerichteten Haus und der Bühnenmalerei im Theater"), Plutarch (Arat von Sikyon 15,2: König Antigonus

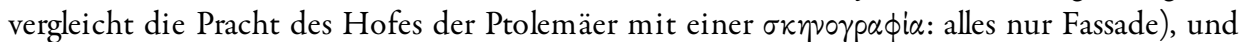
Sextus Empiricus (Adversus mathematicos 7,88: die in einer Bühnenmalerei dargestellten Gegenstände sind wie diejenigen Dingen, die man im Zustand des Traumes oder des Wahnsinns zu sehen vermeint); zit. bei POLLITT 1974, 236f..

98 Unter Berufung auf die folgenden Stellen wurde immer wieder eine Ähnlichkeit der antiken Technik der $\sigma \kappa ı \alpha \gamma \alpha \phi i \alpha$ mit dem Impressionismus des 19. Jh. postuliert; s. beispielsweise SCHUHL 1933 (1952), 11; v.a. aber KEULS 1973, 1975 und 1978b, 59ff.; vgl. WEISBACH 1910, 9ff.. Der Vergleich der Malerei der Antike mit jener Signacs oder Seurats ist Unsinn. Ich verzichte auf eine ausführlichere Behandlung und verweise auf die Erwiderung von PEMBERTON 1976.

99 Ganz ähnlich Parmenides 165 c, allerdings ohne expliziten Vergleich mit der Skiagraphie oder Skenographie.

PLATO, The electronic Journal of the International Plato Society, n 9, 2009.

http://gramata.univ-paris $1 . f r / P l a t o$

(C) All rights of reproduction of any form reserved. 
des Wahrgenommen hinreicht, und einer sinnlichen Wahrnehmung, die dies tut, weil sie relative Qualitäten erkennen lässt und so zur Unterscheidung von Sichtbarem und Intelligiblem führt. Platon lässt seinen Gesprächspartner die Absicht der Argumentation missverstehen und die letztere Kategorie auf "Gegenstände, die aus einer gewissen Entfernung gesehen werden, und Gegenstände der okı $\alpha p \alpha \phi i \alpha "$ beziehen. ${ }^{100}$

Es ist darauf zu achten, dass in allen diesen Stellen die Verwendung des Begriffes der okıарpaфia auf die der ontologischen Natur der Dinge inherente Undeutlichkeit und also Unerkennbarkeit zielt. Nichts wird hier ausgesagt über die subjektiven Beschränkungen des Betrachters oder mögliche objektive Beeinträchtigungen der Objekte hinsichtlich ihrer richtigen Erkenntnis. Sich den Dingen zu nähern mag den Trug ihrer Erscheinung, der durch die Entfernung vorübergehend verunklärt war, offenlegen, kann aber nicht den Grad der Erkennbarkeit erhöhen, denn dieser ist den Objekten wegen ihres ontologischen Standes inherent. Ein Kunstwerk beispielsweise, von dem die Metapher der Verdeutlichung willen ja ausgeht, kann, da es bloße Nachahmung der sinnlich wahrnehmbaren Welt und also verschieden von dieser ist, nicht erkennbarer oder wissbarer dadurch werden, dass es von nahe betrachtet wird, denn es ist wesenhaft ein weniger erkennbares Objekt als sein Vorbild.

\section{Abstrakte Kunst?}

100 Vgl. wieder Aristoteles, Rhethorik 1414 a, wo der Schüler Platons den unbearbeiteten, spontanen Stil einer (mündlichen) öffentlichen Rede, die aus der Entfernung einer großen Versammlung gehört wird, mit dem genau ausgearbeiteten und detaillierten Duktus des (geschriebenen) Diskurs, der in Ruhe gelesen oder gehört einer genauen Untersuchung aus der Nähe unterzogen werden kann, vergleicht und bemerkt: "Der Stil der Volksrede ist durchaus der Schattenmaleri ähnlich: je größer die Zuhörermenge, um so größer der Beobachtungsraum, daher ist Sorgfalt für beide Teile verlorene Mühe und weniger von Bedeutung."; vgl. auch De Sensu 440 a. Die Verwendung des Begriffes $\sigma \kappa \iota \alpha \gamma p \alpha \phi i \alpha$ im Sinne einer trügerischen Erscheinung findet sich auch später noch, beispielsweise bei Dio Cassius (Römische Geschichte 52,7,4) oder Plutarch (Moralia 1091d), allerdings in Abhängigkeit von seiner Verwendung bei Plato und Aristoteles. Ansonsten ist die Verwendung der Begriffe $\sigma \kappa \iota \alpha \gamma \rho \alpha \phi i \alpha$ und $\sigma \kappa \eta \nu o \gamma p \alpha \phi i \alpha$ bei Platon und Aristoteles zu trennen von ihrer späteren Gleichsetzung unter dem scheinbar gemeinsamen Nenner der perspektivischen Darstellung, beispielsweise bei Vitruv (De architectura I,2,2) oder Hesychius (Lexikon, $\sigma \kappa i \dot{\alpha})$; zur späteren Verwendung der Begriffe v.a. TRIMPI 1978; ferner Keuls 1978b, 75 ff.. Bei Geminos (1. Jh. n. Chr.) und Proklos (5. Jh. n. Chr.) ist aus der $\sigma \kappa \eta v o \gamma p a \phi i \alpha$ die Lehre von den optischen Ausgleichsmittel geworden; POLLITT 1974, 232ff..

PLATO, The electronic Journal of the International Plato Society, n 9, 2009.

http://gramata.univ-paris 1.fr/Plato

(c) All rights of reproduction of any form reserved. 
Der zuvor erwähnten Stelle des Sophistes folgt die bekannte Unterscheidung der

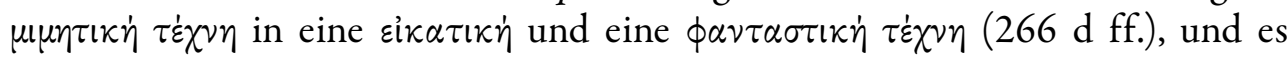
besteht kein Zweifel, dass die zuvor abfällig beschriebene Schattenmalerei ebenso wie die Bühnenmalerei in letztere Kategoie fallen muss. In der der "phantastischen" Kunst entgegengesetzten "eikastischen" Kunst, von der gesagt wird, dass sie ein wahres, in seinen Maßen und Proportionen getreues Abbild der Gegenstände gebe, hat man immer wieder eine von Platon gebilligte alternative

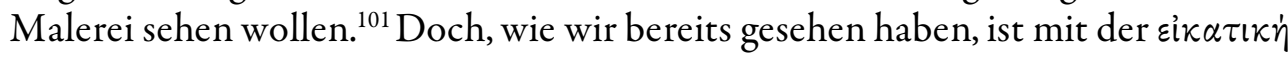
$\tau \dot{\varepsilon} \chi \nu \eta$ nur die Skulptur angesprochen, sodass es auch hier, wie auch sonst, die gesamte Malerei ist, die als phantastischer Trug der Verdammung anheim fällt. ${ }^{102}$

Und auch die in diesem Zusammenhang oft zitierten Sätze des Philebos (50 ff.) lassen sich nicht für die gesuchte "richtige" Kunst verwenden. ${ }^{103}$ Platon spricht dort von der Schönheit der reinen, ungemischten Gestalten und Farben (51 b), worunter er "nicht das verstanden wissen will, was sich die große Menge dabei denkt, wie z. B. die Schönheit von lebenden Wesen oder von Gemälden", sondern eine gerade Linie und ein Kreis, sowie ihre Derivate, nämlich alle Flächen und Körper, deren Maße und Proportionen von Zirkel und Winkel bestimmt sind. Denn diese seien nicht von relativer Schönheit, sondern "immerdar an und für sich schön", insofern sie reine und nicht mit Schmerz vermischte Lust transportieren (51c). In diesen Sätzen hat man ein Plädoyer Platons für eine abstrakte, die Ideenwelt vermittelnde Kunst erkennen wollen, doch schließt die vorangegangene wie nachfolgende Argumentation dergleichen aus: Reine Farben und Formen, wie reine und unreine Lust, stehen letztlich für unreine, also falsche, und reine, also wahre Erkenntnis und Wissen; wieder wird hier die bloße Meinung der Vielen, die es mit dem Werden zu tun hat, mit der wahren Erkenntnis des Philosophen, als der einzigen, die es mit dem Sein zu tun hat, kontrastiert. Und nichts verlautet davon, dass die schönen, weil reinen Farben und Formen diesem ein notwendiges oder auch nur mögliches Transitum auf seinem Weg zur wahren Erkenntnis sind, vielmehr kann eine solche nur durch reines, von keiner sinnlichen Wahrnehmung getrübtes Denken erreicht werden. Sie können dem Philosophen lediglich als Vorstellungsmuster für die Einartigkeit und Unwandelbarkeit der Ideen dienen. Reine Farben und Formen sind also nicht schön, weil sie die Idee der Schönheit oder sonst eine Idee sinnlich erfahrbar werden lassen, sondern nur insofern, als sie die Seinsweise der Ideen

\footnotetext{
101 Beispielsweise HYMAN 1989, 87f..

102 Siehe oben zu Sophistes $233 \mathrm{ff}$. und $264 \mathrm{ff.}$.

103 So beispielsweise TATARKIEWICZ 1979, 148f.; in unserem Sinne BROOS 1951.
}

PLATO, The electronic Journal of the International Plato Society, n 9, 2009.

http://gramata.univ-paris 1.fr/Plato

(C) All rights of reproduction of any form reserved. 
und ihre Entsprechung im reinen Denken versinnbildlichen. Schön ist "das Sichere, Reine, Wahre, kurz das durch und durch Lautere", aber dieses ist keineswegs etwas sinnlich erfahrbares, sondern in gleicher Weise "das immer ohne jeden Zusatz von etwas anderem sich selbst unverbrüchlich Geichbleibende" wie "das, was durch das Band der Liebe mit jenem am nächsten verwandt ist", nämlich "allein Vernunft und Einsicht", "die schönsten Namen, die man dem Schönen beilegen muss" (59 c)..$^{104}$

Im Folgenden wird die Trennung von sinnlich Erfahrbarem und Intelligiblem

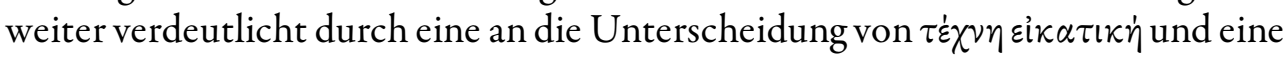
$\phi \alpha \nu \tau \alpha \sigma \tau \iota k \eta$ im Sophistes erinnernde Differenzierung der $\tau \dot{\varepsilon} \chi \nu \alpha \iota$ in jene Kunst der "wissenschaftlichen Köpfe", die sich wie die Baukunst "vor allem der Maße und Werkzeuge bedient" und sich deshalb "durch eine große Genauigkeit auszeichnet", und jene $\tau \dot{\varepsilon} \chi v \alpha \iota$ der "großen Masse", die von großer Ungenauigkeit zeugen, insofern sie ohne "die Arithmetik und die Mess- und Gewichtskunde" beschränkt bleiben auf "ein Mutmaßen und eine Übung der Sinne durch Erfahrung und Praxis, indem man sich eine gewisse Treffsicherheit aneignet, die durch Übung und Fleiß eine Art Meisterschaft erzeugt und darum von vielen als Kunst $(\tau \dot{\varepsilon} \chi \nu \eta)$ bezeichnet wird" ( $55 \mathrm{~d}$ ff.). ${ }^{105}$ Doch wieder wird derjenige, der in dieser Unterscheidung die Möglichkeit einer wissenschaftlichen oder abstraktidealistischen Kunst ausgesprochen sieht, enttäuscht, denn kurz darauf wird "die Rechenkunst und Messkunst in der Baukunst und im Handel" von der "wissenschaftlichen Geometrie und den wissenschaftlichen Rechnungen" nach dem Grad ihrer Reinheit unterschieden, sodass "zwar die genannten Künste sich von den anderen abheben, dass aber über diese selbst sich wieder diejenigen, mit denen es der Forschertrieb der wahrhaft Philosophierenden zu tun hat, unendlich

104 Ähnlich in 65 a - d, wo nicht nur die Idee des Guten, sondern auch die ihr allein entsprechende Einsicht und Vernunft als schön bezeichnet werden, während - um jedes Missverständnis zu vermeiden - die Lust aus diesem Verhältnis wieder ausgeschlossen wird.

105 Hier ist zu erinnern an Politeia 602 c - e, wo zwei Seelenteile unterschieden werden: ein schwacher, auf den es die Betrügereien der Malerei und der anderen Nachahmungskünste abgesehen haben, und der vernünftige, der durch "das Rechnende, Messende oder das Wägende" ein Gegenmittel besitzt. (Die Trias von Rechnen, Messen und Wägen findet sich bekanntermaßen im biblischen Buch der Weisheit 11,20 wieder.) Vgl. oben Anm. 24. Vgl. die als 13. Buch den Nomoi angehängte Epinomis, die zwar sicherlich nicht platonisch ist, doch in ihrem Lob der Mess- und Zählkunst ganz im Sinne Platons klingt (977c). Zum Zusammenhang von Messen, Schönem und Guten zuletzt LOSSAU 1997. Hierher gehört auch die platonische (und dann bekannterermaßen aristotelische) Rede vom "rechten Maß", das tugendhaft, schön und wahr genannt wird; beispielsweise Gorgias 506 e, Philebos $64 \mathrm{~d}$ und 66 b, Politeia 486 d, Politikos 284 b, Nomoi 668 e u.ö..

PLATO, The electronic Journal of the International Plato Society, n 9, 2009.

http://gramata.univ-paris 1.fr/Plato

(C) All rights of reproduction of any form reserved. 
hoch an Genauigkeit und Wahrheit in Bezug auf Maß und Zahl erheben" (57 c d). Als Ergebnis muss also wieder festgehalten werden, dass es allein die Kunst der philosophischen Dialektik ist, die den höchsten Erkenntnisgegenständen zu entsprechen vermag.

Ähnliches ergibt die Diskussion der für die Erziehung der Bürger des platonischen Idealstaates geeigneten Unterrichtsfächer in den Nomoi (522 c ff.). ${ }^{106}$ Zunächst wird die Mathematik als Lehrfach gutgeheißen, denn sie erweist sich als "zugkräftig nach der Wahrheit hin", ist "dem Philosophen zur Erfüllung seiner Aufgabe unerlässlich, die darin besteht, sich über das Gebiet des Werdens zu erheben und das Sein zu erfassen" (525a - b), und "nötigt die Seele sich auf dem Wege des reinen Denkens der reinen Wahrheit zu nähern" (526 a). Ähnliche Billigung erfährt die Geometrie. Die Astronomie hingegen muss aus dem Curriculum ausgeschieden werden, denn sie hat es mit sinnlichen Erscheinungen zu tun, über die kein Weg zur transzendenten Welt führt, deren bloße Mimesis die Sterne und Planeten und ihre Bewegungen sind. ${ }^{107}$ Die Vergeblichkeit der Betrachtung des Himmels wird verglichen mit der Betrachtung von Deckengemälden (529 b). "Man wird zwar die Gestirne, diese Zierden des Himmels, für das Schönste und Regelrechteste halten unter allem Sichtbaren, aber da sie nun einmal im Sichtbaren gebildet sind, so wird man zugeben, dass sie weit hinter dem Wahrhaften zurückbleiben." Die wahren Zahlen, Figuren und Bewegungen der Gestirne sind "nur durch den Verstand und durch Denken zu erfassen, nicht durch den Gesichtssinn (das Sehvermögen)" (529 d). Man solle sich deshalb nicht weiter mit der Astronomie befassen, wenn man "den von Natur vernünftigen Seelenteil statt ihn unbrauchbar werden zu lassen brauchbar zu machen" beabsichtige $(530 \mathrm{~b}-\mathrm{c})$. In dieses negative Urteil wird eine geometrische Kunst ausdrücklich mit einbezogen, und wir dürfen wohl dasselbe für eine mathematische Kunst annehmen. Wenn nämlich ein der Geometrie kundiger "geometrische Modelle und Figuren zu sehen bekäme, die von einem Daidalos oder einem anderen Künstler oder Maler vorzüglich gezeichnet und ausgearbeitet worden wären, ... so würde er sie zwar als Meisterstücke der Kunst anerkennen, aber es doch für lächerlich halten, sich ernstlich auf ihre Betrachtung in der Absicht einzulassen, etwa an ihnen das wahre Wesen des Gleichen oder Doppelten oder sonst irgendeines Entsprechungsverhältnisses zu erfassen" (529

$106 \mathrm{Zu}$ dieser Stelle v.a. MILLER 1999.

107 Neben Mathematik, Geometrie und Astronomie, gehört noch die Harmonie zu den Fächern, in denen die künftigen Philosophen, aus denen die Herrscher rekrutiert werden sollen, auszubilden sind; sie bilden gemeinsam das Proömium der höchsten Kunst, der Dialektik.

PLATO, The electronic Journal of the International Plato Society, n 9, 2009.

http://gramata.univ-paris 1.fr/Plato

(C) All rights of reproduction of any form reserved. 
e). Auch eine abstrakte Kunst, eine auf Mathematik und Geometrie und der Verwendung von reinen Farben und Formen gegründete Malerei oder Plastik kann Platons Billigung nicht finden.

\section{8. Ägyptische Kunst?}

Eine gewisse Ausnahme bildet Platons Lob der Ägyptischen Kunstproduktion in den Nomoi (656 c - 657 a) ${ }^{108}$ Soll in einem idealen Staat, so fragt der Philosoph, "den dichterischen Talenten freistehen alles, woran der Dichter selbst bei seiner Dichterarbeit in Bezug auf Rhythmus oder Melodie oder Text eben gerade Freude findet, auch den Kindern und den heranwachsenden Söhnen der sich guten Gesetzen erfreuenden Bürger als Leiter der Chöre beizubringen und sie so ganz nach den Launen des Zufalls der Tugend oder dem Laster in die Arme zu führen?" (656 c - d). Gerade das sei aber in allen existierenden Staaten, ausgenommen Ägypten, erlaubt. Dort habe man schon vor langem erkannt, dass die Künste von der allerhöchsten Qualität sein müssen, und deshalb hätten die Ägypter schon früh Regeln aufgestellt, von denen abzuweichen den Künstlern seither untersagt geblieben ist. Deshalb, fährt Platon fort, "wird man bei näherer Betrachtung finden, dass dort die vor zehntausend Jahren - und ich meine dies nicht in dem gewöhnlichen unbestimmten Sinn des Wortes, sondern tatsächlich vor zehntausend Jahren - gefertigten Gemälde und Skulpturen weder irgendwie schöner noch hässlicher sind als die der jetzigen Zeit, sondern ganz dieselbe künstlerische Behandlung zeigen" ( $565 \mathrm{~d}$ ). ${ }^{109}$

Man hat gemeint, Platons Begeisterung beträfe lediglich die Regeln des Gesetzgebers, die es ermöglicht haben, dass die Kunstproduktion für derart lange Zeit unverändert geblieben ist, und nicht die Kunst selbst, deren Inhalte und deren Stil. ${ }^{110}$ Doch es könnte durchaus mehr hinter Platons Lob der ägyptischen Kunstproduktion stehen. So sieht er durch die ägyptische "Auffassung und Behandlung der musischen Kunst" bewiesen, "dass es auf solchem Gebiet nur

108 Zum Folgenden v.a. DAVIS 1979; ferner WEIL 1959, 157f.; und FROIDEFOND 1971, v.a. 326ff.. Der Hinweis auf Platons Lob der ägyptischen Kunst soll bei den meisten der in Anm. 40 genannten Autoren die Argumentation stützen, Platon habe eine gute (idealistische) Kunst vertreten; vgl. auch GOMBRICH 2002, $107 \mathrm{ff}$. .

109 Von der Unabänderlichkeit der Spiele (der Kunst) wie der Gesetze im idealen Staat und von der Vorbildhaftigkeit Ägyptens handeln auch Nomoi 797 b - 799 b und 819 a, sowie Politikos 299 a ff..

110 Demand 1975, 19.

PLATO, The electronic Journal of the International Plato Society, n 9, 2009.

http://gramata.univ-paris 1.fr/Plato

(c) All rights of reproduction of any form reserved. 
eines mutigen Eingriffes bedarf, um eine feste gesetzliche Regelung von Sangesweisen herbeizuführen, die das naturgemäß Richtige bieten" (657 a). Platon lobt also an der Ägyptische Kunst nicht nur ihre Traditionsverhaftetheit und Formelhaftigkeit, sondern auch ihre "intrinsische Richtigkeit", ohne uns allerdings zu verraten, worin diese genauerhin besteht. Weiters hebt er ihren göttlichen und sakralen Charakter hervor, denn die Kunst der Ägypter könne nur "das Werk eines Gottes oder eines gottgleichen Mannes sein, wie denn auch dort (in Ägypten) die uralten Sangesweisen als Schöpfungen der Isis gelten" (ibid). Auch wenn Ägyptologen zu Recht einwenden mögen, dass die Ägyptische Kunst keineswegs ohne Veränderungen, nur traditionell und formelhaft, oder immer von religiöser Funktion war, die von Gesetzen standardisierten Typen der ägyptischen Kunst, von denen Platon hier spricht, waren genau dies. Die Beständigkeit ihrer Darstellungen in Malerei und Skulptur, Relief wie Rundplastik, wurden gewährleistet durch ein Netz von Quadraten stets gleicher Zahl, deren Seitenlänge, wie dem metrischen System überhaupt, wohl der menschliche Unterarm mit seinen einzelnen Abschnitten zugrunde lag. ${ }^{111}$ Dieser Kanon der Unterteilung des Körpers wie auch anderer Objekte durch den jeweiligen Quadraten entsprechende Einheiten, die untereinander und zum Ganzen in einem festgelegten Verhältnis stehen, ermöglichte es den ägyptischen Künstlern die Proportionen der Darstellungen beizubehalten trotz der Verschiedenheit individueller Merkmale und der vom Anbringungsort verlangten Dimensionen. Dass diese Arbeitsweise der ägyptischen Künstler in der griechischen Welt bestens bekannt war und also auch hinter den lobenden Bemerkungen Platons zur Traditionsverbundenheit und Formelhaftigkeit der ägyptischen Kunst stehen dürfte, zeigt uns das spätere Zeugnis des Diodorus Siculus: Die beiden Bildhauer Telekles und Theodoros hätten in alten Zeiten (i.e. im 6. Jahrhundert, also in archaischer Epoche) ein Kultbild in zwei getrennten Hälften angefertigt, wobei der eine sein Stück in Samos, der andere das seine in Ephesos gearbeitet habe. Beim Zusammensetzen habe sich gezeigt, dass die beiden Hälften genau aufeinander passten. Diese Arbeitsweise aber, so fährt die Erzählung fort, sei nicht bei den Griechen in Gebrauch gewesen, sondern bei den Ägyptern. Denn bei diesen "werden die symmetrischen Proportionen der Statuen nicht wie bei den Griechen nach der Gesichtsvorstellung bestimmt" ( $\dot{\alpha} \pi \grave{o} \tau \tilde{\eta} s$

111 Zum ägyptischen Kanon v.a. IVERSEN 1955 (1975), 1990 und 1996, MÜLLER 1973, DAVIS 1979; ferner PANOFSKY 1921; weitere Literatur bei BERGER 1992, 20. Das beschriebene System änderte sich nur einmal, etwa zur Zeit der 26. Dynastie, durch die Erweiterung der Zahl der Quadrate in der Höhe von 18 auf 21; der Grund dafür dürfte eine Änderung der Längenmaßeinheiten des zugrundeliegenden metrischen Systems gew esen sein.

PLATO, The electronic Journal of the International Plato Society, n 9, 2009.

http://gramata.univ-paris 1.fr/Plato

(C) All rights of reproduction of any form reserved. 


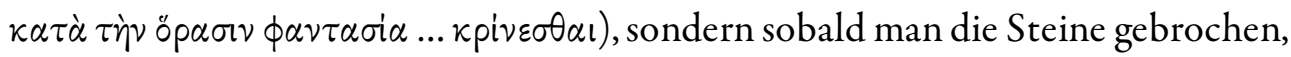
zerlegt und zugerichtet habe, seien "sogleich" die Maße vom größten bis zum kleinsten Stück festgesetzt worden. Man habe nämlich, berichtet uns Diodorus, in Ägypten den ganzen Bau des Körpers in 21 1/4 gleiche Abschnitte geteilt, und deswegen seien die Künstler, wenn man sich einmal auf die Größe der zu schaffenden Figur geeinigt hatte, imstande gewesen, sich auch bei räumlicher Trennung die Arbeit zu teilen und dennoch ein genaues Zusammenpassen der Stücke zu erzielen. ${ }^{122 " S y m m e t r i s c h " ~ m e i n t ~ h i e r ~ n i c h t, ~ w i e ~ m a n ~ n a c h ~ d e r ~ h e u t i g e n ~}$ Bedeutung des Wortes anzunehmen versucht sein mag, Spiegelgleichheit, sondern Rationalität und Kommensurabilität durch ein gleiches Verhältnis der Zahlen. Zwei Dinge sind symmetrisch, wenn sie das gleiche Maß in sich tragen, ihre Proportionen nach diesem gleichen $M a ß$ gemessen sind; nur insofern bedeutet symmetrisch auch übereinstimmend, gleich. ${ }^{113}$ Die Körperteile einer

112 Bibliotheca historia I,98; Paraphrase nach PANOFSKY 2002 (1921), 78. Zu dieser Stelle auch IVERSEN 1975, 48ff.. Die Schilderung des Diodorus stimmt mit unserem, an den Kunstwerken selbst gewonnenen Wissen von der Arbeitsweise der ägyptischen Maler und Bildhauer überein. Auch die Angabe, die 21 Quadrate der Höhe seien nach oben um ein gewisses $\mathrm{Maß} z u$ erweitern, trifft zu, insofern die 21 Quadrate des zweiten ägyptischen Kanons den stehenden menschlichen Körper nur von der Fußsohle bis zum Augenlied abdeckten (wohl wegen der die Grenze nach oben hin verunklärenden Mannigfaltigkeit von Frisur und Kopfschmuck). Allerdings handelt es sich bei dem hinzuzufügenden Maß nicht um $1 / 4$ eines Quadrates, sondern um 1 1 1/2 Einheiten. An dieser Stelle kann keine genauere Analyse des ägyptischen Kanons gegeben werden; stattdessen seien die für den mit der ägyptischen Kunst nicht Vertrauten erhellenden Worte PANOFSKYS, 2002 (1921), 72f., zitiert: "Den Sinn dieses Netzes wird man am besten dann erkennen, wenn man es mit der täuschend ähnlichen Quadrierung vergleicht, deren sich der neuzeitliche Künstler zur Übertragung seiner Komposition von einer kleineren auf eine größere Fläche bedient. Während nämlich dieses Verfahren eine Vorzeichnung voraussetzt, die - an und für sich an keine Quadratur gebunden - dann an willkürlich gewählten Stellen mit senkrechten und wagerechten Linien überzeichnet wird, lässt der Ägypter die Form allererst aus dem Quadratnetz entstehen: Da die Linien signifikanter und ein für allemal auf ganz bestimmte Stellen der Figur festgelegt sind, muss umgekehrt das ägyptische Quadratnetz dem Maler und Bildhauer ohne weiteres den Aufbau der Figur indizieren - er wird von vornherein wissen, dass er den Fußknöchel auf die erste, das Knie auf die sechste, die Schulter auf die sechzehnte Horizontallinie zu legen hat usw. ... Kurz, das Quadratnetz der Ägypter hat nicht transportative, sondern konstruktive Bedeutung." Die Stelle bei Diodorus dürfte auch darauf schließen lassen, dass ein konstruktives Quadratnetz noch von den griechischen Künstlern der archaischen Zeit verwendet wurde, der die genannten Künstler Telekles und Theodoros zuzurechnen sind.

113 Zwei Dinge können auch dasselbe Maß in sich tragen, wenn sie beide ein Vielfaches einer bestimmten Einheit darstellen, etwa das Verhältnis 24:16, das die gemeinsame Einheit 4 oder 8 enthält (Beispiel aus der pseudo-aristotelischen Schrift De lineis insecabilibus 2). Die Gleichsetzung der Symmetrie mit der Spiegelgleichheit war vom französischen Sprach-

PLATO, The electronic Journal of the International Plato Society, n 9, 2009.

http://gramata.univ-paris 1.fr/Plato

(C) All rights of reproduction of any form reserved. 
darzustellenden Figur sind also "symmetrisch", weil sie in einem festgesetzten Verhältnissen zueinander und zum Ganzen stehen. Bei der von Telekles und Theodoros gearbeiteten Statue muss es sich also keineswegs um eine frontal in sich ruhende "Buddhafigur" gehandelt haben; auch bei einem Körper in Profil und tanzender Bewegtheit hätten die beiden, an verschiedenen Orten gehauenen Teile zueinandergepasst.

Nun haben auch die Künstler der griechischen Klassik, also des 5. und 4. Jahrhundert, im Kanon des Polyklet ein Regelwerk der idealen Proportionierung des menschlichen Körpers gekannt. ${ }^{114}$ So sehr seine genauere Eigenart auch um-

gebrauch des 17. Jh. ausgegangen (dazu v.a. KAMBARTEL 1972). Zum Begriff der Symmetrie im Altertum SCHLikKer 1940, 60ff., Frey 1949, WeYl 1955, POLliTt 1974, $14 \mathrm{ff.}$ und 256ff., Hommel 1987, WASCHKies 1992, Berger 2003, 183ff.. Der Begriff hat seine ursprüngliche Bedeutung auch in der Neuzeit noch lange behalten, etwa bei Albrecht Dürer, De symmetria partium humanorum corporum (Von menschlicher Proportion), Nürnberg 1528 (Nachdr. Nördlingen 1996).

114 Die "Kanon" genannte Schrift des Polyklet ist verloren und nur spätere Quellen geben uns spärliche Hinweise auf ihren Inhalt. Die wichtigsten davon sind Philon von Byzanz (Mechanike syntaxis IV,1, vom Geschützbau handelnd: "Daher passt die Aussage des Bildhauers Polyklet zu dem, was ich sagen will. Er sagt nämlich, dass das Gelingen mittels vieler Zahlenverhältnisse zustande kommt. Und Kleines gibt dabei den Ausschlag. In derselben Weise kommt auch bei unserer Kunst eine Vollendung der Werke mittels Zahlenverhältnisse zustande; eine kleine Abweichung in Teilen ergibt am Ende bei der Summation einen großen Fehler.") und Galen (Deplacitis Hippocratis et Platonis 5: "(Chrysipp) machte dies nämlich sehr deutlich durch das, was er weiter oben sagte, wo er behauptete, dass die Gesundheit des Körpers eine Symmetrie von warm zu kalt und trocken zu feucht sei - was ja körperliche Elemente sind -; er glaubt aber, dass die Schönheit nicht in der Symmetrie der Elemente, sondern in der der Teile liege, in der Symmetrie eines Fingers zum andern und aller Finger zur Handfläche und zum Handgelenk und dieser zur Elle und der Elle zum Oberarm und aller zu allem, wie im Kanon Polyklets geschrieben steht. Denn alle Symmetrien des Körpers hat Polyklet uns in seiner Schrift gelehrt; in seinem Werk hat er diese Lehre bekräftigt, indem er ein Standbild schuf gemäß den Vorschriften in seiner Abhandlung und das Standbild selbst dann 'Kanon' nannte wie auch seine Schrift. Die Schönheit des Körpers besteht also nach allen Ärzten und Philosophen in der Symmetrie der Teile."; vgl. De temperamentis I,9: "Irgendwo wird auch ein Standbild Polyklets gelobt, das den Namen 'Kanon' trägt, weil alle Teile sich genau symmetrisch zueinander verhalten."). Nach den zitierten Stellen bei Galen, sowie nach Plinius (Naturalis Historia 34,55) scheint der Name der polykletischen Schrift auch auf den Doryphoros oder eine andere seiner Skulpturen übertragen worden zu sein (nach Plinius von seinen Schülern, nach Galen von Polyklet selbst). Nachdem 1862 eine in Pompeji gefundene, längst bekannte Marmorstatue als Kopie nach dem Doryphoros identifiziert worden war, fanden sich auch in anderen Museen weitere Kopien und Kopienfragmente, deren Überlieferung sich im Vergleich als derart gut erwies, dass eine Rekonstruktion des Originals in Bronze möglich war, die ohne die bei den Marmorkopien technisch unentbehrlichen

PLATO, The electronic Journal of the International Plato Society, n 9, 2009.

http://gramata.univ-paris $1 . f r / P l a t o$

(C) All rights of reproduction of any form reserved. 
stritten bleibt, der Unterschied zu seinem ägyptischen Vorgänger ist - zumindest hinsichtlich des Ergebnisses - offensichtlich: Während der ägyptische Kanon eine unveränderliche Formel unter Ausschluss aller raum-zeitlicher Bestimmungen und ihrer subjektiven Wahrnehmung angestrebt hatte, verfolgte der griechische Kanon die Gestaltung eines idealen Körpers, wie er dem Auge

Stützen dessen ursprüngliche Wirkung besser veranschaulichen konnte. Seither sind mit dem Ziel den Polykleitischen Kanon zu extrahieren unter den unterschiedlichsten Prämissen und Perspektiven Messungen an der Statue vorgenommen worden, ohne allerdings zu einem befriedigenden Ergebnis zu gelangen. Zum Kanon des Polyklet und zum Doryphoros v.a. der anlässlich der Ausstellung "Polyklet: Der Bildhauer der griechischen Klassik" im Liebieghaus in Frankfurt am Main erschienene Katalog (BECK 1990), mit umfassender Dokumentation zum Stand der Forschung und zur Wirkunsgeschichte, sowie eine Sammlung aller mit Polyklet in Verbindung stehender Quellen mit deutschen Übersetzungen; sowie die im Anschluss an ein Symposion an der Universität von Wisconsin-Madison herausgegebene Aufsatzsammlung MOON 1995; ferner HAFNER 1997. In diesem Zusammenhang auch bemerkenswert die Notiz des Plinius über den Bildhauer Lysipp: "Für die Bildhauerkunst soll er am meisten dadurch beigetragen haben, dass er das Haar naturgetreu darstellte, die Köpfe kleiner machte, als es die Alten taten, die Körper zierlicher und schlanker, wodurch die Höhe der Bildwerke größer erschien. Es gibt im Lateinischen kein Wort für Symmetrie; diese beachtete er sehr sorgfältig, indem er durch ein neues und noch nicht versuchtes Verfahren die signa quadrata der Alten veränderte und gewöhnlich sagte, die von jenen geschaffenen Bildwerke zeigten die Menschen wie sie sind, die von ihm geschaffenen aber, wie sie zu sein scheinen. Das besonders Ausdrucksvolle in den Werken dieses Künstlers scheint darin zu bestehen, dass er auch die kleinsten Dinge beachtete." (Naturalis historia 34,65). Der Ausdruck "quadratus" ist vieldeutig und deshalb umstritten. Übersetzungsmöglichkeiten sind: "vierschrötig", "untersetzt", bis "hässlich", aber auch "wohlgebaut", "wohlgefügt", "harmonisch", "gesund" u.ä.. Die meisten Kommentatoren entscheiden sich für "untersetzte Gestalten", "grobe Arbeitsweise" o.ä., also für einen pejorativen Sinn der Aussage, und beziehen diese auf die Werke der Lysipp vorangegangenen Generation, also auf die des Polyklet. Als Stützung dieser Ansicht wird auf die Parallelstelle 34,55 verwiesen, wo Plinius Varro zitiert, wonach die Figuren des Polyklet "quadratus" seien und "alle sozusagen auf ein einziges Modell zurück gehen". Doch spricht gerade diese Stelle für eine Übersetzung mit "wohlgebaut", "wohlgefügt" oder einem ähnlich positiven Ausdruck, denn niemand hätte wohl die gerade für ihre perfekten Proportionen hochberühmten Werke des Polyklet als schlecht proportioniert o.ä. bezeichnet. Dagegen spricht auch eine Stelle bei Cicero (Brutus 296), wonach Lysipp den Doryphoros des Polyklet als seinen Lehrmeister bezeichnet habe. Vielleicht bezieht sich der Ausdruck "quadratus" auch einfach auf die Regelhaftigkeit der mathematischen Maßverhältnisse oder gar auf ein unter den (in den Fußstapfen der ägyptischen Kunst stehenden) archaischen Künstlern noch verwendetes Quadratnetz. Eine Sammlung der Quellen für quadratus/ $\tau \varepsilon \tau \dot{\alpha} \gamma \omega \omega$ os findet sich bei POLLITT 1974, 263ff.. Zu einem möglichen pythagoräischen Hintergrund der Begriffe wie des polykletischen Kanons FERRI 1940, STEFANINI 1949, ferner RAVEN 1951; in Anschluss an FERri und STEFANINI: POLLITT 1974, 267 f., POLLITT 1995, LEFTWICH, 1995; ferner GRASSI, 1980 (1962), $61 \mathrm{ff}$. , und ONIANS 1999, $36 \mathrm{ff} .$.

PLATO, The electronic Journal of the International Plato Society, n 9, 2009.

http://gramata.univ-paris $1 . \mathrm{fr} /$ Plato

(C) All rights of reproduction of any form reserved. 
erscheint. Das zeigen uns nicht nur die Kunstwerke der griechischen Klassik, wie beispielsweise der Doryphoros des Polyklet, der wegen seiner Modellhaftigkeit selbst "Kanon" bezeichnet wurde, sondern findet sich auch in der eben zitierten Stelle bei Diodor von Sizilien ausgesprochen. Der Kanon der Ägypter reichte für sich alleine bereits hin, die Darstellung in allen Einzelheiten festzulegen, sodass der ägyptische Künstler zur Anfertigung seines Werkes weiter nichts nötig hatte als die Maßangaben und allein auf sie gestützt die Figuren an beliebigem Orte und in beliebig vielen Teilen dar- oder besser herzustellen vermochte. Der Künstler der griechischen Klassik hingegen konnte seinen Kanon nicht ohne weiteres auf das Material applizieren, sondern musste sich von Fall zu Fall bei der

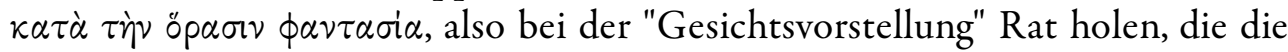
organische Beweglichkeit des darzustellenden Körpers, die Mannigfaltigkeit der dem Auge sich darbietenden Verkürzungen und vielleicht auch die besonderen Umstände, unter denen das fertige Werk gesehen werden soll, in Rechnung stellen. Ein Kanon, der sich zwar auf Maß, Zahl und Symmetrie stützt, diese aber der Darstellung einer Illusion dienstbar macht, musste Platons Missbilligung finden, weshalb ihn der Philosoph in seinen Dialogen trotz seiner großen Berühmtheit auch keiner Erwähnung würdigt. ${ }^{115}$ Der ägyptische Kanon hingegen, der die Bedeutung von Maß, Zahl und Proportion hochhält, nicht nur ohne einem Illusionismus zu dienen, sondern mit dem Ziel, einen solchen vielmehr gesetzlich auszuschließen, ein solches Programm musste Platons Zustimmung finden.

Allerdings bleibt auch die ägyptische Kunst letztlich Kunst und als solche mindestens "nutzlose Spielerei". An dieser Stelle ist besonders an die zum Schluss des vorangegangenen Abschnittes zitierte Stelle aus den Nomoi (529 f.) erinnert, wo eine auf Mathematik und Geometrie gegründete Kunst der Zugang zu der Welt der Ideen ausdrücklich abgesprochen worden war. ${ }^{16}$ Wohl nicht aus Zufall war dort Daidalos als beispielhafter Vertreter einer solchen Kunst angeführt worden, galt er doch als Erfinder der Künste und wurde mit Ägypten in Verbindung gebracht. ${ }^{117}$ Neben der von den Gesetzgebern garantierten

115 Zwar wird Polyklet von Platon zweimal als ein herausragender Künstler genannt (Protagoras 311 c: gemeinsam mit Phidias als Bildhauer, die Schüler gegen Bezahlung unterrichtet hätten; Protagoras 328 c: seine Söhne hätten nichts vom Talent ihres Vaters geerbt), aber kein bestimmtes Kunstwerk, geschweige denn seine Schrift, der "Kanon", wird erwähnt.

116 KeULS 1978b, 90 und 124, hat in dieser Stelle der Politeia gar eine versteckte Anspielung auf den Kanon des Polyklet erkennen wollen.

117 Frontisi-DUCROUX 1992.

PLATO, The electronic Journal of the International Plato Society, n 9, 2009.

http://gramata.univ-paris 1.fr/Plato

(C) All rights of reproduction of any form reserved. 
Unveränderlichkeit der Kunst, findet die ägyptische Kunst also keineswegs Platons Lob, weil sie einen Zugang zu der Welt der Ideen eröffnet, sondern nur deshalb, weil sie im Gegensatz zur zeitgenössischen griechischen Kunst harmlos ist, insofern sie den so verderblichen Illusionismus aus ihren Darstellungen ausgeschlossen hatte. Ägyptischer Kunst ist epistemologisch und also heilsgeschichtlich nutzlos, wie alle Kunst, stellt aber keine Gefahr für die Seele dar und ist so die für den platonischen Idealstaat akzeptabelste Kunstform. Wenn Kunst überhaupt sein soll, dann soll sie so sein: ewigkeitlich, variantenlos. Wenn sie das Wahre schon nicht vergegenwärtigen kann, so soll sie wenigstens in ihrer Konstanz ein Gleichnis von dessen Unveränderlichkeit geben und soll nicht durch Rücksichten, Hinsichten, Perspektiven und anderen Akkomodationen den Blick auf das Wahre verunklären.

Platons Verurteilung der Kunst ist innerhalb seines Denkens konsistent und ausweglos. Kunst ist unüberbrückbar fern von Wahrheit und Wissen, im besten aller Fälle nutzloses Spiel, in allen anderen Fällen aber der Seele Verderb. Da schon die Gegenstände der Sinneswahrnehmung Nachahmungen der letztlich nur der Vernunfterkenntnis zugänglichen Urbilder, der Ideen, sind, so ist der Künstler der Nachahmer eines Nachgeahmten; denn er rührt nur an den Schein einer Wirklichkeit, die ihrerseits schon eine defiziente, veränderliche und vergängliche Nachahmung der einzig wahren, unveränderlichen und ewigen Urbilder ist. Platon tritt nicht ein für irgendeine Form idealistischer Kunst, die uns - im Gegensatz zu den Gegenständen der alltäglichen Wahrnehmung transzendente Wahrheiten zugänglich machen könnte; auch göttliche Inspiration kann seiner Ansicht nach den Graben nicht überbrücken; und ebenso wenig vermag dies eine ästhetisch schöne Kunst. Der Philosoph macht sich auch nicht zum Anwalt der alten ägyptischen Kunst, oder zum Propheten einer modern-abstrakten. Aus seinen Stellungnahmen zur Kunst lässt sich auch keine Ablehnung oder Befürwortung einer spezifischen zeitgenössischen Kunstrichtung herauslesen.

Diese Feststellung, dass sich in Platons Äußerungen keine Entwicklung der Kunst spiegelt, wird übrigens - was hier nicht mehr weiter ausgeführt werden kann auch durch die antiken Kunstwerke selbst bestätigt. ${ }^{118}$ Betrachtet man erhaltenen Darstellungen der zeitgleichen Kunst, so lässt sich keineswegs eine Umwälzung hin zu einer Illusionskunst feststellen, die etwa mit der Kunst zur Zeit der

${ }^{118}$ Weiterführend HUB 2008.

PLATO, The electronic Journal of the International Plato Society, n 9, 2009.

http://gramata.univ-paris 1.fr/Plato

(C) All rights of reproduction of any form reserved. 
Renaissance vergleichbar wäre. Vielmehr zeichnet sich nicht nur die Kunst zur Zeit Platons, sondern die antike Kunst insgesamt, durch ihre hartnäckige Verweigerung der Angleichung des Dargestellten an die optischen Gesetze der natürlichen, nämlich räumlichen Wahrnehmung aus. Relief, Mosaik wie Malerei vermeiden auffällig das Verbindende, sei es die Darstellung von Innenräumen, sei es die Wiedergabe von Landschaft, sei es auch nur die Abnahme der Größen der einen Bildgegenstände in Relation zu den anderen. Einzelne architektonische Elemente und einzelne Gegenstände oder Figuren werden gerade nicht eingebunden in den sie umgebenden Raum, sondern vielmehr aus diesem herausgehoben und ihm entgegengestellt. Durch Vereinzelung, sowie durch den Wechsel von Perspektiven und Größenverhältnissen bewahren sie eine Eigengesetzlichkeit jenseits der subjektiven Wahrnehmung. Verlässt man die bis heute üblichen Bahnen einer evolutiven Kunstgeschichtsschreibung und anerkennt diese radikale Alterität der antiken Kunst, dann kommt man zu dem paradoxen Schluss, dass zwischen kunstfeindlichem platonischem Denken und antiker Kunst sogar in ihrer illusionistischsten Ausprägung keineswegs ein unüberbrückbarer Gegensatz herrscht, sondern vielmehr eine innerste Verwandtschaft. 


\section{BIBLIOGRAPHIE}

ADAM, James, The Republic of Plato, 2 Bd., Cambridge 1963 (1. Aufl. 1902)

Adorno, Francesco, Art. Platone e Aristotele, in: Enciclopedia dell'Arte Antica Classica e Orientale, Bd. 6, Rom 1965, 226-243

AleXANDRAKIS, Aphrodite (Hg.), Neoplatonism and Western Aestetics, Albany 2002

ALLEN, Reginald E., Plato's Parmenides: Translation and Analysis, Minnesota 1983

ANNAS, Julia, On the Intermediates, in: Archiv für Geschichte der Philosophie 57 (1975), 146-166

ANNAS, Julia, An Introduction to Plato's Republic, Oxford 1981

Asmis, Elizabeth, Plato on Poetic Creativity, in: Richard Kraut (Hg.), The Cambridge Companion to Plato, Cambridge 1992, 338-364

BARKAN, Leonard, The Heritage of Zeuxis: Painting, Rhetoric, and History, in: Alina Payne et al. (Hg.), Antiquity and Its Interpreters, Cambridge 2000, 99-109

BECK, Herbert et al. (Hg.), Polyklet. Der Bildhauer der griechischen Plastik, Ausst.-Kat. Frankfurt am Main 1990, Mainz 1990

BECKER, Andrew S., A Short Essay on Deconstruction and Plato's Ion, in: Electronic Antiquity 1 (1993), http://scholar.lib.vt.edu/ejournals/ElAnt/V1N4/becker.html

BeIL Waugh, Joanne, Art and Morality: The End of an Ancient Rivalry? Plato's Arguments, in: The Journal of Aesthetic Education 20 (1986), 5-17

BELFIORE, Elizabeth, The Role of the Visual Arts in Plato's Ideal State, in: Journal of the Theory and Criticism of the Visual Arts 1 (1981), 115-127

BELFIORE, Elizabeth, $A$ Theory of Imitation in Plato's Republic, in: Transactions of the American Philological Association 114 (1984), 121-146

Berger, Ernst et al. (Hg.), Der Entwurf des Künstlers. Bildhauerkanon in der Antike und Neuzeit, Ausst.-Kat. Basel 1992

Berger, Monika, Proportion bei Platon, Trier 2003

BERNARD, Wolfgang, Spätantike Dichtungstheorien. Untersuchungen zu Proklos, Herakleitos und Plutarch, Stuttgart 1990 (Beiträge zur Altertumskunde 3)

BIANCHI BANDINELLI, Ranuccio, Osservazioni storico-artistiche a un passo del Sofista platonico, in: Studi in onore di Ugo Enrico Paoli, Florenz 1955, 81-95 (und in: Idem, Archeologia e cultura, Mailand 1961, 153-171)

Bianchi BANDINelli, Ranuccio, Plato und die Malerei seiner Zeit, in: Antiquitas Graeco-Romana ac tempora nostra. Acta Congressus internationalis habiti Brunae diebus 12 - 16 mensis Aprilis 1966, Prag 1968, $426 f$.

BORMANN, Karl, Platon, Freiburg i. Br. 1987

Bouchery, H. F., Plato en de beeldende kunst, in: Gentse Bijdragen tot de Kunstgeschiedenis 15 (1954), 125-159

BOURbon Di Petrella, Fiammetta, Il problema dell'arte e della bellezza in Plotino, Florenz 1956

PLATO, The electronic Journal of the International Plato Society, n 9, 2009.

http://gramata.univ-paris 1.fr/Plato

(c) All rights of reproduction of any form reserved. 
HUB, Berthold, "Platon und die bildende Kunst. Eine Revision"

BOURRIOT, Félix, Kalos kagathos - kalokagathia. D'un terme de propagande de sophistes à une notion sociale et philosophique. Étude d'histoire athénienne, 2 Bd., Hildesheim 1995

BRENTLINGER, John A., The Divided Line and Plato's Theory of Intermediates, in: Phronesis 8 (1963), 146-166

Broos, Huibrecht Jacobus Melle, Plato's beschouwing van kunst en schoonheid, Diss. Leiden 1948

Broos, Huibrecht Jacobus Melle, Plato and Art: A new Analysis of the Philebos, in: Mnemosyne 4. Ser. 4 (1951), 113-128

BRUNO, Vincent J., Form and Color in Greek Painting, New York 1977

BUNDY, Murray Wright, The Theory of Imagination in Classical and Medieval Thought, Urbana 1927 (Nachdr. Folcroft/Pa. 1970 \& 1980)

BÜTTNER, Stefan, Die Literaturtheorie bei Platon und ihre anthropologische Begründung, Tübingen 2000

BYVANCK, Alexander W., Platon et l'art grec, in: Bulletin Antieke Beschaving 30 (1955), 35-39

BYVANCK, Alexander W., De beeldende kunst in den tijd van Plato, in: Mededelingen der koninklijke nederlandse akademie van wetenschappen, afd. letterkunde, nieuwe reeks, deel 18 (1955), 429475

CARABBA, Carla, La non scienza dell'idea del bello nello Ione platonico, Rom 1998

CASSIRER, Ernst, Eidos und Eidolon. Das Problem des Schönen und der Kunst in Platos Dialogen, in: Vorträge der Bibliothek Warburg 1 (1921/22), Leipzig \& Berlin 1923, 1-27

Cavarnos, Constantine, Plato's Critique of the Fine Arts, in: Philosophia 1 (1971), 296-314

CHEN, Ludwig C. H., Acquiring Knowledge of the Ideas: A Study of Plato's Methods in the Phaedo, in the Symposium, and the Central Books of the Republic, Stuttgart 1992

CHILDS, William A. P., Platon, les images et l'art grec du IVe siècle avant J.-C., in: Revue Archéologique 1 (1994), 33-56

Cludius, Martin, Die Grundlegung der Erkenntnistheorie in Platons Politeia. Ein Kommetar zu Platons Unterscheidung von Meinung und Wissen und zum Liniengleichnis, Marburg 1998

CoHen, S. Marc, The Logic of the Third Man, in: The Philosophical Review 80 (1971), 448-475

Collingwood, Robin George, Plato's Philosophy of Art, in: Mind 34 (1925), 154-172

COLLINGWOOD, Robin George, The Republic of Plato, Oxford 1945

CrombIE, Ian M., An Examination of Plato's Doctrines, 2 Bd., London $1962 \mathrm{f}$.

Cross, Robert C. \& WoOzley, Anthony D., Plato's Republic: A Philosphical Commentary, London 1964

D Alfen, Joachim, Polis und Poiesis. Die Auseinandersetzung mit der Dichtung bei Platon und seinen Zeitgenossen, München 1974

D AVIS, Whitney M., Plato on Egyptian Art, in: The Journal of Egyptian Archaeology 65 (1979), 121 127

Demand, Nancy, Plato and the Painters, in: Phoenix 29 (1975), 1-20

DESJARDINS, Rosemary, Plato and the Good: Illuminating the Darkling Vision, Leiden 2004

PLATO, The electronic Journal of the International Plato Society, n 9, 2009.

http://gramata.univ-paris 1.fr/Plato

(c) All rights of reproduction of any form reserved. 
DORTER, Kenneth, The Ion: Plato's Characterization of Art, in: The Journal of Aesthetics and Art Criticism 32 (1973), 65-78

EBERT, Theodor, Meinung und Wissen in der Philosophie Platons. Untersuchungen zum Charmides, Menon und Staat, Berlin 1974

ELSE, Gerald Frank, Imitation in the Fifth Century, in: Classical Philology 53 (1958), 73-90

ELSE, Gerald Frank, Plato and Aristotle on Poetry, hrsg. Peter Burian, London 1986

FERBER, Rafael, Platons Idee des Guten, Sankt Augustin 1984

Ferrari, G. R. F., Plato and Poetry, in: The Cambridge History of Literary Criticism, Bd. 1: Classical Criticism, hrsg. George A. Kennedy, Cambridge 1989, 92-148

FERRI, Silvio, Nuovi contributi esegetici al 'canone' della scultura greca, in: Rivista del Reale Istituto d'Archaeologia e Storia dell'Arte 7 (1940), 117-152

FIGAL, Günter, Die Wabrheit und die schöne Täuschung. Zum Verhältnis von Dichtung und Philosophie im Platonischen Denken, in: Philosophisches Jahrbuch 107 (2000), 301-315

FINE, Gail, Knowledge and Belief in Republic V, in: Archiv für Geschichte der Philosophie 60 (1978), 121-139 (und in: Terence Irwin (Hg.), Plato's Metaphysics and Epistemology, New York 1995, 105-123)

Fine, Gail, Knowledge and Belief in Republic V-VII, in: Stephen Everson (Hg.), Companions to Ancient Thought: Epistem ology, Cambridge 1990, 85-115 (und in: Nicholas D. Smith (Hg.), Plato: Critical Assessments, Bd. 2: Plato's Middle Period: Metaphysics and Epistemology, London 1998, 235-265; sowie in: Gail Fine, Plato 1: Metaphysics and Epistemology, Oxford 1999, 215246)

FINE, Gail, On Ideas: Aristotle's Criticisms of Plato's Theory of Forms, Oxford 1993

FLASH AR, Hellmut, Der Dialog Ion als Zeugnis Platonischer Philosophie, Berlin 1958

FLASCH, Kurt, Ars imitatur naturam. Platonischer Naturbegriff und mittelalterliche Philosophie der Kunst, in: Parusia. Studien zur Philosophie Platons und zur Problemgeschichte des Platonismus. Festgabe für Johannes Hirschberger, hrsg. Kurt Flasch, Frankfurt am Main 1965, 265-306

FREY, Dagobert, Zum Problem der Symmetrie in der bildenden Kunst, in: Studium Generale 2 (1949), 268-278 (und in: Idem, Bausteine zu einer Philosophie der Kunst, Darmstadt 1976, 236-259)

FROIDEFOND, Christian, Le mirage égyptien dans la littérature grecque d'Homèr à Aristote, Paris 1971

FroNTISI-DuCrouX, Françoise, Dédale: mythologie de l'artisan en Grèce ancienne, Paris 1975

FuHRMANN, Manfred, Die Dichtungstheorie der Antike: Aristoteles - Horaz- 'Longin'. Eine Einführung, 2. Aufl. Darmstadt 1992

GADAMER, Hans Georg, Wahrheit und Methode, Tübingen 1960

GAISER, Konrad, Platons ungeschriebene Lehre. Studien zur systematischen und geschichtlichen Begründung der Wissenschaften in der platonischen Schule, Stuttgart 1963

GALloP, David, Image and Reality in Plato's Republic, in: Archiv für Geschichte der Philosophie 47 (1965), 113-131 (und in: Terence Irwin (Hg.), Plato's Metyphysics and Epistemology, New York $1995,153-171)$

GeBAUER, Gunter \& Wulf, Christoph, Mimesis. Kultur, Kunst, Gesellschaft, Hamburg 1992

GERSON, Lloyd P., A Note on Tripartition and Immortality in Plato, in: Apeiron 20 (1987), 81-96

PLATO, The electronic Journal of the International Plato Society, n 9, 2009.

http://gramata.univ-paris 1.fr/Plato

(c) All rights of reproduction of any form reserved. 
Gerson, Lloyd P., Knowing Persons: A Study in Plato, Oxford 2003

GILL, Christopher, Plato's Republic: An Ideal Culture of Knowledge, in: Ideal and Culture of Knowledge in Plato. Akten der 4. Tagung der Karl-und-Gertrud-Abel-Stiftung vom 1. - 3. Sept. 2000 in Frankfurt am Main, hrsg. Wolfgang Detel et al., Stuttgart 2003, 37-55

GLaSER, K., Platons Stellung zum Kampfe von Philosophie und tragischer Dichtung, in: Wiener Studien: Zeitschrift für klassische Philologie und Patristik 58 (1940), 33-67

Golden, Leon, Plato's Concept of Mimesis, in: The British Journal of Aesthetics 15 (1975), 118-131

GOMBRICH, Ernst H., Kunst und Illusion. Zur Psychologie der bildlichen Darstellung, Berlin 2002 (Art and Illusion: A Study in the Psychology of Pictorial Representation, London 1960)

Goodrich, R. A., Plato on Poetry and Painting, in: The British Journal of Aesthetics 22 (1982), 126-137

GUIDELLI, Chiara, Dall'ordine alla vita. Mutamenti del bello nel platonismo antico, Bologna 1999

Graeser, Andreas, Platons Auffassung von Wissen und Meinung in Politeia V, in: Philosophisches Jahrbuch 98 (1991), 365-388

GRAESER, Andreas, Platos Parmenides, Stuttgart 2003

GRASSI, Ernesto, Die Theorie des Schönen in der Antike, Köln 1980 (1. Auf. Köln 1962)

Greene, William Chase, Plato's View of Poetry, in: Harvard Studies in Classical Philology 29 (1918), $1-75$

GREY, D. R., Art in the Republic, in: Philosophy: The Journal of the Royal Institute of Philosophy 27 (1952), 291-310

GRUBE, George Maximilian Antoine, Plato's Thought, London 1935

GSCHWANTLER, Kurt, Zeuxis und Parrhasios. Ein Beitrag zur antiken Künstlerbiographie, Wien 1975

HaCK, R. K., Rez. Pierre-Maxim Schubl, Platon et l'Art de son temps (Arts plastiques), Paris 1933, in: Classical Philology 30 (1935), 273-275

HAFNER, German, Polyklet Doryphoros. Revision eines Kunsturteils, Frankfurt am Main 1997

HaLl, Robert W., Plato's Theory of Art: A Reassessment, in: The Journal of Aesthetics and Art Criticism 33 (1974), 75-82

Halliwell, Stephen (Übers. und Komm.), Plato Republic 10, Warminster 1988

Halliwell, Stephen, Plato and Painting, in: N. Keith Rutter (Hg.), Word and Image in Ancient Greece, Edinburgh 2000, 99-116

Haluiwell, Stephen, The Aesthetics of Mimesis: Ancient Texts and Modern Problems, Princeton \& Oxford 2002

Havelock, Eric A., Preface to Plato, Cambridge/Mass. 1963

Heidegger, Martin, Platons Lehre von der Wahrheit. Mit einem Brief über den 'Humanismus', Bern 1947

HeIDEgGer, Martin, Der Ursprung des Kunstwerkes. Mit einer Einfübrung von Hans Georg Gadamer, Stuttgart 1960

PLATO, The electronic Journal of the International Plato Society, n 9, 2009.

http://gramata.univ-paris $1 . \mathrm{fr} /$ Plato

(c) All rights of reproduction of any form reserved. 
Heidegger, Martin, Platons Staat. Der Abstand der Kunst (Mimesis) von der Wabrheit (Idee), in: Idem, Nietzsche: Seminare 1937 und 1944, Bd. 1: Nietzsches metaphysische Grundeinstellung (Sein und Schein), Pfullingen 1961, 198-217

HeLBIG, Wolfgang, Zeuxis und Parrhasios, in: Jahrbücher für Classische Philologie 13 (1867), 650675

HendriX, John \& De Girolami Cheney, Liana (Hg.), Neoplatonism and the Arts, Lewiston, New York 2002

HendriX, John \& De Girolami Cheney, Liana (Hg.), Neoplatonic Aesthetics: Music, Literature, and the Visual Arts, New York 2004

HendriX, John, Neoplatonic Architectonics: Platonic Philosophies \& Visual Arts, New York 2004

HöFfE, Otfried (Hg.), Zur Analogie von Individuum und Polis, in: Idem (Hg.), Platon: Politeia, Berlin $1997,69-94$

Hogrebe, Wolfgang, Die Politisierung der Kunst und der Künste durch Platon, in: Zeitschrift für Ästhetik und allgemeine Kunstwissenschaft 23 (1978), 130-138

HOMMEL, Hildebrecht, Symmetrie im Spiegel der Antike, Sitzungsberichte der Heidelberger Akademie der Wissenschaften, Philosophisch-Historische Klasse, Heidelberg 1987

HuB, Berthold, Die Perspektive der Antike. Archäologie einer symbolischen Form, Frankfurt a. M. 2008

Huber-Abrahamowicz, Elfriede, Das Problem der Kunst bei Platon, Diss. Basel 1954

Hughes FOWLER, Barbara, Skenographia, Skiagraphia, and Phantasia, in: Eadem, The Hellenistic Aesthetic, Madison/Wisc. 1989, 168-186

HYMAN, John, The Imitation of Nature, Oxford 1989

IVERSEN, Erik, Canon and Proportions in Egyptian Art, Warminster 1975 (1. Auflage London 1955)

IVERSEN, Erik, Metrology and Canon, in: Mitteilungen des Deutschen Archäologischen Institutes, Abt. Kairo 46 (1990), 113-125

IVERSEN, Erik, Canon and Proportions in Egyptian Art: A Supplement and a Summary, Kopenhagen 1996

JAEGER, Werner, Paideia. Die Formung des griechischen Menschen, Berlin 1954 (Paideia: The Ideals of Greek Culture, New York 1939)

Janaway, Christopher, Plato's Analogy between Painter and Poet, in: The British Journal of Aesthetics 31 (1991), 1-12

JANAW AY, Christopher, Images of Excellence: Plato's Critique of the Arts, Oxford 1995

JANKE, Caroline, Schiller und Platon: Vom Staate der Vernunft und dem Scheine der Kunst. Untersuchungen zur politiko-ästhetischen Antinomie, Amsterdam 1999 (Fichte-StudienSupplementa 11)

JIYUAN, Yu, On Plato's Theory of the Metheksis of Ideas, in: Philosophical Inquiry 13 (1991), 27-37

KAMBARTEL, Walter, Symmetrie und Schönheit. Über mögliche Voraussetzungen des neueren Kunstbewusstseins in der Architekturtheorie Claude Perraults, München 1972

Karasmanis, Vassilis, Plato's Republic: The Line and the Cave, in: Apeiron 21 (1988), 147-171

PLATO, The electronic Journal of the International Plato Society, n 9, 2009.

http://gramata.univ-paris 1.fr/Plato

(c) All rights of reproduction of any form reserved. 
HUB, Berthold, "Platon und die bildende Kunst. Eine Revision"

KARDAUn, Maria, Der Mimesisbegriff in der griechischen Antike. Neubetrachtung eines umstrittenen Begriffes als Ansatz zu einer neuen Interpretation der platonischen Kunstauffassung, Amsterdam 1993

Kardaun, Maria, Why Plato Banished the Artist. Some Jungian Observations, in: Literature and Psychoanalysis. Proceedings of the Thirteenth International Conference on Literature and and Psychoanalysis, hrsg. Frederico Pereira, Lissabon 1997, 197-204

Kardaun, Maria, Platonic Art Theory: A Reconsideration, in: The Winged Chariot: Collected Essays on Plato and Platonism in Honour of L. M. de Rijk, hrsg. Maria Kardaun \& Joke Spruyt, Leiden 2000, 135-164

Karelis, Charles, Plato on Art and Reality, in: The Journal of Aesthetics and Art Criticism 34 (1976), 315-321

KEULS, Eva, Impressionism in Ancient Painting?, in: American Jounal of Archaeology 77 (1973), 216217

KEULS, Eva, Skiagraphia once again, in: American Journal of Archaeology 79 (1975), 1-16 (kommentiert von Elizabeth G. Pemberton, ibid. 80 (1976), 82-84) (und in: Eadem, Painter and Poet in Ancient Greece: Iconography and the Liberal Arts, Stuttgart 1997)

KEULS, Eva, Plato on Painting, in: American Journal of Philology 95 (1978), 100-127

KeUls, Eva, Plato and Greek Painting, Leiden 1978 (Columbia Studies in the Classical Tradition 5)

KeRSTING, Wolfgang, Platons Staat, Darmstadt 1999

KetChum, Richard J., Plato on Real Being, in: American Philosophical Quarterly 17 (1980), 213-220

Koller, Hermann, Die Mimesis in der Antike. Nachahmung, Darstellung, Ausdruck, Bern 1954

KRIEGER, Carl, Die Aussagemöglichkeit der sogenannten Abbildungen und der gegenständlichen Malerei. Der Begriff des "Zuwachs an Sein" durch das Kunstwerk bei Hans Georg Gadamer, in: Kerygma und Dogma. Zeitschrift für theologische Forschung und kirchliche Lehre 31 (1967), 1-7

KuHN, Helmut, The True Tragedy: On the Relationship between Greek Tragedy and Plato, in: Harvard Studies in Classical Philology 52 (1941), 1-40 und 53 (1942), 37-88

KuHn, Helmut, Plykleitos and Hippocratic Medicine, in: Warren G. Moon (Hg.), Polykleitos, the Doryphoros, and Tradition, Madison 1995, 38-51

LENTZ, Tony M., The Third Placefrom Truth: Plato's Paradoxical Attack on Writing, in: Idem, Orality and Literacy in Hellenic Greece, Illinois 1989, 11-34

LESSES, Glenn, Weakness, Reason and the Divided Soul in Plato's Republic, in: History of Philosophy Quarterly 4 (1987), 147-161

LeVIn, Susan B., The Ancient Quarrel between Philosophy and Poetry Revisited: Plato and the Greek Literary Tradition, Oxford 2001

LODGE, Rupert C., Plato's Theory of Education, London 1947

LODGE, Rupert C., Plato's Theory of Art, London 1953

LOSSAU, Manfred, Kunstverächter Platon?, in: Ètudes Classiques. Publications du centre universitaire de Luxembourg 5 (1993), 1-24 (zuvor: Platón, enemigo del arte?, in: Minerva 6, 1992, 117-139)

Lossau, Manfred, Die Messkunst und das Schöne und Gute, in: Archiv für Kulturgeschichte 79 (1997), 1-11

PLATO, The electronic Journal of the International Plato Society, n 9, 2009.

http://gramata.univ-paris $1 . \mathrm{fr} /$ Plato

(c) All rights of reproduction of any form reserved. 
HUB, Berthold, "Platon und die bildende Kunst. Eine Revision"

Maguire, J. P., Beauty and the Fine Arts in Plato. Some aporiae, in: Harvard Studies in Classical Philology 70 (1965), 171-193

Mastrangelo, Marc \& HARRIS, John, The Meaning of Republic 606a3-b5, in: The Classical Quarterly 47 (1997), 301-305

MeInwald, Constance C., Plato's Parmenides, New York 1991

MelBer, Johann, Kalokagathia, 2 Bd., Bamberg 1935

MelBerg, Arne, Theories of Mimesis, Cambridge 1995

MenZA, Victor G., Poetry and the Techné Theory: An Analysis of the Ion and the Republic, Books III and $X$, Diss. Baltimore 1972

Mille R, Fred D., Plato on the Parts of the Soul, in: Nicholas D. Smith, (Hg.), Plato: Critical Assessments, Bd. 3: Plato's Middle Period: Psychology and Value Theory, London 1998, 48-65

Miller, Fred D., Figure, Ratio, Form: Plato's Five Mathematical Studies, in: Mark L. McPherran (Hg.), Recognition, Remembrance and Reality, Edmonton 1999 (Apeiron Supplementbd. 32), 73-88

Moon, Warren G. (Hg.), Polykleitos, the Doryphoros, and Tradition, Madison 1995

Moravcsik, Julius \& Temko, Philip (Hg.), Plato on Beauty, Wisdom, and the Arts, Totowa 1982

Moreno, Paolo, Il Realismo nella pittura greca del IV secolo A.C., in: Rivista dell'Istituto Nazionale d'Archeologia e Storia dell'Arte, N.S. 13/14 (1964-65), 27-92

Morgan, Michael L., Belief, Knowledge, and Learning in Plato's Middle Dialogues, in: Francis Jeffrey Pelletier \& John King-Farlow (Hg.), New Essays on Plato, Alberta 1983 (Canadian Journal of Philosophy, Supplementbd. 9), 63-100

Morgan, Michael L., Plato, Inquiry, and Painting, in: Apeiron 23 (1990), 121-145

MÜLLER, Armin, Autonome Theorie und Interessedenken. Studien zur politischen Philosophie bei Platon, Aristoteles und Cicero, Wiesbaden 1971

MülLER, H. W., Der Kanon in der ägyptischen Kunst, in: Sigrid Braunfels (Hg.), Der vermessene Mensch. Anthropometrie in Kunst und Wissenschaft, München 1973, 9-31

MurraY, Penelope, Inspiration and Mimesis in Plato, in: Andrew Barker (Hg.), The Language of the Cave, Edmonton 1992, 27-46

NeHamas, Alexander, Plato on the Imperfections of the Sensible World, in: American Philosophical Quarterly 12 (1975), 105-117 (und in: Gail Fine (Hg.), Plato 1: Metaphysics and Epistemology, Oxford 1999, 171-191)

NeHAmas, Alexander, Plato on Imitation and Poetry in Republic 10, in: Julius Moravcsik \& Philip Temko (Hg.), Plato on Beauty, Wisdom, and the Arts, Totowa 1982, 47-78 (und in: Nicholas D. Smith, (Hg.), Plato: Critical Assessments, Bd. 3: Plato's Middle Period: Psychology and Value Theory, London 1998, 296ff.; sowie in: Alexander Nehamas, Virtues of Authenticity: Essays on Plato and Socrates, Princeton 1999, 251-278)

NeHamas, Alexander, Plato and the Mass Media, in: The Monist 71 (1988), 214-234 (und in: Idem, Virtues of Authenticity: Essays on Plato and Socrates, Princeton 1999, 279-302)

NeTTLESHIP, Richard Lewis, Lectures on the Republic of Plato, London 1901 (Nachdr. London 1961)

PLATO, The electronic Journal of the International Plato Society, n 9, 2009.

http://gramata.univ-paris 1.fr/Plato

(c) All rights of reproduction of any form reserved. 
NEU, J., Plato's Analogy of State and Individual: The Republic and the Organic Theory of the State, in: Philosophy 46 (1971), 238-254

Notomi, Noburu, The Unity of Plato's Sophist: Between the Sophist and the Philosopher, Cambridge 1999

OATES, Whitney J., Plato's View of Art, New York 1972

ONG, Walter J., Orality and Literacy: The Technologizing of the Word, New York 2002 (1. Aufl. London 1986)

ONIANS, John, Classical Art and the Cultures of Greece and Rome, New Haven \& London 1999

OsBorne, C., The Repudiation of Representation in Plato's Republic and Its Repercussions, in: Proceedings of the Cambridge Philological Society 213, N.S. 33 (1987), 53-73

PAPPAS, Nickolas, Plato and the Republic, London 1995

PANOFSKY, Erwin, Die Entwicklung der Proportionslebre als Abbild der Stilentwicklung, in: Monatshefte für Kunstwissenschaft 14 (1921), 188-219 (zuletzt in: Idem, Sinn und Deutung in der bildenden Kunst, Köln 2002, 68-124)

PANOFSKY, Erwin, Idea. Ein Beitrag zur Begriffsgeschichte der älteren Kunsttheorie, Leipzig 1924 (zuletzt Berlin 1993)

Pemberton, Elisabeth G., A Note on Skiagraphia, in: American Journal of Archaeology 80 (1976), $82-84$

PERL, Eric, Sense-Perception and Intellect in Plato, in: Revue de philosophie ancienne 15 (1997), 15-34

Petrochilos, George A., Kalokagathia: The Ethical Basis of Hellenic Political Economy and Its Influence from Plato to Ruskin and Sen, in: History of Political Economy 34 (2002), 599-631

PFUHL, Ernst, Malerei und Zeichnung der Griechen, 3 Bd., München 1923

POLLITT, Jerome J., The Ancient View of Greek Art. Criticism, History, and Terminology, New Haven 1974

POLLITT, Jerome J., The Art of Rome: Sources and Documents, Cambridge 1989

POLLITT, Jerome J., The Canon of Polykleitos and other Canons, in: Warren G. Moon (Hg.), Polykleitos, the Doryphoros, and Tradition, Madison 1995, 19-24

PRITCHARD, Paul, Plato's Philosophy of Mathematics, Sankt Augustin 1995

RAVEn, John E., Polyclitus and Pythagoreanism, in: The Classical Quarterly 45 (1951), 147-152

REALE, Giovanni, Zu einer neuen Interpretation Platons. Eine Auslegung der Metaphysik der großen Dialoge im Lichte der 'ungeschriebenen Lehre', Paderborn 1993 (Per una nuova interpretazione di Platone, Mailand 1989)

RingBOM, Sixten, Plato on Images, in: Theoria 31 (1965), 86-109

RODENWALDT, Gerhart, Wölfflins 'Grundbegriffe' und die antike Kunst, in: Zeitschrift für Ästhetik und allgemeine Kunstwissenschaft 11 (1916), 432-441

RODENWALDT, Gerhart, Beautiful City: The Dialectical Character of Plato's Republic, Ithaka \& London 2003

RodenW ALDT, Gerhart, The Quarrel between Philosophy and Poetry: Studies in Ancient Thought, London 1988

PLATO, The electronic Journal of the International Plato Society, n 9, 2009.

http://gramata.univ-paris $1 . \mathrm{fr} /$ Plato

(c) All rights of reproduction of any form reserved. 
RosCALla, Fabio, 'Kalokagathia' e'Kaloi Kagathoi' in Senofonte, in: Xenophon and his World. Papers from a Conference Held in Liverpool in July 1999, Stuttgart 2004, 115-124

Ross, William D., Plato's Theory of Ideas, Oxford 1971

ROUVERET, Agnès, Histoire et imaginaire de la peinture ancienne, Rom 1989

Rowe, Christopher J. (Übers.), Plato, Phaedrus, Warminster 1986

SANTAS, Gerasimos X., Plato on Goodness and Rationality, in: Revue Internationale de Philosophie 156 (1986), 96-114

SARTORIUS, M., Plato und die Malerei, in: Archiv für Geschichte der Philosophie, N.F. 2 (1895), 123148

SAUNDERS, Trevor J., The Structure of the Soul and the State in Plato's Laws, in: Eranos 60 (1962), 37 55

SAUnders, Trevor J., Plato's Later Political Thought, in: The Cambridge Companion to Plato, hrsg. Richard Kraut, Cambridge 1992, 464-492

SCHLIKKER, Friedrich Wilhelm, Hellenistische Vorstellungen von der Schönheit des Bauwerkes nach Vitruv, Berlin 1940

SCHÖNDORF, Hildegard, Plotins Umformung der platonischen Lehre vom Schönen, Bonn 1974

SCHUberT, Andreas, Platon: Der Staat. Ein einführender Kommentar, Paderborn 1995

SCHUHL, Pierre-Maxime, Platon et l'art de son temps (Arts plastiques), Paris 1933 (2. erw. Aufl. 1952)

SCHUHL, Pierre-Maxime, Plato critique de l'art, in: Bulletin périodique de l'office des Institute d'Archéologie 4,10 (1937), 34-49

SCHWeItZer, Bernhard, Mimesis und Phantasia, in: Philologus 89 (1934), 286-300

SCHWEITZER, Bernhard, Vom Sinn der Perspektive, Tübingen 1953

SCHWEITZER, Bernhard, Platon und die bildende Kunst der Griechen, Tübingen 1953

SHARVY, Richard, Plato's Causal Logic and the Third Man Argument, in: Noûs 20 (1986), 507-530

SHEPPARD, Anne D., Studies on the $5^{\text {th }}$ and $6^{\text {th }}$ Essays of Proclus' Commentary on the Republic, Göttingen 1980

SHINER, R., Soul in Republic X, in: Apeiron 6 (1972), 23-30

SHOREY, Paul (Übers.), Plato: The Republic, Cambridge/Mass. 1935

Silverman, Alan, Plato on Phantasia, in: Classical Antiquity 10 (1991), 123-147

Smith, Nicholas D., Plato's Divided Line, in: Ancient Philosophy 16 (1996), 25-46 (oder in: Idem (Hg.), Plato: Critical Assessments, Bd. 2: Plato's Middle Period: Metaphysics and Epistemology, London 1998, 292-316)

SMITH, Nicholas D., Plato on Knowledge as Power, in: Journal of the History of Philosophy 38 (2000), 145-168

SÖRBOM, Göran, Mimesis and Art: Studies in the Origin and Early Development of an Aesthetic Vocabulary, Uppsala 1966

STEFANINI, Luigi, Ispirazione pitagorica del 'Canone' di Policleto, in: Giornale critica della filosofia italiana 28 (1949), 84-94

PLATO, The electronic Journal of the International Plato Society, n 9, 2009.

http://gramata.univ-paris $1 . f r / P l a t o$

(c) All rights of reproduction of any form reserved. 
STEINER, Deborah Tarn, Images in Mind: Statues in Archaic and Classical Greek Architecture and Thought, Princeton \& Oxford 2001

Steven, R. G., Plato and the Art of his Time, in: The Classical Quarterly 27 (1933), 149-155

SZAIF, Jan, Platons Begriff der Wabrheit, Freiburg \& München 1998

SZLEZÁK, Thomas Alexander, Unsterblichkeit und Trichotomie der Seele im zehnten Buch der Politeia, in: Phronesis 21 (1976), 31-58

TATARKIEWICZ, Wladyslaw, Two Philosophies and Classical Art, in: The Journal of Aesthetics and Art Cricism 22 (1963), 3-8

TATARKIE WICZ, Wladyslaw, Geschichte der sechs Begriffe Kunst, Schönheit, Form, Kreativität, Mimesis, Ästhetisches Erlebnis, Frankfurt am Main 2003 (poln. Originalausg. Warschau 1976)

TATARKIEWICZ, Wladyslaw, Geschichte der Ästhetik, Bd. 1: Die Ästhetik der Antike, Basel 1979

TATE, J., Imitation in Plato's Republic, in: The Classical Quarterly 22 (1928), 16-23

TATE, J., Plato and Imitation, in: The Classical Quarterly 26 (1932), 161-169

TAURECK, Bernhard, Mythos und Paideia. Ein Beitrag zu einem anderen philosophischen Verständnis des Schönen bei Platon, in: Wiener Jahrbuch für Philosophie 14 (1981), 123-134

ThOMAS, Rosalind, Literacy and Orality in Ancient Greece, Cambridge 1992

TIGERSTEDT, Eugène Napoléon, Plato's Idea of Poetical Inspiration, Helsinki 1969

TimmermanN, J., Platon, in: Julian Nida-Rümelin \& Monika Betzler (Hg.), Ästhetik und Kunstphilosophie von der Antike bis zur Gegenwart in Einzeldarstellungen, Stuttgart 1998, 631640

TRIMPI, W., The Early Metaphorical Uses of Skiagraphia and Skenographia, in: Traditio 34 (1978), 403-13

TÖPLITZ, O., Das Verhältnis von Mathematik und Ideenlehre bei Plato, in: Quellen und Studien zur Geschichte der Mathematik, Astronomie und Physik, Abt. B, 1 (1929-1931), 3-33 (und in: Oskar Becker (Hg.), Zur Geschichte der griechischen Mathematik, Darmstadt 1965, 45-75)

Turnbull, Robert G., The Third Man Argument and the Text of Parmenides, in: John Anton \& Anthony Preus (Hg.), Essays in Ancient Greek Philosophy III: Plato, New York 1989, 203-225

UTERMÖHLEn, Oswald, Die Bedeutung der Ideenlehrefür die platonische Politeia, Heidelberg 1967

VERDENIUS, Willem J., L'Ion de Platon, in: Mnemosyne 3. Ser. 11 (1943), 233-262

Verdenius, Willem J., Platon et la poésie, in: Mnemosyne 3. Serie 12 (1944), 118-150

VERDENIUS, Willem J., Mimesis: Plato's Doctrine of Artistic Imitation and Its Meaning to us, Leiden 1949

VICAIRE, Paul, Platon Critique littéraire, Paris 1960

Vlastos, Gregory, The Third Man Argument in the Parmenides, in: The Philosophical Review 63 (1954), 319-349 (und in: Reginald E. Allen (Hg.), Studies in Plato's Metaphysics, London 1965, 231-263)

VÖHLER, Martin, Dichtung als Begeisterungserfahrung. Zur Konzeption des Platonischen Ion, in: Gert Mattenklott Ästhetische Erfahrung im Zeichen der Entgrenzung der Künste. Epistemische, ästhetische und religiöse Formen von Erfahrung im Vergleich, Hamburg 2004, 195-210

PLATO, The electronic Journal of the International Plato Society, n 9, 2009. http://gramata.univ-paris $1 . \mathrm{fr} /$ Plato

(c) All rights of reproduction of any form reserved. 
VOLKMANN-SCHLUCK, Karl-Heinz, Platos metaphysischer Angriff auf die Kunst und das Problem der Tragödie, in: Idem, Von der Wahrheit der Dichtung, Würzburg 1984, 57-70

W AGNER, H. R., Idealität und Allgemeinheit. Zwei Aspekte der antiken Mimesistheorie, in: Platon 21 (1969), 234-249

WASCHKIES, Hans-Joachim, Symmetrie als Begründungsprinzip in der vorgriechischen und griechischen Geometrie, in: Antike Naturwissenschaft und ihre Rezeption, Bd. 1, Bamberg 1992, 155-183

Watson, Gerard, Phantasia in Classical Thought, Galway 1988

Webster, Thomas Bertram Lonsdale, Rez. Pierre-Maxim Schubl, Platon et l'Art deson temps (Arts plastiques), Paris 1933, in: The Classical Review 48 (1934), 239

WEBSTER, Thomas Bertram Lonsdale, Greek Art and Literature 530-400 B.C., Oxford 1939

WeBSTER, Thomas Bertram Lonsdale, Plato and Aristotle as Critics of Greek Art, in: Symbolae Osloenses 29 (1952), 8-23

WEHRLI, Fritz, Die antike Kunsttheorie und das Schöpferische, in: Museum Helveticum 14 (1957), 3949

WEIL, Raymond, L'archéologie de Platon, Paris 1959 (Ètudes \& Commentaires 32)

WEISBACH, Werner, Impressionismus. Ein Problem der Malerei in der Antike und Neuzeit, Berlin 1910

WelsCH, Wolfgang, Das Zeichen des Spiegels. Platons philosophische Kritik der Kunst und Leonardo da Vincis künstlerische Überholung der Philosophie, in: Philosophisches Jahrbuch 90 (1983), 230245

WEYL, Hermann, Symmetrie, Basel 1955

Wiegmann, Hermann, Plato's Critique of the Poets and the Misunderstanding of his Epistemological Argumentation, in: Philosophy and Rhetoric 23 (1990), 109-124

Williams, Bernard, The Analogy of City and Soul in Plato's Republic, in: Edward Nicholls Lee et al. (Hg.), Exegesis and Argument: Studies in Greek Philosophy presented to Gregory Vlastos, Assen 1973 (Phronesis, Ergänzungsbd. 1), 196-206

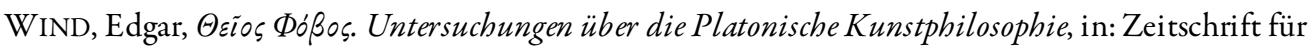
Ästhetik und allgemeine Kunstwissenschaft 26 (1932), 349-373

WoOdruff, Paul, What Could Go Wrong with Inspiration? Why Plato's Poets Fail, in: Julius Moravcsik \& Philip Temko (Hg.), Plato on Beauty, Wisdom, and the Arts, Totowa 1982, 137 150

WoODS, Michael J., Plato's Division of the Soul, in: Proceedings of the British Academy 73 (1987), 23-47

WORTHINGTON, Ian \& FOLEY, John Miles, Epea and Grammata: Oral and Written Communication in Ancient Greece, Leiden 2002 (Mnemosyne Supplementum 230)

ZIMBRICH, Ulrike, Mimesis bei Platon. Untersuchungen zu Wortgebrauch, Theorie der dichterischen Darstellung und zur dialogischen Gestaltung bis zur Politeia, Frankfurt am Main 1984

PLATO, The electronic Journal of the International Plato Society, n 9, 2009.

http://gramata.univ-paris 1.fr/Plato

(C) All rights of reproduction of any form reserved. 